\title{
EVALUATING THE IMPACT OF SOLAR ENVELOPE ZONING ON SOLAR ACCESS AND DEVELOPMENT DENSITY: A STUDY OF MID-RISE BUILDINGS IN TORONTO
}

\author{
by \\ Kelsey Saunders \\ BArchSc, Ryerson University, 2013

\begin{abstract}
A major research project
presented to Ryerson University

in partial fulfillment of the

requirements for the degree of

Master of Building Science (MBSc)

in the program of Building Science
\end{abstract}

Toronto, Ontario, Canada, 2018

CKelsey Saunders, 2018 


\section{AUTHOR'S DECLARATION}

I hereby declare that I am the sole author of this major research project (MRP). This is a true copy of the MRP, including any required final revisions.

I authorize Ryerson University to lend this MRP to other institutions or individuals for the purpose of scholarly research.

I further authorize Ryerson University to reproduce this MRP by photocopying or by other means, in total or in part, at the request of other institutions or individuals for the purpose of scholarly research.

I understand that my MRP may be made electronically available to the public. 


\title{
EVALUATING THE IMPACT OF SOLAR ENVELOPE ZONING ON SOLAR ACCESS AND DEVELOPMENT DENSITY: A STUDY OF MID-RISE BUILDINGS IN TORONTO
}

\author{
Kelsey Saunders, Master of Building Science \\ Building Science Program, Ryerson University, 2018
}

\begin{abstract}
The global population is growing exponentially with a trend of people moving to cities, resulting in rapid growth in the urban built environment. It is critical for urban planners to promote health, comfort, and resiliency in urban areas through integrated solar access requirements within zoning regulations. This paper evaluates the potential for the Solar Envelope Zoning (SEZ) method as a zoning tool in Toronto, Canada. The SEZ method is compared with current zoning regulations and mid-rise buildings guidelines using parametric modelling to establish the solar envelope on a typical building site. The resulting development density and solar radiation incident on adjacent building facades is evaluated. A similar study is performed on a site that is currently proposed for development along one of Toronto's main avenues. The results show that by redefining solar access requirements to include climate dependent variables, SEZ can provide competitive development density while improving solar access.
\end{abstract}




\section{ACKNOWLEDGEMENTS}

I would like to express my sincere gratitude and appreciation to the various people that have been paramount in the successful completion of this MRP, without whom it would not have been possible.

First and foremost, I need to thank my supervisor, Dr. Miljana Horvat. Thank you for your knowledge and guidance, your patience, and for never giving up on me. There is no doubt in my mind that I would not have completed this MRP without your support. Your kind, caring nature has been a blessing through this process and has helped me to stay positive and persevere.

Second, I would like to thank my friends and colleagues at SUSTAINABLE.TO Architecture + Building. Paul and team, thank you for your endless support in my pursuance of my master's degree, your patience of my absenteeism during this time, and most of all your inspiration to push the envelope and strive to accomplish great things for the betterment of our society and our environment.

Finally, thank you to my friends and family for your unwavering love and support, for listening to my rants and raves, the good and bad, and always believing in me, supporting me, and pushing me to achieve my goals.

It has been a long journey. Thank you all! 


\section{TABLE OF CONTENTS}

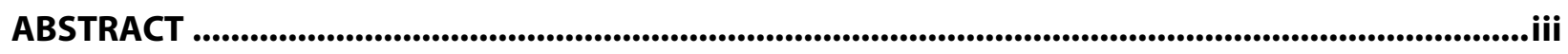

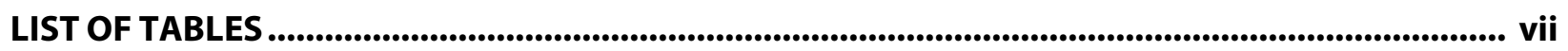

LIST OF FIGURES

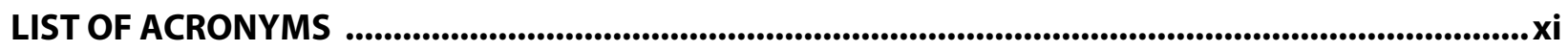

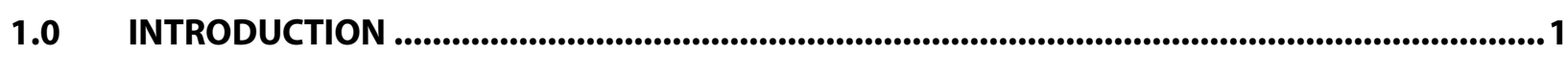

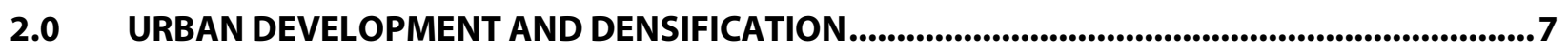

$\begin{array}{lll}2.1 & \text { Solar Access and the Right to Light } & 8\end{array}$

$\begin{array}{lll}2.2 & \text { Development Trends in Toronto } & 11\end{array}$

$\begin{array}{lll}\text { 2.3 Development Potential for Mid-rise Buildings } & 15\end{array}$

$\begin{array}{lll}2.4 & \text { Eglinton Avenue } & 18\end{array}$

$\begin{array}{lll}2.5 & \text { Summary } & 18\end{array}$

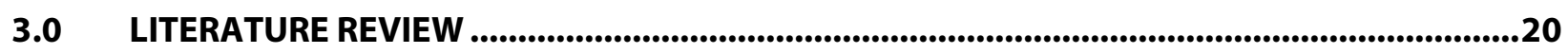

$\begin{array}{ll}3.1 & \text { Solar Energy in Urban Planning }\end{array}$

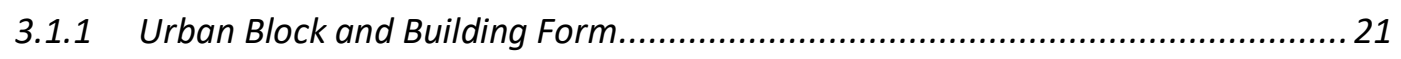

3.2 Tools for Evaluation Solar Potential in Urban Areas 27

$\begin{array}{lll}3.3 & \text { Solar Envelope Zoning } & 30\end{array}$

3.3.1 Methods for Generating the Solar Envelope................................................ 35

$\begin{array}{lll}3.4 & \text { Summary } & 44\end{array}$

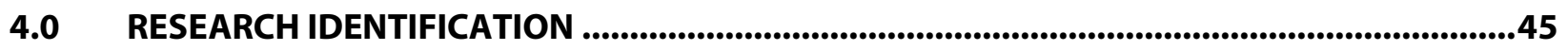

5.0 METHODOLOGY .........................................................................................................................46

$\begin{array}{lll}5.1 & \text { Tools } & 48\end{array}$ 
$\begin{array}{ll}5.2 & \text { Modelling the Solar Envelope }\end{array}$

5.3 Radiation Map Creation to Evaluate Solar Access $\quad 55$

$\begin{array}{lll}5.4 & \text { Case Study: Eglinton Avenue West } & 57\end{array}$

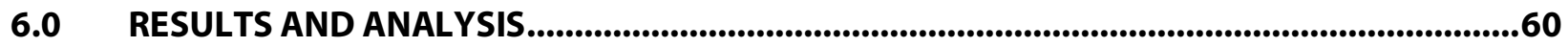

$\begin{array}{lll}6.1 & \text { Typical Site } & 60\end{array}$

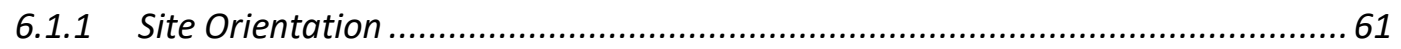

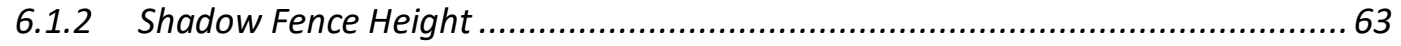

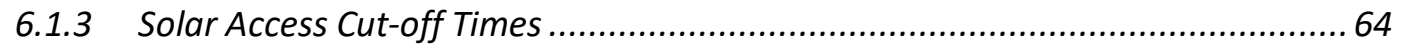

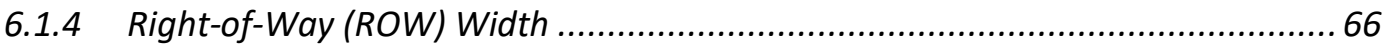

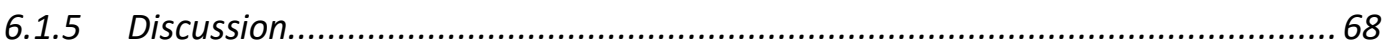

$\begin{array}{lll}\text { 6.2 Case Study: Eglinton Avenue West } & 71\end{array}$

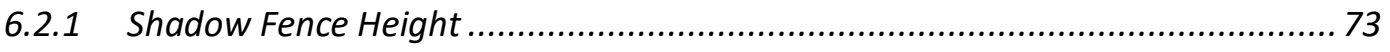

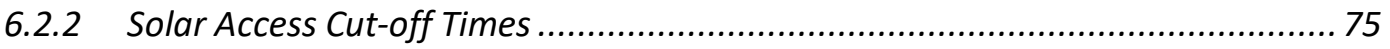

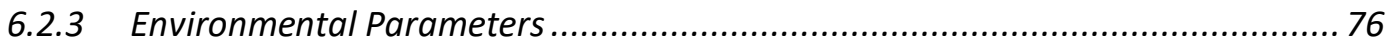

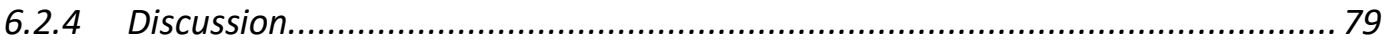

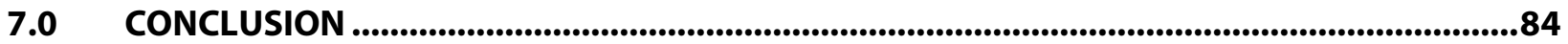

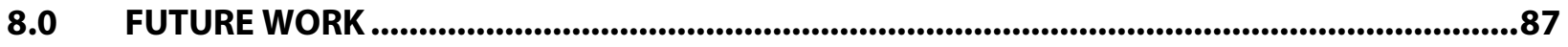

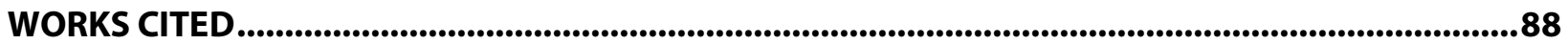

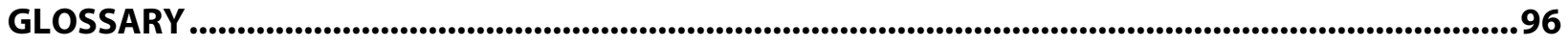




\section{LIST OF TABLES}

Table 5.2.1. Comparison of City of Toronto zoning regulations for a typical commercial lot on Eglinton Avenue with the Mid-Rise Buildings Guidelines and the Solar Envelope.

Table 6.1.1.1. Impact of street orientation and site location on development density (FSI) and solar radiation density $\left(\mathrm{kWh} / \mathrm{m}^{2}\right)$ on adjacent facades.

Table 6.1.2.1. Impact of residential Shadow Fence height on development density (FSI) and solar radiation density $\left(\mathrm{kWh} / \mathrm{m}^{2}\right)$ on adjacent facades

Table 6.1.3.1. Impact of solar access cut-off time on development density (FSI) and solar radiation density $\left(\mathrm{kWh} / \mathrm{m}^{2}\right)$ on adjacent facades.

Table 6.1.4.1. Impact of right-of-way (ROW) width on development density (FSI) and solar radiation density $\left(\mathrm{kWh} / \mathrm{m}^{2}\right)$ on adjacent facades.

Table 6.2.1. The development density (FSI) and annual average façade solar radiation density $\left(\mathrm{kWh} / \mathrm{m}^{2}\right)$ for various potential building typologies.

Table 6.2.1.1. Impact of shadow fence height on development density (FSI) and solar radiation density $\left(\mathrm{kWh} / \mathrm{m}^{2}\right)$ on adjacent facades.

Table 6.2.2.1. Impact of solar cut-off time on development density (FSI) and solar radiation density $\left(\mathrm{kWh} / \mathrm{m}^{2}\right)$ on adjacent facades.

Table 6.2.3.1. Impact of environmental parameters on development density (FSI) and solar radiation density $\left(\mathrm{kWh} / \mathrm{m}^{2}\right)$ on adjacent facades. 


\section{LIST OF FIGURES}

Figure 1.0.1 Average Electricity Price by Country in U.S. dollars per kWh. (Source: Statista, 2016.) ..........3

Figure 1.0.2 Building section showing passive design principles such as natural ventilation and passive solar design (Source: Sustainable.TO, 2017).

Figure 2.0.1. SolarCity in Linz, Austria: aerial showing urban planning (left) and buildings expressing solar architecture (right). 7

Figure 2.2.1. Development boundary of the City of Toronto (orange) and the Greater Toronto Hamilton Area (GTHA).

Figure 2.3.1. Land Use as a Percent of Avenue Frontage (Adapted from Brooke Mcllroy, 2010). 16

Figure 3.1.1.1. Example of horizontal randomness (left) (Source: Cheng, Steemers, Montavon, \& Compagnon, 2006)

Figure 3.1.1.2 Okiel's three generic neighbourhood forms including site statistics, showing the linear urban form (top), block urban form (middle), and residential solar block (RSB) (bottom).

Figure 3.1.1.3. Urban design parameters affecting solar access (left), and various roof shapes and the defined urban canyon (dark line) (right) (van Esch, Looman, \& de Bruin-Hordijk, 2012)............... 26

Figure 3.2.1. Solar map of Canada (left) and Ontario (right) in average solar energy yield of kWh/kWp per year (Source: EcoSmart, 2014).

Figure 3.3.1. Examples of the solar envelope volume showing the solar envelope volume (left) and street section (right) for varying site and street orientations (Knowles, 2003).

Figure 3.3.2 Typical house showing shadow fence requirements of a) whole building lot, b) whole building, c) ground floor window, and d) whole roof.

Figure 3.3.3. Specifying different cut-off times changes the sun angles for the solar envelope. Higher solar altitudes provide greater solar envelope volume (right) (Knowles, 2003)

Figure 3.3.4. Housing project which permits a minimum of 4 hours of sunlight to each dwelling. Conceptual design using the solar envelope (left) and fully designed buildings with architectural features (right) (Knowles, 2003).

Figure 3.3.1.1. Iso-solar rights surfaces on a case study site in Milan based on an irradiation value of 260 $\mathrm{W} / \mathrm{m} 2$ applied to all surroundings, for (a) all open spaces, and (b) the exact boundaries of the case study site (Morello \& Ratti, 2009). 38 
Figure 3.3.1.2. Comparison of the developable volume of the SRE created by redefining the conditions which constitute a violation of solar rights such as temperature (B) and solar radiation (C). 41

Figure 3.3.1.3. Flowchart of the algorithm developed by De Luka and Voll. Off the shelf components are in white and tools developed by the authors are in grey (Source: De Luka \& Voll, 2017).

Figure 3.3.1.4. Solar envelope volume generated in a low-density area (left) and high-density area (right), showing the solar envelope created by the context only (top) and the volume created by the context and the Estonian solar access requirements (bottom) (Source: De Luka \& Voll, 2017).

Figure 5.0.1 Aerial of Eglinton Avenue West, showing mid-rise commercial/residential buildings along the avenue, with low-rise single-family residential neighbourhoods in behind. 46

Figure 5.0.2 Six typical blocks surrounding the typical site (top middle) located on the north side of Eglinton Avenue West.

Figure 5.2.1. Typical blocks on Eglinton Avenue West generated in Rhinoceros ${ }^{\circledR}$ (left) and Grasshopper ${ }^{\mathrm{TM}}$ (right) showing the typical site on the north side of the street. 50

Figure 5.2.2. Screenshot of Grasshopper ${ }^{\mathrm{TM}}$ script showing a) analysis parameters for the sun path to determine the sunVectors, and b) input parameters for the Solar Envelope component. 51

Figure 5.2.3. Creation of the solar envelope on a typical site showing a) the solar envelope mesh, b) the extruded solar envelope volume, and the solar building model c) from the south and d) from the north

Figure 5.3.1. Grasshopper script evaluating the average annual solar energy density (SED) incident on adjacent roofs and facades.

Figure 5.3.2. Creation of the radiation map simulation showing a) the surrounding context including the solar envelope, b) the surrounding context input into the radiation map component, c) the analysis grid surfaces, and d) the radiation analysis results.

Figure 5.4.1. Google Earth view of the property 859-875 Eglinton Avenue West proposed for development of an 11-storey mixed-use commercial/residential (CR) building (top). Toronto Zoning height map showing maximum height of adjacent lots (bottom left) and Toronto Zoning designated land use map showing CR land uses in red, and residential (R) land uses in yellow (bottom right).....

Figure 5.4.2. Creation of the solar envelope at 859-875 Eglinton Avenue West showing a) the solar envelope mesh, b) the extruded solar envelope volume, and the solar building model c) from the south and d) from the north. 
Figure 6.1.1.1. Building forms generated by solar envelope volume by varying site location and orientation. The top two images are E-W streets showing a N site (a) and S site (b). The bottom two images are N-S streets showing a W site (c) and E site (d).

Figure 6.1.2.1. Building forms generated by solar envelope volume by varying the residential shadow fence height from a) $0 \mathrm{~m}$, b) $1.5 \mathrm{~m}$, c) $3 \mathrm{~m}$, and d) $6 \mathrm{~m}$......

Figure 6.1.3.1. Building forms generated by solar envelope volume by varying the cut-off times from 6 hours (a), 4 hours (b), and 2 hours with a designated maximum height of $27 \mathrm{~m}(\mathrm{c})$ and $50 \mathrm{~m}(\mathrm{~d}) \ldots 65$

Figure 6.1.4.1. Building forms generated by solar envelope volume on a south lot by varying right-of-way width. From top to bottom, examples shown are $20 \mathrm{~m}, 23 \mathrm{~m}$, and $27 \mathrm{~m}$ ROW.

Figure 6.2.1. Resulting building volume (left) and solar radiation map (right) resulting from (a) City of Toronto zoning, (b) mid-rise guidelines, (c) proposed development, and (d) baseline solar envelope.

Figure 6.2.1.1. Building forms generated by solar envelope volume by varying the shadow fence height from a) site and context, b) $0 \mathrm{~m}$, c) $4.5 \mathrm{~m}$, and d) $10.5 \mathrm{~m}$.

Figure 6.2.2.1. Solar envelope volume resulting from varying solar access cut-off time from (a)9:00 to 15:00 (6h), (b)10:00 to $16: 00$ (6h), (c)10:00 to 14:00 (4h), and (d)11:00 to 13:00 (2h).

Figure 6.2.3.1. Grasshopper ${ }^{\mathrm{TM}}$ script defining the sunVectors from the sunPath used to generate the solar envelope volume.

Figure 6.2.3.2. Building forms generated by the solar envelope volume showing (a) the baseline solar envelope, (b) $a+T d b<18 C$, (c) $a+G H R<472 W h / m 2$, (c) by varying the shadow fence height from a) site and context, b) $0 \mathrm{~m}, \mathrm{c}) 4.5 \mathrm{~m}$, and d) $10.5 \mathrm{~m}$. 


\section{LIST OF ACRONYMS}

\begin{tabular}{ll} 
BIPV & building integrated photovoltaic \\
BPS & building performance simulation \\
CAD & Canadian dollar \\
FSI & floor space index \\
GFA & gross floor area \\
GHG & greenhouse gas \\
IPCC & Intergovernmental Panel on Climate Change \\
KWh & kilowatt-hour \\
MRG & mid-rise guidelines \\
PV & photovoltaic \\
RSB & residential solar block \\
SCE & solar collection envelope \\
SE & solar envelope \\
SEZ & solar envelope zoning \\
SRE & solar rights envelope \\
USD & Tolar thermal \\
\hline
\end{tabular}




\subsection{INTRODUCTION}

The global population is rising at an exponential rate, with a growing trend of people moving to urban areas. According to the United Nations (UN) Department of Economic and Social Affairs (2014), 54\% of the world's population was living in urban areas in 2014 , compared to $30 \%$ in 1950 . By 2050 , this is expected to increase to $66 \%$. In North America, the number of people living in cities is even greater than the global average, with 82 percent living in urban areas (UN, 2014). Combined with the overall estimated global population increase, this equates to a possible 2.5 billion people moving to cities over the next 35 years. The leading cause of this massive influx of movement toward cities is accessibility. What was once "location, location, location", is now "access, access, access!" People want to live, work and play within an easily accessible radius, and most employment opportunities are in and around urban centers.

To support growing population demand, a significant amount of energy and resources is required to develop urban infrastructure, resulting in rising greenhouse gas (GHG) emissions contributing to global warming. According to the Intergovernmental Panel on Climate Change (IPCC) (2014), the annual rate of accumulation of GHG emissions has nearly doubled on average over the last 15 years compared to the previous 30-year average. As a result, climate change is projected to increase risks for people, assets, economies and ecosystems, including heat stress, storms and extreme precipitations, air pollution, and storm surges, especially in urban areas. In order to adapt to the implications of climate change, urban areas must invest in environmentally sound infrastructure that can facilitate a reduction in GHG emissions and enhance urban resilience to the associated risks.

In 2009 the Canadian federal government signed the Copenhagen Accord, a commitment to reduce GHG emissions by $17 \%$ (based on 2005 levels) by 2020. The Ministry of Ontario expects to reduce its GHG 
emissions by 15\% below 1990's levels by 2020 (Environment Canada, 2012). They plan to achieve this by offsetting the continually growing energy demand by improving energy codes and standards and implementing incentive programs to reduce energy use and promote renewable energy generation. Achieving these targets requires access to solar energy. Therefore, ensuring solar access in urban environments is a critical component to meeting these targets.

There are three important steps to achieving urban resilience effectively. First, the demand for energy and natural resources required by the built environment must be reduced in terms of both construction/development and building operation. Second, future development and planning of cities should be guided by natural environmental processes to utilize what nature provides for free, such as the sun and wind. Finally, active renewable energy systems should be integrated into the planning of buildings and neighbourhoods to diversify the energy supply.

\section{Reducing Energy Demand}

In Canada, the perceived cost of energy is relatively low compared to many developed countries around the world. Figure 1.0.1 shows the relative cost of electricity in key countries in U.S. dollars (USD) per kilo-watt hour (kWh), developed by Statista (2016). The electricity cost in Canada of \$0.13 USD is almost a third less than Germany and Italy (\$0.33 USD and \$0.31 USD per kWh respectively), and nearly a quarter the cost of electricity in Australia (US\$0.49 per kWh). As a result, there is little incentive to improve the performance of buildings to reduce energy use and operating costs. However, the perceived cost of energy to the consumer is different from the real cost of energy. In Canada, the fossil fuel industry is heavily subsidized by government programs, paid for by Canadian residents through their

tax dollars. Between 2013 and 2015, government subsidies to fossil fuel production averaged $\$ 3.3$ billion in Canadian dollars (CAD) (Touchette, 2015), or $\$ 19$ CAD per tonne of $\mathrm{CO}_{2}$. These programs not only disincentivize the reduction of fossil fuel consumption and hinder our ability to meet carbon emission 
reduction targets, but they also cost Canadian tax-payers money. According to a report by Touchette (2015), every Canadian unknowingly pays at least $\$ 94$ in their taxes each year to these subsidies. By closing programs that provide subsidies to the fossil fuel industry, consumers would be made aware of the true cost of energy and there would be greater incentive to reduce the energy demand of buildings. Even now, as energy prices continue to rise, the cost of operating poor-performing "energy hogs" are becoming a financial burden to building owners and tenants. As such, subsidies should instead be allocated to the retrofitting of the existing housing stock, which would simultaneously reduce energy demand and GHG emissions.

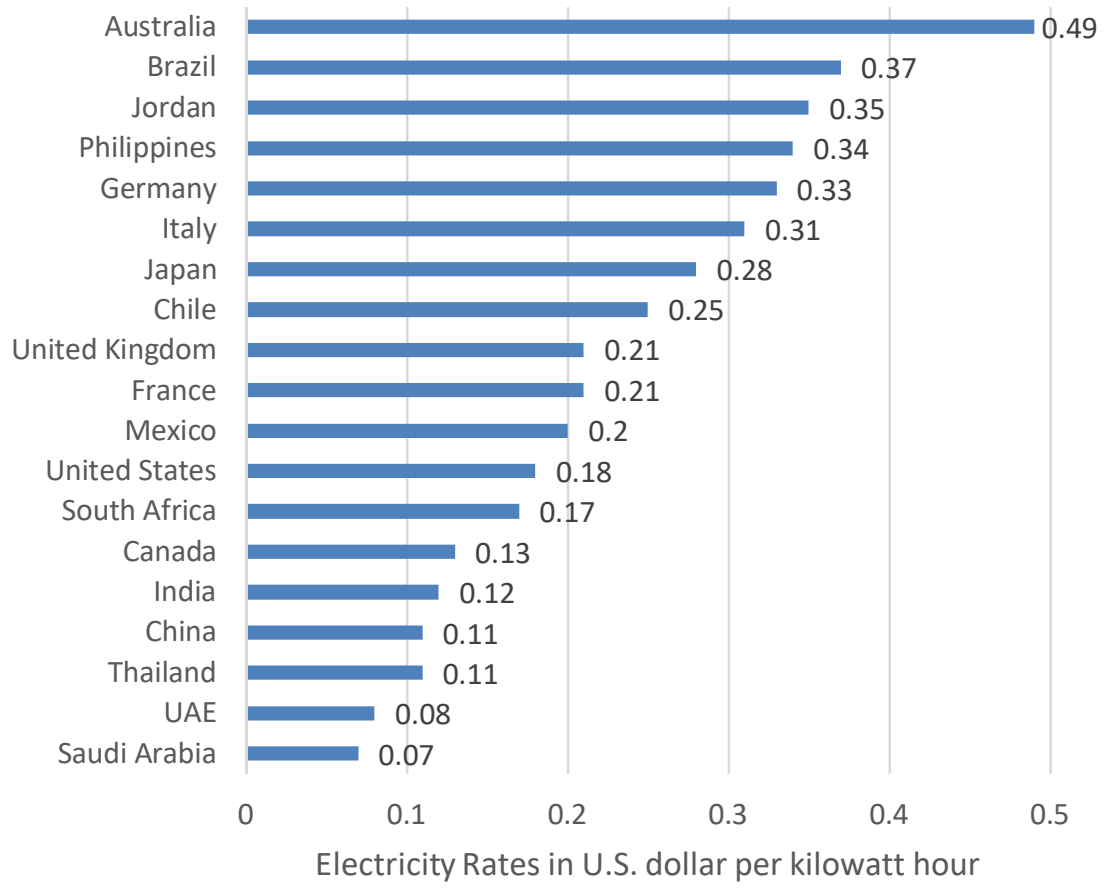

Figure 1.0.1 Average Electricity Price by Country in U.S. dollars per kWh. (Source: Statista, 2016.)

\section{Designing with Nature}

Once the performance of existing buildings has been improved and new buildings are regulated to meet high-performance targets, the remaining loads on the building for heating, cooling, and lighting can often be substantially provided using passive design strategies. Passive design comprises many 
components but primarily it is the ability to address and utilize local climate conditions to the benefit of the site or building, i.e. designing with nature. These principles were commonly used by ancient civilizations out of necessity to ensure health and comfort for residents and date back over 8,000 years. One well-known example is the Greek city of Olynthus, which was built in the $4^{\text {th }}$ century BC using passive solar strategies to ensure that all residents had access to the winter sun, and were shaded from the summer sun (Perlin, 2013). In more recent history, the dawn of the industrial revolution and technological advances resulted in a diversion from designing with nature and instead relying heavily on manufactured systems for health and comfort. The resilience of our built environment would benefit to learn from these ancient methods of designing buildings in ways which capitalize on the surrounding climate to provide lighting, heating, cooling, and ventilation passively.

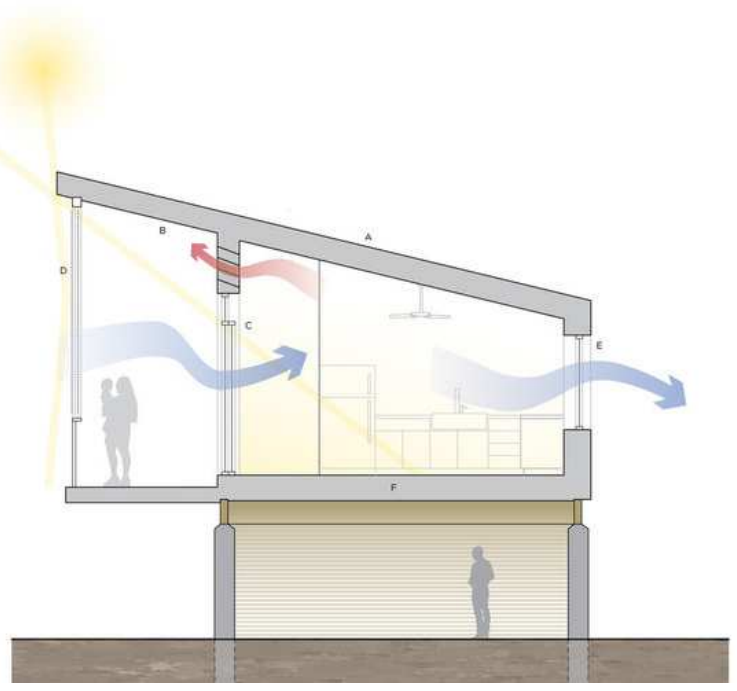

Figure 1.0.2 Building section showing passive design principles such as natural ventilation and passive solar design (Source: Sustainable.TO, 2017).

Passive solar design (PSD) uses the energy of the sun (for daylighting, heating, and cooling) when desired, and shades or distorts the sunlight when it is not. In heating months, a passive solar building will capture free heat from the sun through a combination of strategically placed windows and thermal mass. In cooling months, the design will provide calculated shading devices to reduce unwanted heat gain. Studies have shown that PSD can have a significant impact in reducing building energy demand. 


\section{Integrating Renewable Energy}

Energy supply diversification is an important step in increasing urban resilience. Distributed generation is redefining the role of utilities and the need for transmission lines by employing small-scale utility stations throughout the city close to the end user. Urban distributed generation systems can take many shapes. On-site solar energy collection systems using solar energy technologies such as building integrated photovoltaics (BIPV) and solar thermal systems (ST) are a popular solution and are becoming increasingly viable in terms of return on investment (ROI). Since 2009, costs for solar photovoltaic systems have dropped internationally by $75 \%$ (IRENA, 2015). As rates continue to drop, solar power is expected to become the most significant contributing source to electricity production globally by 2050 (IEA, 2014).

There are two main factors influencing the feasibility of solar energy collection in urban environments. The first is cost of the system and relative payback period. The cost of electricity in Australia, Germany, and Italy (\$0.49, $\$ 0.33$, and $\$ 0.31$ USD per kWh respectively) were highlighted above because these countries are leaders in the solar energy generation industry, and the reasons for this become glaringly obvious when assessing the cost of energy. The wide-spread uptake of these technologies in Canada is less desirable due to longer payback periods. The low cost of electricity means that solar technology takes a long time to see a ROI. For example, if the cost of electricity in Germany is $\$ 0.33 / \mathrm{kWh}$ and the cost in Canada is $\$ 0.13 / \mathrm{kWh}$, it will take Canadians more than twice as long to see a return on their investment. However, there are incentive programs in place in many regions, such as Ontario's Feed-in Tariff (FIT) and MicroFIT programs. These incentives offer to purchase the electricity generated from the owners' solar modules at a higher rate than the current price of electricity. The purpose of this incentive is to promote the installation of renewable energy systems such as solar photovoltaics by maintaining a reasonable ROI (IESO, 2016). Therefore, as electricity rates increase and the costs of installing renewable 
energy systems decrease, the purchasing rate offered by the provider (the Independent Electricity System Operator (IESO) in Ontario) decreases. The MicroFIT and FIT programs in Ontario were phased out at the end of 2017, since the ROI for these systems will soon reach parity with the cost of system installation versus cost of electricity. 


\subsection{URBAN DEVELOPMENT AND DENSIFICATION}

The densification of global cities frequently leads to an influx of high-rise buildings and developments.

Development is occurring so rapidly in many urban areas that it is not being adequately monitored and

it is becoming increasingly difficult to distinguish one city from another since the urban fabric is

dependent on densification and profit, and independent from its climate and context. For improved

urban resilience, cities should grow to optimize the use of natural systems such as solar energy that do

not rely on energy for comfort, health, and safety. Lessons can be learned from the solar city concept as

deployed in the solarCity in Linz, Austria, shown in figure 2.0.1. A solar city is one that has a developed

strategy for solar energy utilization within the built environment, with a plan that embraces and

implements solar energy as design criteria during the preliminary design phases (Treberspurg, 2008). In

contrast to current development trends, a solar city will display the features of solar architecture. The

approach to the implementation of solar energy will create a unique vernacular character to each city

and acts as a cornerstone for further urban development. Ultimately, a solar city understands the

potential for solar energy to become a contributing factor to the overall energy demand and reflects this concept into the design of its communities.
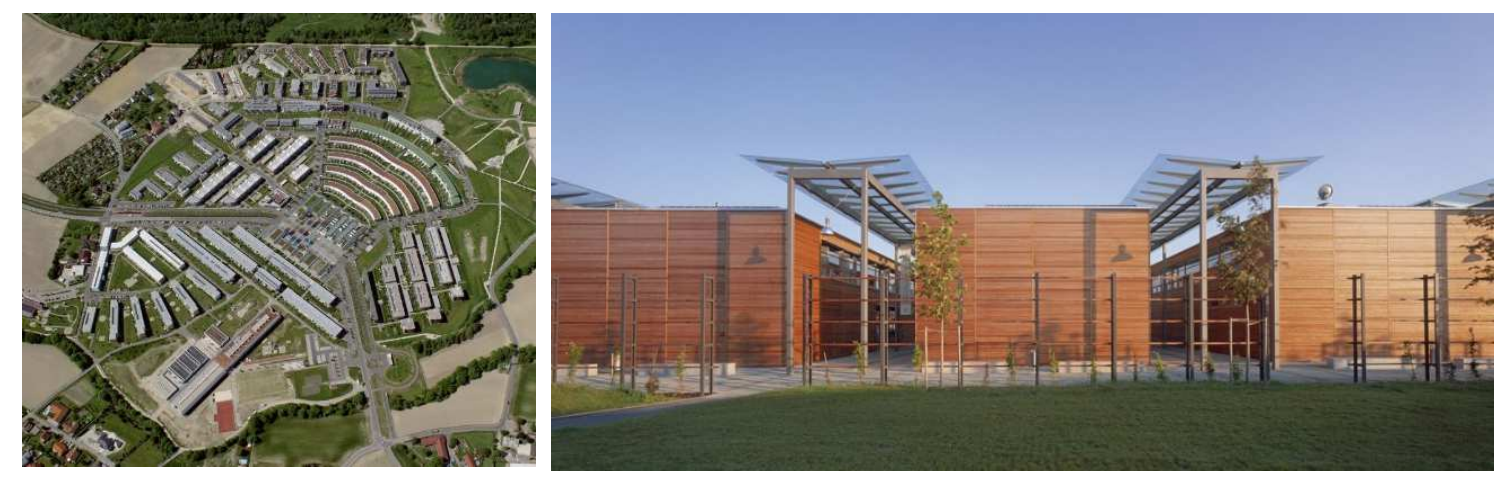

Figure 2.0.1. SolarCity in Linz, Austria: aerial showing urban planning (left) and buildings expressing solar architecture (right). 
Planning for solar energy in urban areas requires a holistic approach for successful integration, since solar energy feasibility is directly affected by land use patterns. There are several key barriers to the integration of solar access into existing urban planning regulations in major cities that are already substantially developed. These issues include development costs, the cost of energy and resulting operating costs, desirable greenspace, and the growing population density in cities. Despite these challenges, there are many opportunities for development and densification in urban areas, such as midrise development along major urban arteries which have the potential to provide a balance between densification and solar access. In the following section, these key challenges and opportunities will be discussed through the lens of solar access and 'right to light' in the context of Toronto, Canada.

\subsection{Solar Access and the Right to Light}

Solar access is defined as the ability to have uninterrupted direct rays of sunlight fall onto one's property (Gibson, 2014). The purpose of solar access is to improve the quality of space in and around buildings, not only for daylighting but also to improve the health and comfort of occupants. Solar access can also contribute to the reduction in building energy use due to solar gains and access to daylight, in addition to improving the potential to generate electrical energy through active solar energy technologies located on the building roof or facade. In one hour, more solar energy will reach the earth's surface than will be consumed by humans in one year (Suzuki and Boyd, 2008) (Colucci, 2013). Annually, solar energy can theoretically provide up to 2,850 times the current world energy demand (EREC, 2010). However, the viability of the sun as an energy source is limited by our access to it. In this way, the abundant energy available from the sun is being significantly underutilized - particularly in urban environments. Without both planning for and providing solar access, it is difficult to achieve urban resilience. In addition, the importance of solar access goes beyond free heating, daylighting, and active energy generation. Solar access is also imperative for the growing of crops, plants and trees and the health of 
the natural environment within cities. Solar access is also critical for human health and well-being. It is the source of our vision and guides our "internal clock", known as the circadian rhythm (Lockley, 2009). "Its movements inform our perceptions of time and space and our scale in the universe." (Knowles, 1981).

\section{Right to Light}

The term 'right to light' is an ancient doctrine which prevented owners of adjoining structures from building or placing on their own land anything that has the effect of obstructing the light of the dominant tenement (England, 1611). 'Right to light' was used in the prescription act of 1832 and stated that if a user has had access and use of light for "the full period of 20 years without interruption, the right thereto shall be deemed absolute and indefeasible". The 'right to light' was then incorporated in many of the common provincial laws in Canada. Once Canada began to flourish economically and the population of cities began to grow, the 'right to light' doctrine was effectively removed to better suit the development opportunities that were beginning to arise. British Colombia was the first to abolish the doctrine in 1906, and the rest of the provinces soon followed (Gibson, 2014). However, solar access was reintroduced to land use regulation and policy in North America in the 1970's when the United States was experiencing an energy crisis. They deemed solar access important so that photovoltaic (PV) systems would have access to direct sunlight. Photovoltaics were monetized, rationalizing the movement of land use regulations toward the adoption of solar 'right to light.' Since the 1970's, thirtysix states have integrated solar rights statutes into their legislation (Krivitsky, 2010). In the state of California, the Solar Rights Act was implemented to ensure that local agencies do not adopt ordinances that create unreasonable barriers to the installation of solar energy systems. California also developed the Solar Easement Law, which is attached to the deed of a property and provides a legal right for that property to receive sunlight well into the future (Gibson, 2014). California has set a precedent for the 
importance of solar access in the resiliency of cities in the future. In 2008, Kettles performed a comprehensive review of access laws in the United States and developed a model solar statute to outline a comprehensive approach to protecting solar access based on best practices. Based on his review, Kettles defined modern solar rights as the ability to install solar energy systems on residential and commercial property that is subject to private restrictions. In the United States, specific statutory authority is being established to protect the rights of solar users to both install solar systems and ensure these systems maintain access to sunlight once they are installed (Kettles, 2008). There are several methods of guaranteeing solar access and 'right to light'. O'Neill (1986) described these methods as; lot by lot regulations, such as nuisance law and the ancient light doctrine; compensatory regulations, such as restrictive covenants and solar easements; or by integrating solar access requirements into zoning regulations. O'Neill concludes that zoning regulations are the most advantageous method of implementing solar access requirements since they are already established, uniformly implemented, and would cost little to administer once in place (O'Neill, 1986).

In Canada, as is in the United States, there is no common-law right to sunlight. Most policies surrounding solar energy in Canada thus far have focused on incentive programs and accessibility of solar energy generation through photovoltaics but have not yet outlined considerations for solar access. However, in 2007 the Saskatchewan environment minister commissioned a review of the 'right to light', recognizing the growing integration of solar energy technology on new buildings and exploring appropriate laws for solar protection (Bernier, 2015).

In the context of Toronto, Gibson (2014) evaluated the current state of urban planning legislation and the potential for integration of solar access laws into land use policy and regulation as Toronto densifies. The current growth trend in Toronto is the development of high-rise buildings around the downtown core and at main arterial centres, such as Yonge Street and Eglinton Avenue. Due to their height, these 
buildings cast significant shadows on neighbouring properties. As part of the municipal approvals process, developers must submit a shadow study when developing in areas designated as "sensitive", including parks, schools, ravines, and cemeteries. These areas are still not, however, fully protected and there are currently no solar access requirements for sites located outside of "sensitive" areas.

In contrast, the City of Toronto is beginning to encourage the use of renewable energy systems through recommendations and guidelines for development. For example, the Toronto Green Standard (TGS) voluntary Tier 2 recommends that all new buildings above a specified gross floor area (GFA) install renewable energy systems that can supply at least $5 \%$ of the total energy loads of the building (City of Toronto, 2010). The City of Toronto incentivizes developers to meet the requirements of Tier 2, above and beyond the mandatory Tier 1 , by offering rebates on development charges. However, these regulations and guidelines do not address the issue of 'right to light' nor do they address the importance of solar access for passive solar energy. It is important that the city simultaneously integrate solar access laws into urban planning regulations to mitigate some of these issues.

As urban areas continue to densify, the importance of solar energy as a design driver for the built environment is ever increasing to ensure that urban populations can benefit from passive and active strategies and that they see a reduction in energy demand and improved urban resilience. Gibson concludes that the most effective suite of land use regulatory tools to ensure solar access in Toronto would include solar zoning, an Ontario Solar Rights Act, and the use of solar easements in the right situations.

\subsection{Development Trends in Toronto}

The City of Toronto is forecast to grow by $20 \%$ to 3 million people by 2031 , which means that over 500,000 people are expected to move into the City of Toronto over the next 15 years. The map in figure 
2.2.1 shows the development boundary of the Greater Toronto Hamilton Area (GTHA) and the City of Toronto (orange). Toronto is located at $43.6532^{\circ} \mathrm{N}, 79.3832^{\circ} \mathrm{W}$ in the southern part of Ontario, Canada. With a rapidly growing population, the current trend in Toronto's development is one in which the party involved in the building design and construction is not the tenant. As a result, property developers have little incentive thus far to concern themselves of the long-term energy costs of keeping buildings comfortable and well maintained. Therefore, operating costs for heating, cooling, lighting, and maintenance throughout the life of the building are not an initial concern or design consideration.

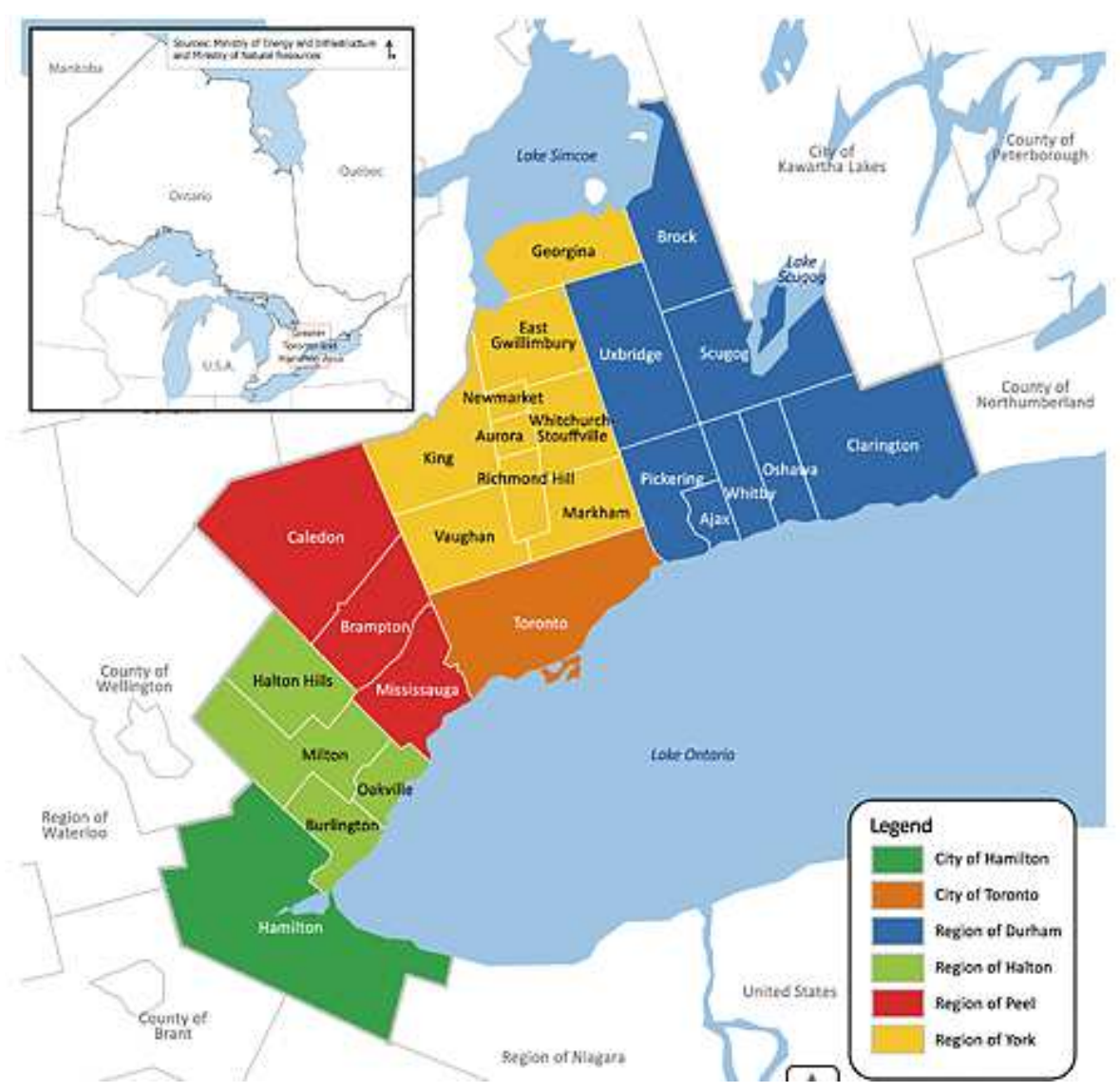

Figure 2.2.1. Development boundary of the City of Toronto (orange) and the Greater Toronto Hamilton Area (GTHA).

The desire to develop (build) fast and sell quickly is increasingly common. In Knowles words, "we grow cheap and maintain expensive" (2003). The result is poorly constructed, poorly performing buildings with high operation and maintenance costs. These buildings become a burden on the owner and the 
tenants, with increasing condo fees and potential health and safety issues for tenants over the life of the building. In downtown Toronto, this problem has been deemed the "condo crisis". Another result of this dilemma is the construction of high-rise buildings, since increased site density is more profitable for developers. The result is limited solar access to adjacent buildings and the pedestrian streetscape, leading to little or no solar access in the built environment.

\section{Development Cost}

The process and fees associated with developing high-rise buildings are comparable to the costs for midrise buildings, however the occupant density for high-rise buildings is greater and therefore a higher profit margin is achievable. A mid-rise is defined as a building that is no taller than the street right-ofway (ROW). Generally, this dictates a building height of between five and eleven storeys (Brook Mcllroy Planning and Urban Design, 2010). In order to promote the development of mid-rise buildings and a more human-scale urban environment, the process for mid-rise development must be streamlined and the fees reduced accordingly. Some strides have been made in Toronto in recent years with the planning study conducted by several prominent planning and design firms in Toronto resulting in the creation of the Toronto Avenues and Mid-rise Buildings Guidelines in 2010. This document outlines recommendations for the form of mixed use, mid-rise development along Toronto's avenues that promote a healthy and vibrant pedestrian streetscape focused on providing human-scale development to increase density along these wide streets while considering sunlight and privacy.

\section{Height and Density Bonusing}

Under section 37 of the Ontario Planning Act, developers may request a zoning amendment to increase the height and density of development proposals in exchange for community benefits (Bernier 2015). This is a significant source of revenue for the City of Toronto, accounting for a total of $\$ 136$ million in revenue from 2007-2011 (Moore, 2013). 


\section{Conflicting Planning Policies}

It is often the case that municipal policies conflict with solar energy applications, such as the City of Toronto's Eco-Roof incentive program or the Green Roof By-law, promoting the adoption of green rooftops and cool rooftops but not solar rooftops. Solar energy collection systems would serve the same purpose of rooftop cooling while also serving a secondary purpose of energy collection, and therefore it makes sense for these and other heat-island reduction incentive programs to include solar energy as an option, rather than potentially discouraging solar energy in favour of green roofs and cool roofs.

\section{City of Toronto Official Plan}

Despite these setbacks, the City of Toronto has well-intentioned goals of sustainable development, evident in their Official Plan drafted in 2010 where they state that "building a successful Toronto means that we have to make sustainable choices about how we grow. We have to see connections and understand the consequences of our choices. We have to integrate environmental, social and economic perspectives in our decision making. We have to meet the needs of today without compromising the ability of future generations to meet their needs".

The Official Plan requires that most development occur within $25 \%$ of the City's geographic area, leaving the other $75 \%$ to mature and evolve (Wright, 2010). The official plan focuses heavily on development in areas accessible to transit and live/work neighbourhoods, such as on avenues and in centres, employment districts, and the downtown core. 


\subsection{Development Potential for Mid-rise Buildings}

\section{Toronto Avenues and Mid-Rise Buildings Study}

The Toronto Avenues and Mid-Rise Buildings Study was initiated by the City of Toronto to build on the city's Official Plan, to further investigate the development along Toronto's main corridors. The study applies only to segments of the avenues that were identified in the Official Plan as areas to be reurbanized and targeted for growth, such as areas designated as mixed-use, employment, institutional or regeneration areas. The aim of the study was to develop a series of guidelines for mid-rise building along Toronto's avenues to revitalize and densify the avenues at a human scale, while protecting adjacent neighbourhoods to ensure that sunlight, privacy, and overlook are considered in each development proposal. The guidelines developed as a result of this study will be referred to as the MidRise Guidelines (MRG) for the remainder of this paper.

The study defines avenues as important corridors along major streets where reurbanization is anticipated and encouraged to create new housing and job opportunities while improving the pedestrian environment, the look of the street, shopping opportunities, and transit service for community residents. A recurring theme throughout the document, reurbanization is defined as $a$ coordinated approach to the redevelopment of land within the existing urban fabric to accommodate regional growth (Brook Mcllroy Planning and Urban Design, 2010). It improves and makes better use of existing urban infrastructure and services before introducing new ones on the urban fringe, reducing impacts on the natural environment and improving livability of the urban region.

The study recommends implementing as-of-right zoning for developments that fall within the guidelines to speed up the approvals process for mid-rise developments and encourage development of mid-rise buildings by overcoming some of the challenges mentioned in the previous section. Although the study 
considers access to sunlight as one of the drivers of the MRG, there guidelines are uniform for each site, regardless of street direction, site orientation, or adjacent context.

\section{Land Use and Potential for Growth}

Placed end-to-end in a straight line, Toronto's avenues have a total length of about $162 \mathrm{~km}$, which translates to $324 \mathrm{~km}$ of property frontage (City of Toronto, 2010). Figure 2.3 .1 shows a breakdown of the land use designation along the avenue frontage in the City of Toronto. Areas identified by the study as 'growth areas' are shown in blue, and include mixed use, employment, institutional and regeneration areas. These areas designated for growth account for approximately $75 \%$ of the avenue frontage, equal to nearly 250 kilometers of avenue frontage offering great opportunities for growth in areas where the City of Toronto is promoting densification.

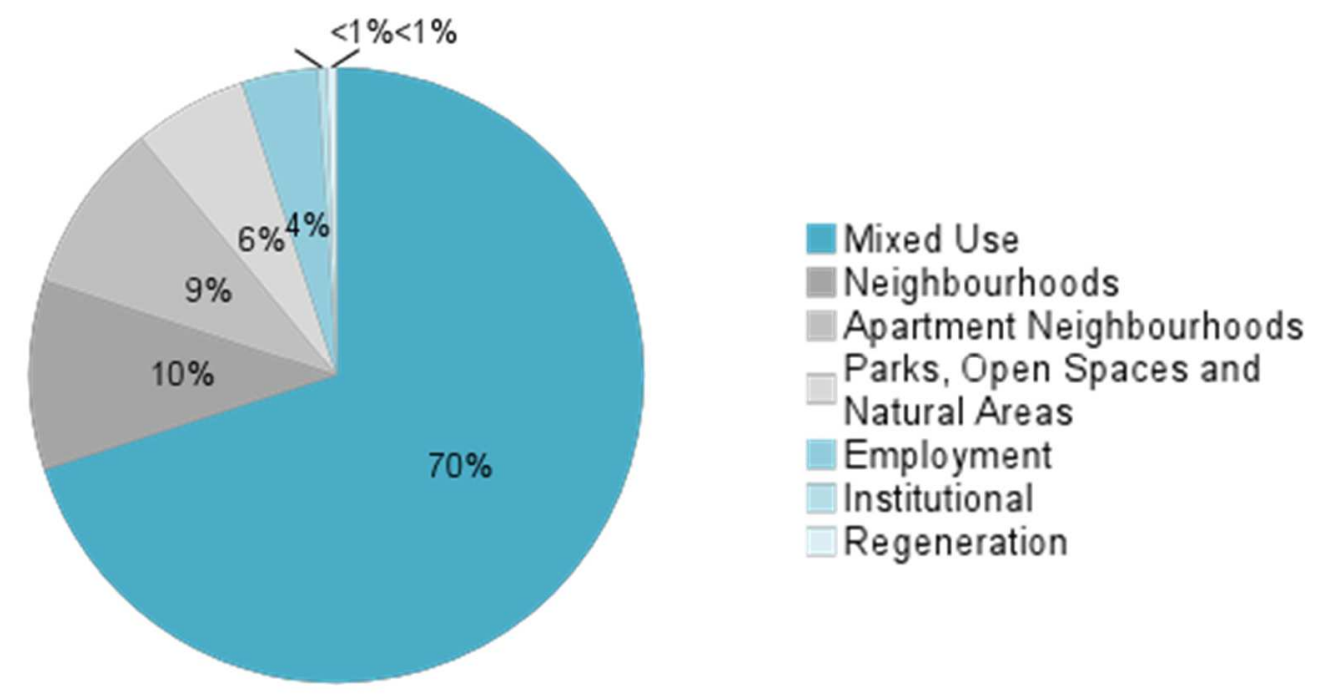

Figure 2.3.1. Land Use as a Percent of Avenue Frontage (Adapted from Brooke Mcllroy, 2010).

A City of Toronto planning study conducted by Burda and Collins-Williams found that even if only one in every ten of all properties now zoned for mixed use were redeveloped as six storey mid-rise buildings, the density potential would increase to generate about 120,000 new housing units in the City of Toronto (Burda and Collins-Williams, 2015), equal to roughly 336,000 people (StatsCan, 2011). With over 500,000 
people expected to move to the City of Toronto in the next 15 years, it is evident that mid-rise development along Toronto's avenues can meet this need while creating human-scale, vibrant neighbourhoods.

The reason we are not seeing a large uptake in the development of mid-rise as opposed to high-rise buildings is that, for the same property, the cost and planning process for a mid-rise development is roughly equal to that of a high-rise development. This leads to a much better return on investment for high-rise buildings. If developers accept the higher costs of mid-rise, the additional costs are ultimately passed on to the homebuyer. Therefore, units become too costly for families. Burda and Collins-Williams (2015) suggest five important changes that the City must make in order to make mid-rise more viable:

1. Require minimum densities along rapid transit lines.

2. Eliminate minimum parking requirements.

3. Pre-approve mid-rise development along avenues and transit corridors.

4. Require retail planning before mid-rise is built.

5. Make parkland dedication rules more equitable.

The study concludes that the uptake of mid-rise developments along avenues will not occur until zoning is updated along these corridors. However, some strides were made in favour of mid-rise at the beginning of 2015, when the 2012 Ontario Building Code was amended to permit wood construction for residential and commercial buildings up to a maximum of six-stories (Morrison Hershfield, 2015). The purpose of this amendment was to help make mid-rise more affordable and therefore more desirable. 


\subsection{Eglinton Avenue}

Currently, $75 \%$ of the land area in the City of Toronto is devoted to parks, neighbourhoods, ravines, watercourses and valleys. By focusing the majority of new development in centres and along avenues and other strategic locations, the City aims to preserve the existing shape and nature of existing established neighbourhoods. (City of Toronto, 2010)

The Eglinton Connects Planning Study executive summary report from 2010 outlines Toronto's plan for the redevelopment of Eglinton Avenue with the aim of improving travel, greenery, and the built environment along Eglinton Avenue. The study recommends the use of as-of-right regulations for midrise buildings along the avenue to promote densification, while creating complete streets that will include dedicated lanes for cyclists and pedestrians, wider street right-of-way's (ROWs), and more greenery along the street (City of Toronto, 2014).

Eglinton Avenue is becoming a major artery in the City of Toronto, running the entire length of the city from east to west. As such, the City of Toronto has been working on an Eglinton Light Rail Transit (LRT) system expected to be completed in 2021 that will service Eglinton Avenue from Weston Road in Etobicoke to Kennedy Road in Scarborough, to further support accessibility along this avenue and to the Yonge-University subway line. Development along this avenue is critical in promoting the use of transit and reducing reliance on alternate methods of transportation that consume fossil fuels.

\subsection{Summary}

Learning from the challenges discussed in this section, it is important to balance the benefits and drawbacks of each factor affecting the built environment, such as solar access, development density and cost, environmental impact, and occupant health and comfort. Also, the scale of the urban environment 
must be considered - what would the City of Toronto look and feel like if every block had a high-rise building? What about solar access?

The most effective means of achieving solar access is by integrating solar access requirements into zoning regulations, through methods such as solar envelope zoning which will be defined in the following section. Although Canada does not currently have solar rights laws in place, there are many cities around the world that have successfully integrated 'solar rights' laws into their legislation and as such it is feasible. In the context of Toronto, there is ample opportunity for the densification of the city through mid-rise buildings along Toronto's main avenues. Studies have shown that the growing population in Toronto can be met through densification of Toronto avenues with carefully considered mid-rise buildings. Furthermore, mid-rise developments have become increasingly feasible in recent years since the OBC was amended in 2015 to allow six storey wood buildings. The MRG developed for the City of Toronto offer a great starting point for the consideration of adjacent buildings in terms of sunlight, privacy, and overlook. However, guidelines are limited in that they are uniform for each site and do not adequately address the varying impact street direction, site orientation, or adjacent context on solar access. To achieve urban resilience, a strategic plan must be implemented to guide further densification of the city that embraces and encourages development patterns that support solar access for both passive and active solar energy, emulating the solar city concept.

This paper will focus on the importance of solar access and passive solar design for optimal health, comfort, and resilience in urban environments. The potential for solar envelope zoning as a method for achieving solar access will be reviewed, specifically in the context of Toronto, Canada. 


\subsection{LITERATURE REVIEW}

The overarching topic driving this major research project is the integration of solar energy into urban planning regulations and the development of mid-rise buildings for urban densification. Based on a preliminary literature review, several key topics were isolated and investigated further, including: the consideration of solar energy in urban planning, tools for modelling solar potential in the urban environment, and methods and tools for creating the solar envelope. An extensive review of relevant literature was conducted, and the relevant findings are summarized in the section below. Gaps in the literature were identified to arrive at a research problem.

\subsection{Solar Energy in Urban Planning}

The quintessential model for solar energy integration in urban planning is the Solar City concept described in the previous section. A Solar City is planned to embrace and implement solar energy for passive and active purposes from the very early stages of its design (Treberspurg, 2008). For cities such as Toronto that are already substantially developed, this is far more challenging. However, the principles that guide passive solar design are consistent despite the context and can be integrated into any urban planning strategy to ensure as-of-right solar access from future development. In this way, our cities would begin to develop organically, working with nature instead of against it and thus improving urban resilience to the risks associate with climate change. In this section, the impact of urban block and building form on urban solar access and building energy efficiency will be discussed, including the tools used to assess solar access in urban environments. 


\subsubsection{Urban Block and Building Form}

A great deal of research has been conducted to quantify the impact of solar access in the urban environment. Hachem, Athienitis, and Fazio stand out as prominent authors in the area of research related to the impact of building form on solar potential and energy demand, focusing on low- and midrise residential buildings. In 2011, Hachem, Athienitis, and Fazio assessed the effect of housing shapes and arrangement within a site layout on solar potential and energy demand in low- to mid- density suburban areas. They hypothesized that neighbourhood spatial characteristics and land use regulations affect the solar potential and energy demand of buildings. They found that the shade from adjacent surfaces in self-shading shapes, such as L-shaped buildings, can affect solar radiation on equatorialfacing facades. The authors concluded that orientation and location have a significant impact on accessibility to solar radiation, as well as energy transfer mechanisms (Hachem, Athienitis, \& Fazio, 2011a). Building upon this study in 2013, Hachem and Athienitis investigated the effect of building design on energy performance, specifically looking at self-shading building forms such as L-shaped buildings. They found that a south-facing window-to-wall ratio (WWR) between $35-40 \%$ can optimize the heat gain versus losses ratio across glazed openings. They also found that the aspect ratio (AR) of south-facing façade to perpendicular façade is optimized at 1.3 to 1.7 in northern climates, since heating load is reduced by increasing south-facing areas (Hachem \& Athienitis, 2013). These studies are useful in helping to define appropriate urban zoning regulations for solar access, such as appropriate WWR targets for passive solar design.

In a further study, Hachem, Athienitis, and Fazio (2014) shifted focus away from low-rise development and investigated the effect of increasing residential density in multistory buildings on the overall energy use and solar potential for Building Integrated Photovoltaic (BIPV) systems in Montreal, Canada (a heating dominated climate). They found that as the number of stories in a multistory building increases, 
the cooling load increases and the heating load decreases. However, the heating load plateaus at a building height of 10 storeys. They also found that as building height increases, the photovoltaic potential of the roof decreases and the façade increases, and that using east and west-facing facades can reduce the time peak of generation (Hachem, Athienitis, \& Fazio, 2014). From these results, it can be surmised that a 10-storey mid-rise building is ideal to optimize heating load, and that buildings taller than 10-storeys do not reap the benefits of densification from an energy perspective. The study also outlines the important of solar access to adjacent building facades, especially in the case of taller building and higher-density neighbourhoods. As building height increases, the roof area to gross floor area ratio decreases and the solar generation potential of the roof alone cannot support the loads of the building.

As the density of the urban environment increases, the complexity of design considerations and their implications also increases, such as building height, building layout, and street width. The influence of building form and urban block form on solar access to adjacent streets and buildings is another heavily researched topic in this research area. Sanaiein, Tenpierik, van den Linden, Seraj, and Shemrani (2014) gave an overview of studies focusing on the effect of urban blocks on energy performance from three perspectives - the influence of urban form on energy efficiency and energy generation; the impact of built form on solar access for thermal comfort, daylight, and ventilation; and, the relationship between urban built form, development density, and solar access.

In 2006, Cheng, Steemers, Montavon, and Compagnon conducted a study on high-rise, high-density urban developments to evaluate the impact of building form and layout on solar access using three criteria: openness at ground level, daylight factors on the façade, and photovoltaic potential. The results showed that horizontal randomness, depicted in figure 3.1.1.1, is the most important design aspect of dense urban environments in terms of maximizing solar potential on the building façade. Also, building 
taller buildings with less footprint combined with a more random horizontal pattern provides better solar access than shorter buildings that are equally spaced. Finally, they concluded that horizontal randomness combined with vertical randomness provides more solar radiation and a more open configuration (Cheng, Steemers, Montavon, \& Compagnon, 2006). Although these findings provide an interesting insight into urban solar access in high-density neighbourhoods, horizontal and vertical randomness cannot be considered a reliable zoning strategy.

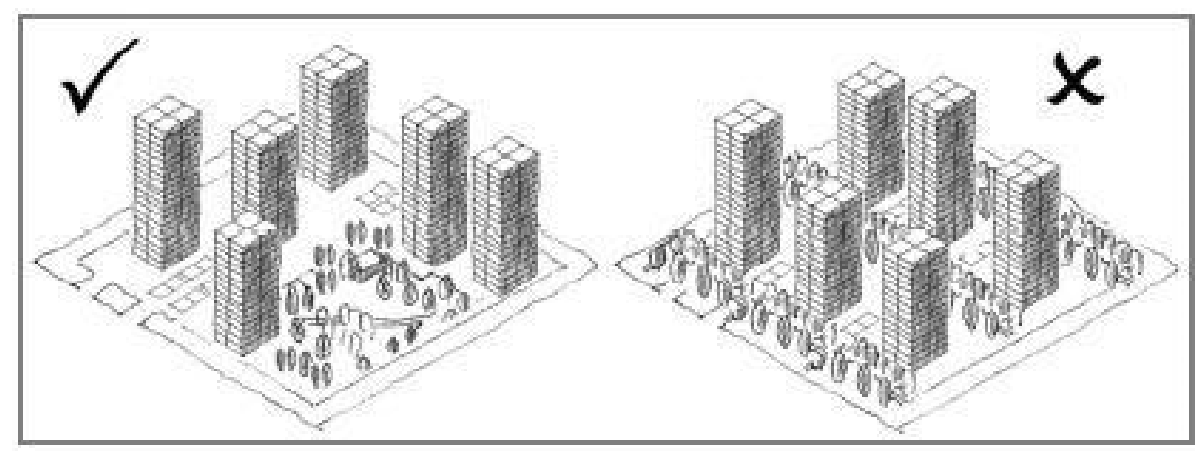

Figure 3.1.1.1. Example of horizontal randomness (left) (Source: Cheng, Steemers, Montavon, \& Compagnon, 2006)

In 2000, Baker and Steemers evaluated the effect of five building factors on energy performance climate, urban geometry, building design, systems efficiency, and occupant behaviour. They found that although urban geometry, i.e. urban block form, affects the amount of solar radiation on the building envelope, they did not find a direct correlation between urban geometry and building energy performance. For future work, studies designed to evaluate urban solar access should include the implications not only for solar access itself, but also for urban energy demand and generation.

In a study in 2010, Okiel evaluated the relationship between urban built form on the urban climate and solar access for passive and active solar energy utilization (Okiel, 2010). The purpose of the study was to maximize built-up volume without casting shadow on adjacent buildings, i.e. to balance and optimize development density and solar access. Okiel evaluated two generic building forms - the linear urban form (top) and the block urban form (middle) - against a proposed holistic residential solar block (RSB) 
(bottom) shown in figure 3.1.1.2. He concluded that designing for a holistic "solar block" to reduce solar heat gain in summer and increase solar exposure in winter can produce a more energy efficient development. In fact, the results showed 7-20\% more solar radiation in winter (Okiel, 2010). Okiel's research identifies the need for a holistic approach to building energy performance and confirms the important of solar access for reducing energy demand in the urban environment.

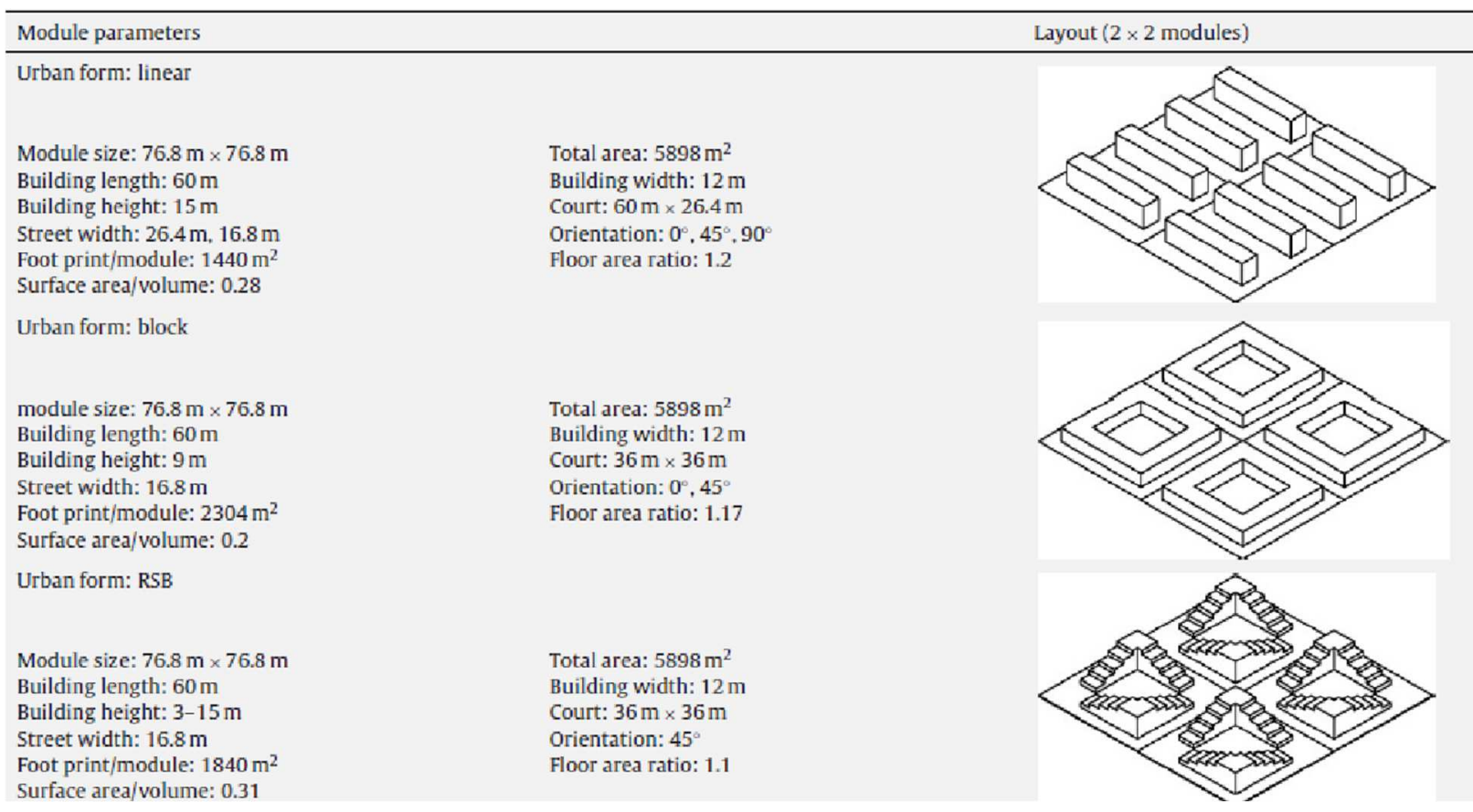

Figure 3.1.1.2 Okiel's three generic neighbourhood forms including site statistics, showing the linear urban form (top), block urban form (middle), and residential solar block (RSB) (bottom).

In 2012, Kanters and Horvat investigated how urban building forms affect the amount of energy that can be generated by solar. When solar is accounted for in newly designed urban areas, a significant amount of energy can be generated. They found that as development density (measure in floor space index (FSI) increases for the same plot, the photovoltaic potential of the buildings (roofs and facades) decreases by upwards of $70-75 \%$ when the FSI is increased from 1 to 5 , depending on building and street orientation (Kanters \& Horvat, 2012). However, other studies have shown that increasing building height (and therefore site density) can also result in a decrease in building energy demand up to a height of 10stories (Hachem, Athienitis, \& Fazio, 2014). These findings reiterate the importance of developing a 
holistic and context-dependent tool for site development that can optimize the balance between site density (FSI) and solar access for both passive and active solar projects.

Kanters, Wall, and Kjellsson (2014b) built on the previous study by Kanters and Horvat (2012) by performing a parametric study of four city blocks in Sweden using Rhinoceros and DIVA-for-Rhino. The purpose of the study was to investigate the potential for implementing active solar energy in urban planning processes by targeting key issues such as legal framework, processes, methods and tools, good examples, and further education. They found that urban block layout and density (FSI) are the two most important parameters to consider during the implementation process. As density increases, the ratio of solar potential to floor area decreases. Also, high density urban blocks are less dependent on building layout due to a decrease in roof area.

In 2013, Colucci explored the potential of harvesting solar energy by implementing design parameters that will increase access to solar radiation in Toronto, Canada. He investigated three urban typologies: high-rise towers, mid-rise buildings, and single-family detached dwellings. Colucci used Autodesk Vasari and Ecotect software to model various building morphologies. The urban blocks consisting of high-rise towers downtown Toronto had the lowest insolation levels with a high degree of overshadowing, while urban blocks of mid-rise buildings and single detached dwellings, respectively, received higher levels of insolation and to roughly the same degree. He also found that increasing the building surface area to the south is equally as important as providing solar access to the buildings due north (Colucci, 2013).

Although this paper focuses on the development of a solar zoning method to improve solar access to adjacent buildings, it is true that it is equally important to ensure that the building being developed are also optimized for solar access to benefit from passive and active solar strategies. Colucci concludes that there are many opportunities for zoning regulations to shape the future built environment in the City of Toronto. 


\section{The Urban Canyon}

The urban canyon is the area defined by the street right-of-way (ROW), the street-facing facades of buildings, and the street-facing half of roof surfaces, as outlined on the right in figured 3.1.1.3 for various roof shapes. van Esch, Looman, and de Bruin-Hordijk evaluated various configurations of urban canyons with a residential function to assess the ideal variation of parameters to benefit both indoor and outdoor solar conditions in a heating dominated climate. The objective was to provide as much solar irradiation in colder seasons and shade in warmers seasons. The paper analyzed the influence of urban and architectural parameters, such as street width, direction, orientation, roof shape and building envelope design on energy performance and solar irradiation. A diagram of the various parameters affecting solar access is shown in figure 3.1.1.3, with the baseline reference situation highlighted.

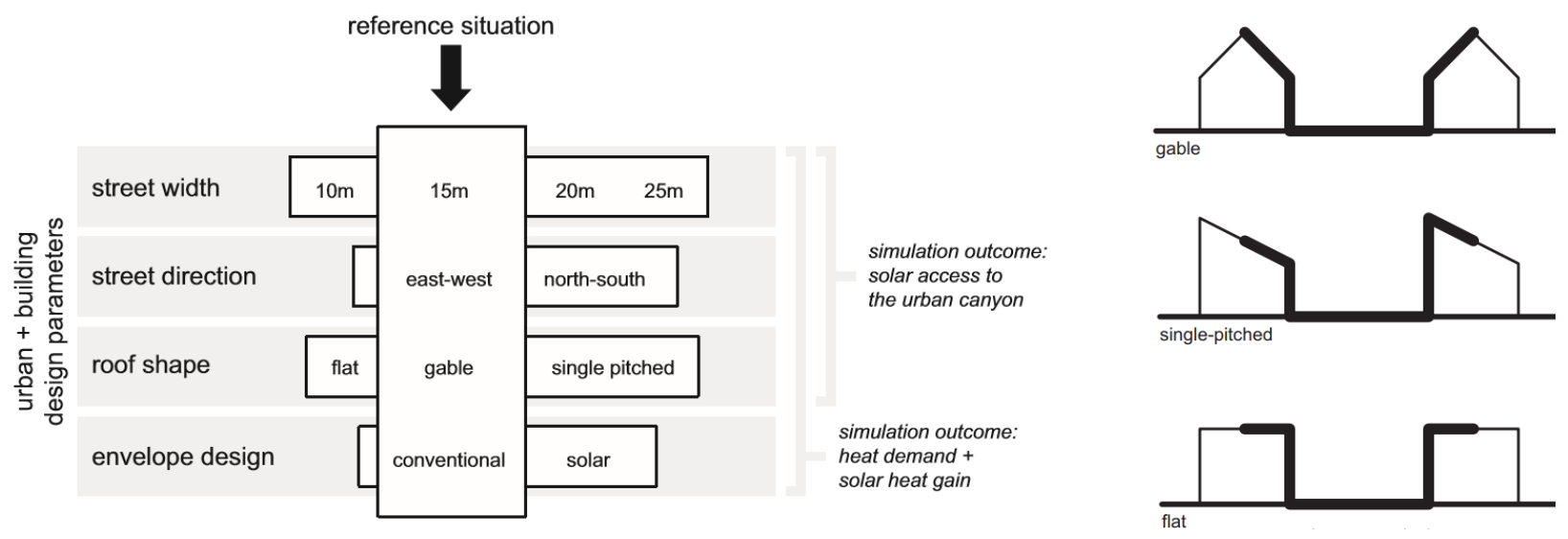

Figure 3.1.1.3. Urban design parameters affecting solar access (left), and various roof shapes and the defined urban canyon (dark line) (right) (van Esch, Looman, \& de Bruin-Hordijk, 2012).

Simulations were run in TRNSYS to evaluate solar gain. TRNSYS is a transient simulation tool that simulates thermal energy systems such as buildings. They found that street width has a significant impact on total global radiation yield of the canyon, with wider streets providing more radiation and therefore better heat gains in winter, especially for east-west oriented streets. Street direction had no real effect on total global radiation, but did affect distribution on the street, roof and facades, and thus passive solar heating potential. All canyons with east-west streets showed a decrease in radiation from 
winter to summer, which is good for passive heating. They concluded that east-west oriented streets with maximum street width and a single-pitched roof is ideal for solar access. (van Esch, Looman, \& de Bruin-Hordijk, 2012)

\subsection{Tools for Evaluation Solar Potential in Urban Areas}

In 2015, Freitas, Catita, Redweik, and Brito reviewed various computational models that are commonly used to evaluate solar radiation and potential. One of the most extensively used and validated tools for evaluating solar radiation is RADIANCE, a highly accurate freeware lighting simulation software developed at the Lawrence Berkeley National Laboratory (LBNL) in 1994 that uses a light-backwards raytracing techniques to compute radiance values (light passive through a specific point in a specific direction) (McNeil \& Chadwell, 2012). RADIANCE includes a series of functions to generate continuous sky luminance distributions, for example using the CIE definitions for clear, intermediate and overcast skies using the Perez diffuse radiation model. When a ray intersects the sky vault, the coordinates are parsed to the sky function, which returns the associated luminance/radiance (Robinson \& Stone, 2004). Another validated RADIANCE-based daylighting analysis software is Daysim, which generates an annual

illuminance profile at each point in and around buildings. Typically, the results are slightly more accurate than RADIANCE, however the computation times are much longer (Freitas, Catita, Redweik, \& Brito, 2015)

Compagnon and Raydan used RADIANCE hourly solar irradiation results through a pre-defined grid of points to produce synthesized irradiation output as a function of built area in the form of histograms (2000). The limitation of this method is that the user is unable to directly diagnose the location of surfaces with high or low solar exposure (Robinson \& Stone, 2004). Mardaljevic and Rylatt used RADIANCE to produce irradiation images by processing individual direct and diffuse solar irradiance 
images for a statistical subset of sunup hours (2000). This method is computationally complex and therefore time intensive, however it provides highly detailed and accurate diagnostic information (Robinson \& Stone, 2004).

An alternative method for modelling annual irradiation using RADIANCE is the cumulative sky approach introduced by Robinson and Stone in 2004. This technique was developed to address some of the limitations of previously developed techniques by balancing computational accuracy and simulation time efficiency, while also improving the capability to produce annual irradiation images from a single simulation. It is included in RADIANCE in the form of GenCumulativeSky. This method uses a cumulative distribution for some discretized representation of the sky vault, so that one simply aggregates values at discrete points within the vault (Robinson \& Stone, 2004).

Following the cumulative sky approach technique, Compagnon evaluated a method to quantify the global solar radiation and the global illuminance reaching building facades and roofs using RADIANCE (2004). The purpose of the study was to evaluate the potential for active and passive solar heating, photovoltaic electricity production, and daylighting in a specific building zone, and to develop a process of displaying simulation results to provide more useful information for urban planners.

An international survey conducted by Kanters, Horvat, and Dubois evaluated the barriers that building professionals such as architects to identify barriers of existing tools and methods for solar design. The survey indicated that existing software tools are too complex and therefore time intensive, too expensive, and do not integrate well with existing CAD design tools (Kanters, Horvat, \& Dubois, 2014). Furthermore, detailed modelling of buildings can be too complex for the selected software and therefore the building must be simplified, which is not representative of the as-built case and therefore creates a margin of error. Future development of software tools for solar architecture should focus on a user-friendly, visual tool which can generate clear and meaningful results. 
The need to develop user-friendly methods and tools that can be used by architects and urban designers to promote solar design is a common thread throughout much of the literature. As such, there has been continual development of simulation tools that integrate well with commonly used visual 3D modelling software. As an example, the RADIANCE platform has been integrated into the DIVA plug-in for Rhinoceros and Grasshopper, as well as Ecotect for AutoCAD. The building and/or urban form geometry created in the 3D software can easily be assigned a material property (reflectance value) and input into the RADIANCE component to evaluate the solar radiation potential of the site or building while considering the surrounding context and obstructions.

\section{Solar Potential Mapping Tools}

The development of solar potential mapping tools and the creation of solar potential maps for urban areas is increasing. Many of the urban maps and tools that have been created are made publicly available so that they are accessible for use by not only academia, but also the industry and the public. The purpose of solar radiation maps is to promote the integration of active solar generation technologies in urban areas by offering users the ability to easily assess the solar energy potential of their property. Solar maps have been created for many urban areas throughout Europe. In North America, however, there are only a select few.

In 2014, Kanters, Wall, and Kjellsson evaluated existing solar maps in terms of the assumptions made in rating the suitability of surfaces to identify limitations. They found that any existing solar maps only considered roof area and not façade area. They also found that some maps provided users with direct information for suppliers and installers, while some only provided solar irradiation (Kanters, Wall, \& Kjellsson, 2014a). These findings are true for solar maps across North America. There are a variety of solar maps available for the United States and Canada that offer high-level views of the solar potential at the country and province/state level. Figure 3.2.1 shows the average solar energy yield of a fixed solar 
array (calculated at the optimum angle for each location point) in kWh per kilowatt peak (kWp) (peak power of the solar module) per year for Canada (left) and Ontario (right) developed by EcoSmart (2014). As is evidenced by the measured metric, these maps are developed to evaluate solar energy potential for active solar energy generation, and do not address solar energy potential for passive solar design. Solar maps should be designed at the urban scale to address solar energy incident on all surface, including the building façade and roof, and the ground plane (street, etc.).
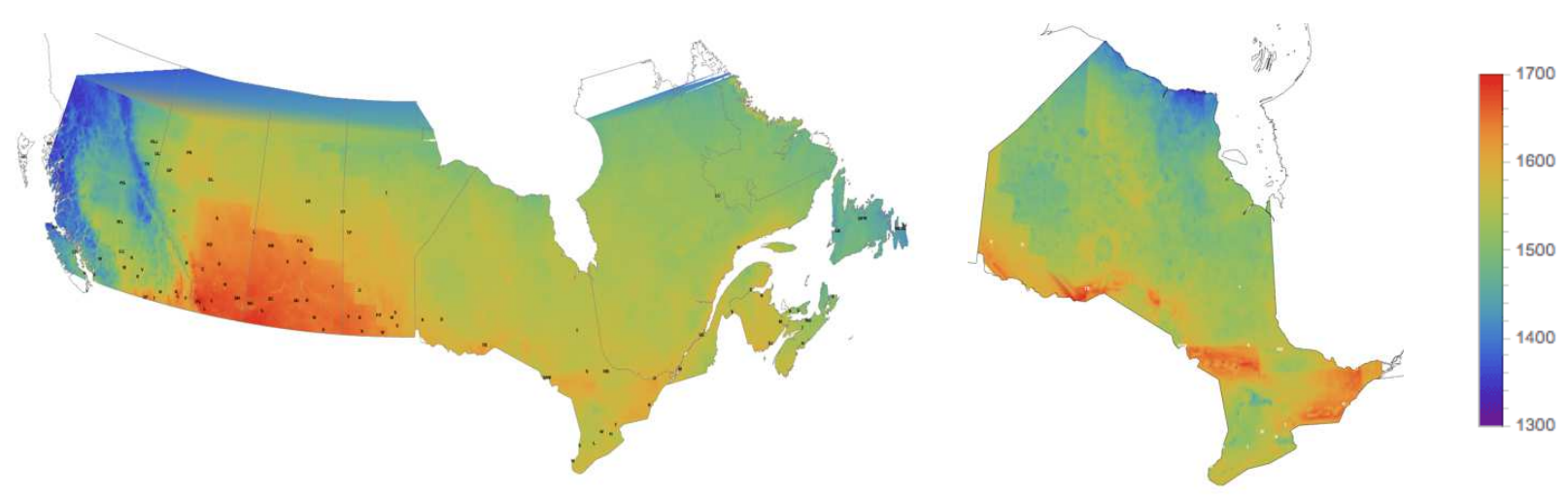

Figure 3.2.1. Solar map of Canada (left) and Ontario (right) in average solar energy yield of kWh/kWp per year (Source: EcoSmart, 2014).

\subsection{Solar Envelope Zoning}

Around the same time that the 'right to light' doctrine was being reintroduced in the United States, Ralph Knowles, a professor of architecture at the University of Southern California, was developing a new method of zoning sites that would ensure solar access to adjacent lots for a set period of time each day throughout the year. He coined the term "solar envelope zoning." Knowles began to develop and test the solar envelope in 1976 as a zoning device to achieve solar access by regulating development within limits derived from the sun's relative motion (Knowles, 2003). The driver of his research was the idea that this type of zoning would eventually cause a shift away from fossil fuel energy to more 
sustainable sources such as solar energy. Although this concept has been well researched over the past 40 years, it has yet to make the leap from academia to industry practice.

Between 1976 and 1981, Knowles published several journal articles describing the manual method of creating the solar envelope. The purpose of the literature was to develop a zoning tool used to create the solar envelope on a given site in order to balance the right to develop a given property with the right of access to direct sun for all properties including those adjacent to the given site. The solar envelope creates the largest developable volume on a parcel of land while ensuring solar access to neighbouring properties. Within this concept, there is a space and a time dimension. Figure 3.3.1 shows several examples of the solar envelope concept on four adjacent blocks with varying street and block orientation. The solar envelope volumes generated on each block, shown in the left of the figure, represent the volume within which a building can be constructed so as not to shade the neighbouring building within the given solar access constraints. The idea is no different than current zoning practices, which prescribe a certain developable volume on a parcel of land based on specific setbacks and height requirements. However, current zoning does not dynamically account for solar access, although there are few countries and states that do integrate shading restrictions into their by-laws in some way. Moreover, the floor space index (FSI) requirements allow developers flexibility to vary the shape of the building, greatly varying the potential for overshadowing, or conversely limiting the developable density of a site without considering the surrounding context. 

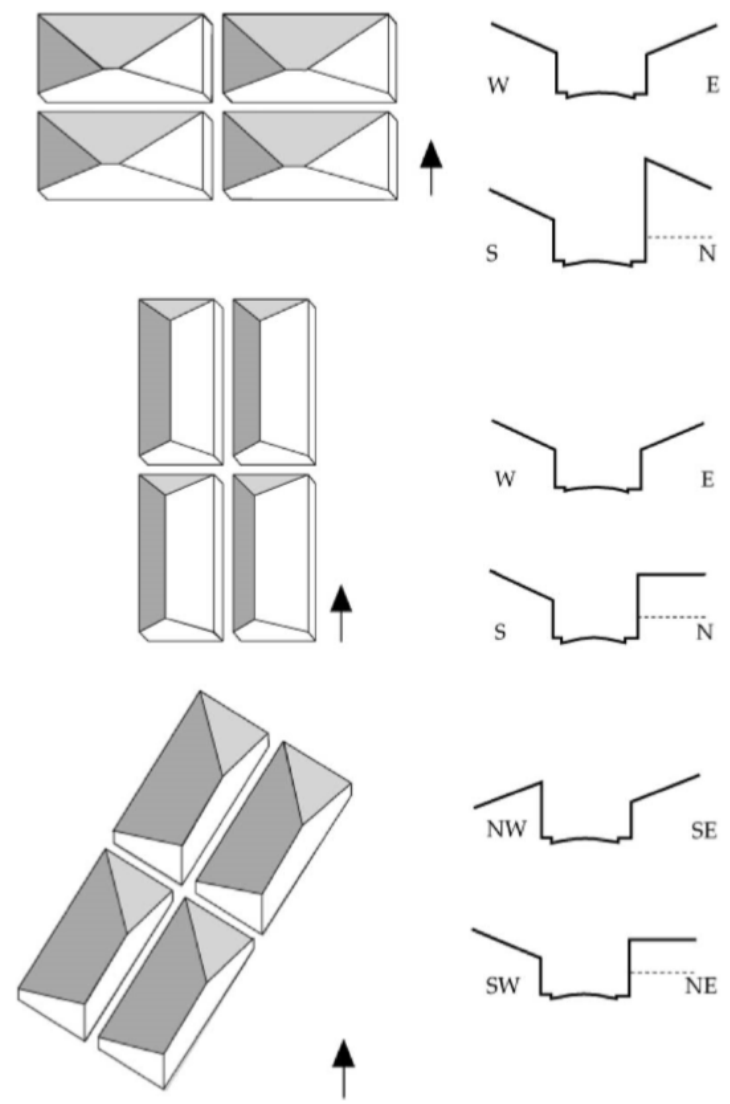

Figure 3.3.1. Examples of the solar envelope volume showing the solar envelope volume (left) and street section (right) for varying site and street orientations (Knowles, 2003).

\section{Shadow Fences}

The solar envelope avoids unacceptable shadows above designated boundaries called "shadow fences."

The desired shadow fence is located on all adjacent properties. The location of the shadow fence on the property is determine by adjacent land uses and solar access needs. Figure 3.3 .2 shows four examples of potential shadow fence locations, at (a) the property line, (b) the building footprint, (c) the base of windows, and (d) the edge of roofs of adjacent buildings. For example, a residential lot may require solar access to their entire property at certain times of day for urban agriculture, or at minimum to the base of windows for passive solar gains. Knowles suggests that for high-density urban areas, it is often more practical to designate adjacent roof surfaces as the shadow fence, which he refers to as "roof-top conversion." However, the ideal scenario is what Knowles calls "whole-building conversion," which 
designates the entire building surface for solar access. In this case, there is a greater potential for natural daylighting and the use of solar gains using thermally massive materials, but it is most appropriate for moderate density development.

a)

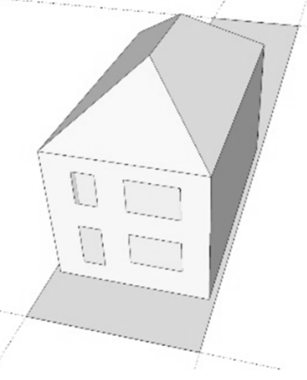

b)

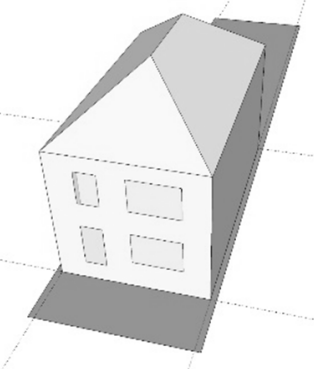

c)

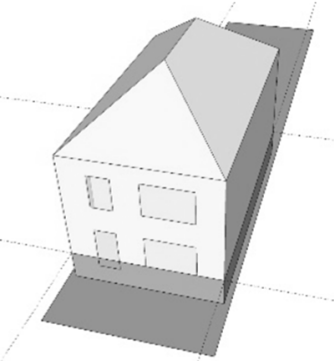

d)

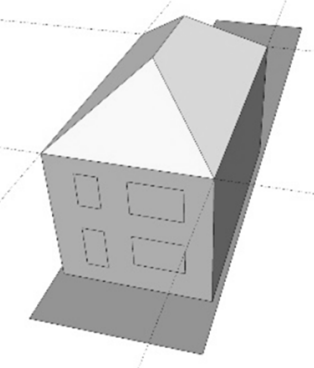

Figure 3.3.2 Typical house showing shadow fence requirements of a) whole building lot, b) whole building, c) ground floor window, and d) whole roof.

Using the shadow fence as a boundary line around the site, the angles of solar azimuth and altitude created by the solar path can be transferred to the edges and corners of the shadow fence. Then, the entire solar envelope volume can be created from these surfaces. Differing heights of shadow fences can be recommended for varying uses, resulting in contrasting shapes and sizes of the solar envelope.

\section{Cut-off Times}

The solar envelope is determined by time as well as the constraints of the given parcel of land. The time parameter is a set period within which direct solar radiation must reach above the designated shadow fence (Knowles, 1981). The solar cut-off times are typically placed equally before and after 12:00, since this is when the sun is at it's highest altitude. As the solar access times move away from 12:00 in either direction, the sun altitude angle decreases and therefore the volume of the solar envelope will be reduced. For example, the solar access period may be desired between 10:00 and 14:00 for a total of four hours, represented by the diagram on the left in figure 3.3.3. On the right, a two-hour solar access period is shown with cut-off times between 11:00 and 13:00. The resulting volume of the solar envelope on the right is larger than the volume on the left. In 1981, Knowles studied the development density 
potential using solar envelope principles in California. He found a "minimum period of six hours a day [to be] practical" for passive and active solar projects. The result is a smaller solar envelope volume and lower development density, but optimal solar access for passive solar design. According to Pereira, Nome Silva, and Turkienikz (2011), as early as the 1950's, minimum solar access windows have been recommended for human health and wellbeing in the built environment. To ensure the bacteriological effect of insolation and to satisfy certain human psychological requirements, a minimum solar insolation duration of 1.5 to 2.5 hours per day was recommended. However, the desired cut-off times for a site depend heavily on the climate and context.

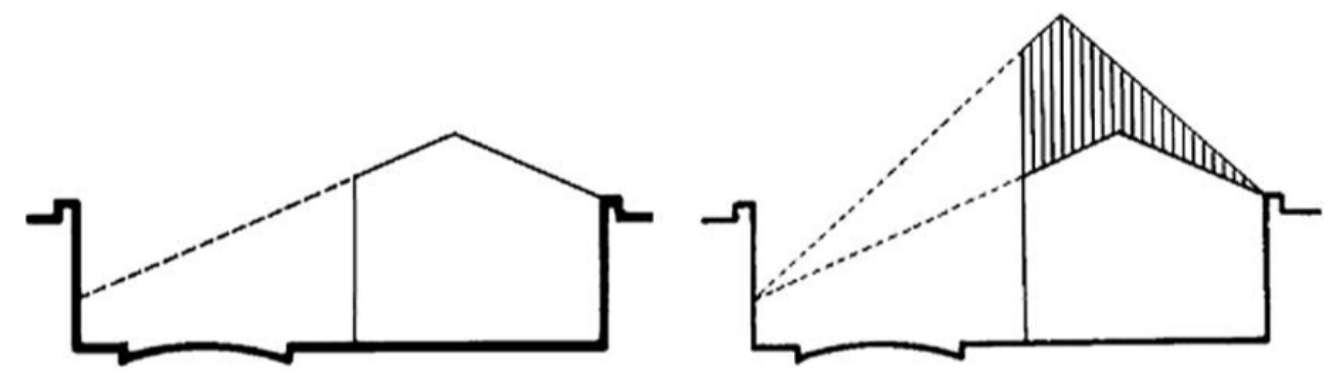

Figure 3.3.3. Specifying different cut-off times changes the sun angles for the solar envelope. Higher solar altitudes provide greater solar envelope volume (right) (Knowles, 2003).

\section{Sustainable Growth under Solar Envelopes: A California Case Study}

In 2003, Knowles discussed the results of a 10-year housing study performed by students in USC's School of Architecture's Solar Study program which evaluated the possibilities for sustainable growth under the solar envelope in California. The parameters used to create the solar envelope on each site were as follows:

- $6 \mathrm{~h}$ of sunshine on a winter day

- $10 \mathrm{~h}$ of sunshine on a summer day (for outdoor recreation and gardening)

- Shadow fence height of 2.5 meters ( 8 feet) at front and rear property lines 
The study showed that buildings with a low volume to surface area ratio (V/S), such as detached dwellings, have a stronger architectural connection to sunlight, fresh air, and view than larger buildings with a high $\mathrm{V} / \mathrm{S}$. As density increases, buildings become larger and solar access and cross-ventilation to individual dwelling units (du) becomes harder to achieve. The author found that the maximum desirable $\mathrm{V} / \mathrm{S}$ for passive design projects is ten, corresponding with a maximum density of about $100 \mathrm{du} / \mathrm{acre}$. For a V/S greater than ten, reliance on energy intensive systems is inevitable (Knowles, 2003). The study concluded that mid-rise residential buildings of 3-7 stories generally represent the best size range for passive and low-energy strategies in Los Angeles. Physical models of the conceptual solar envelopes (left) and proposed detailed architectural buildings (right) are shown in figure 3.3.4.
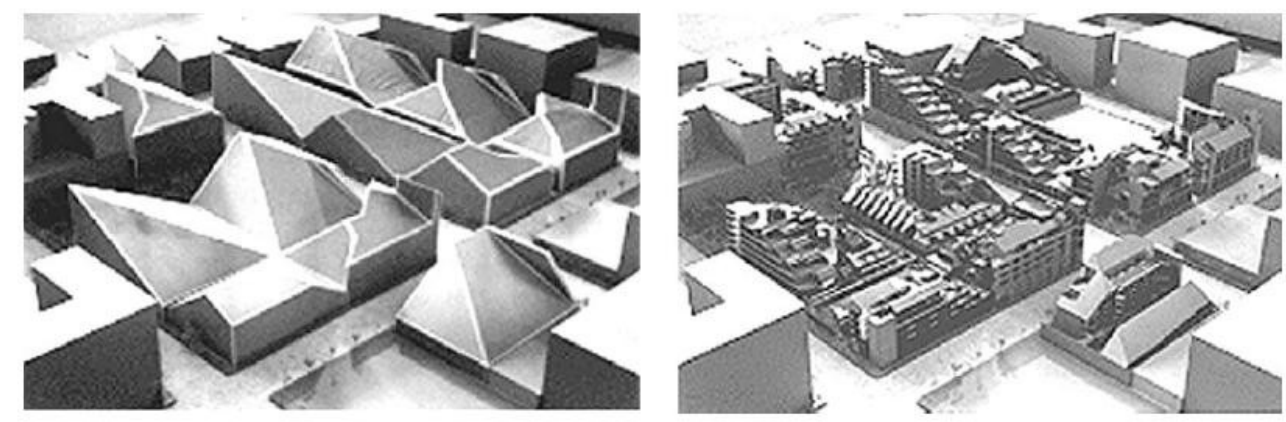

Figure 3.3.4. Housing project which permits a minimum of 4 hours of sunlight to each dwelling. Conceptual design using the solar envelope (left) and fully designed buildings with architectural features (right) (Knowles, 2003).

\subsubsection{Methods for Generating the Solar Envelope}

\section{Manual Methods}

When the solar envelope concept was created by Knowles in the mid 1970's, the solar envelope volumes were created manually by transferring the angles of solar azimuth and altitude created by the solar path onto the edges and corners of the shadow fence. This method was useful in developing the solar envelope concept and testing it in theory on fixed uniform rectangular sites. However, using this method on real urban sites becomes increasingly complex. The process becomes extremely time- 
intensive and the level of accuracy is heavily dependent on the creator. In 1986, Vonderohe investigated the manual method further to develop a mathematical model for the creation of the solar envelope geometry in an attempt to improve the accuracy of the tool and the efficiency of the method. However, the mathematical model was complex and therefore limits its usefulness as a zoning tool that can be used for urban planning.

\section{Computer-Aided Design (CAD)}

When computers became available and accessible to the public in the mid 1980's, the natural progression in the development of the solar envelope was the use of computer-aided design (CAD) tools. In 1992, Ueng-Fang developed SolVelope, a computer program that allowed users to test the solar envelope on a given site for different latitudes, times and dates, site size and orientation, and neighboring site conditions (streets, parks, adjacent buildings). The program was limited to flat, rectangular sites and it was not compatible with the existing CAD tools at the time. In 1996, Cotton developed a methodology for creating solar envelopes using the computer 3D solid modelling program Form Z. He concluded that this method of creating solar envelope is faster and more accurate than the previous method of creating solar envelopes manually, and could be a useful tool for urban planning purposes.

In 1997, Capeluto and Shaviv developed the program SustArc (Sustainable Architecture) to create the solar envelope and evaluate its impact on development density in urban environments. Using this tool, the authors further developed the traditional solar envelope zoning concept for solar access, which they termed the solar rights envelope (SRE), by creating a second solar envelope zoning concept called the solar collection envelope (SCE). The SCE creates a volume similar to the solar envelope above which the building will not be in shadow from adjacent buildings within the given constraints (time, environmental conditions) and will receive solar energy for either passive or active solar collection. The SCE was found 
to be useful in evaluating the impact of self-shading building forms on energy performance (Capeluto, 2003). The SCE and the SRE can be interpreted as the upper and lower limit of the solar volume to balance solar collection and solar access. In a further study by the Capeluto and Shaviv in 2001, the impact of street width and orientation, distance between buildings, and rear yard depth on the solar envelope volume were assessed using SustArc. The authors found that using the SRE, the highest development density potential occurs on NE/SW oriented streets and row buildings.

In 2001, Pereira, Nome Silva, and Turkienikz presented methodological tool for helping authorities, architects, and urban planners to define climate-dependent solar access requirements and develop a method to measure the impact of urban development on solar access to achieve the goals identified in the solar access requirements. In the early 1950's, 1.5 to 2.5 hours of direct sun per day was considered enough in order to ensure the benefit of the bacteriological effect of insolation, and also to satisfy certain human psychological requirements (Pereira, Nome Silva, \& Turkienikz, 2001). As such, insolation duration was the first scientific criteria proposed to regulate solar access in the built environment. The authors used a method developed by Pereira and Noma Silva (1996) which combines the climatic conditions of the site and the psycho-physiological requirements from people (user satisfaction/dissatisfaction based on the outdoor and indoor climate conditions) to calculate the times when insolation is desirable and undesirable on a given façade. The method uses MascaraW, which reads DXF files containing the drawing data of the site. The data is interpreted according to stereographic projection criteria and the obstruction of the sky vault produced by the built environment to a reference position is plotted over the sunpath diagram. This method proposes the generation of planning and land use guidelines on a scientific basis and was adopted by many authors in later publications as a baseline. Leveretto used the method described by Pereira and Nome Silva (2001) for a study published in 2002 that evaluated the solar access of a typical open public square in Buenos Aires, Argentina, using AutoCAD2000. Various building forms were proposed to improve winter solar access to 
open public spaces. The impact of building form on development density was also considered in order to achieve balance between development density and solar access (Leveretto, 2002).

These methods of generating the solar envelope are effective for evaluating the concepts potential on regular urban grids. However, the methods and tools are limited to simple sites and geometric forms and are unable to address the complexity of large and irregular urban sites. These previously discussed methods consider all sun rays to be equal in terms of solar access, however this is not actually the case. The angle of incidence and the intensity of the sun rays greatly impact the available solar irradiation and illumination levels, which have direct implications on energy. To address the limitations of existing solar envelope generation methods, Morello and Ratti (2009) introduced the concept of 'iso-solar surfaces' using urban digital elevation models (DEMs). Iso-solar surfaces are three-dimensional geometric envelopes which describe the maximum building volumes that provide a prescribed amount of solar irradiation on adjacent sites (Morello \& Ratti, 2009). Building on Capeluto and Shaviv's (1997) definition of the SRE and SCE, Morello and Ratti developed two types of iso-solar surfaces: iso-solar rights surfaces (ISRS) to provide solar access (shown in figure 3.3.1.1 on a case study site in Milan, Italy), and iso-solar collection surfaces (ISCS) for solar collection on the given site. The authors found that compared to solar envelopes, iso-solar surfaces allow a more accurate quantification of radiation or illumination values and a more accurate assessment of the impact of the built environment on solar access.
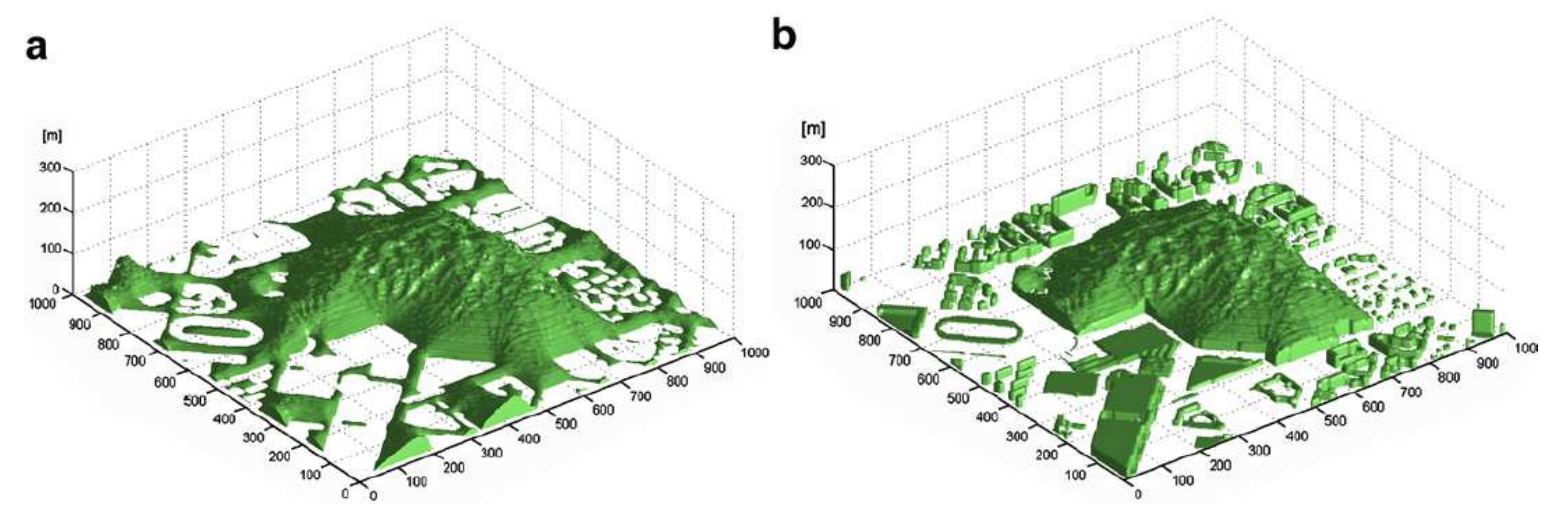

Figure 3.3.1.1. Iso-solar rights surfaces on a case study site in Milan based on an irradiation value of $260 \mathrm{~W} / \mathrm{m} 2$ applied to all surroundings, for (a) all open spaces, and (b) the exact boundaries of the case study site (Morello \& Ratti, 2009). 
In 2011, Niemasz, Sargent, and Reinhart developed a Grasshopper ${ }^{\mathrm{TM}}$ component for Rhinoceros $^{\circledR} /$ Grasshopper $^{\mathrm{TM}}$ (Rutten, 2010) that generates a neighbourhood of solar envelopes in real time based on street plans, site altitude, and required solar access cut-off times. They then exported the models into EnergyPlus to determine solar irradiation potential. Using this tool, they investigated the implications of the solar envelope zoning approach for single-family dwellings in the United States with respect to energy use and developable density. The solar envelope study located in Denver, Colorado used a solar access window of 4 hours, from 10:00 to 14:00, on June 21. They found that increased solar access requirements resulted in a decrease in solar envelope volume and developable density. Specifically, they found the solar envelope has an especially negative impact on developable density for more northern latitudes. In terms of energy, they found that the solar envelope on the building type investigated had limited benefit on energy use in heating dominated climates and no benefits in cooling dominated climates. This raised questions about the overall usefulness of solar envelopes as a feasible tool for development. However, this study exclusively evaluated suburban lots for single-family dwellings. The study did not address the feasibility of the solar envelope as a zoning tool in the urban context, which will present other challenges and opportunities for creating and modifying the solar envelope depending on site size and shape, and the surrounding buildings.

In 2013, Raboudi and Ben Saci evaluated the potential for solar envelope zoning in the urban context using the "Solar Bounding Box (SBB)", a is a spatial delimitation of the optimum volume conditioned by both the urban rules of form (zoning regulations) and the solar envelope rules (solar fence and cut-off times) (Raboudi \& Ben Saci, 2013). The purpose of the study was to optimize the developable volume of the SBB by varying the solar fence and cut-off times. The resulting volumes were compared with the zoning volume created by the urban zoning regulations in Tunisia, such as FAR, Plot ratio, maximum height, setbacks, etc. The author attempts to prioritize urban rules based on their relation to solar control, indicating the setbacks, height, FAR were the most significant. The aim of the work is to assist 
planners to draft urban rules of solar control by providing them an urban specifications document in the form of an interactive 3D volume.

In 2014, Poggi and Amado described a theoretical model inspired by the structure of the atom using Geographic Urban Units Delimitation (GUUD) to address the energy balance of urban environments to support the energy transition to solar power in the urban context. Using Grasshopper ${ }^{\mathrm{TM}}$ for Rhinoceros ${ }^{\circledR}$ and the GECO interface for Ecotect ${ }^{\circledast}$, a solar radiation analysis was performed to calculate the solar radiation incident on each roof and façade surface over the year to estimate the total photovoltaic potential. Future work will focus on integrating this data with urban energy consumption to achieve urban energy balance and resilience using an accessible and easy to use tool.

In 2017, Plotnikov and Capeluto described a method for the generation of climate-based, contextdependent parametric solar envelopes using Grasshopper ${ }^{\mathrm{TM}}$ for Rhinoceros ${ }^{\circledR}$ and the Ladybug suite of environmental analysis tools. The model extends upon the SustArc model, developed by Capeluto and Shaviv (1997). The purpose of the study was to develop an accessible tool for solar envelope generation within easy to use modelling and simulation tools that are currently being used in industry and can therefore be feasibly adopted. The solar envelope component in Ladybug was used to generate the solar envelope. Previous limitations of the parametric solar envelope tool were improved to better address the adjacent context, allowing for more refined and specific solar envelope volumes and solar fence identification. Plotnikov and Capeluto (2017) expanded on earlier work by Capeluto et al. (1997, 2001, 2003) using the SRE and SCE by more clearly defining the goals for solar access and refining the input parameters to mediate between maximizing the solar envelope volume and developable density, and optimizing solar access for adjacent buildings. The authors proposed that by redefining the conditions which constitute a violation of solar rights using real-world requirements for solar access such as temperature, radiation levels, relative humidity, and wind, the solar envelope can be optimized 
(Plotnikov \& Capeluto, 2017). The authors evaluated the impact of limiting the number of sun vectors within the analysis period. Figure 3.3.1.2 shows the resulting simulated SRE's and corresponding developable volume for (A) the baseline SRE with cut-off time from 10:00 to 15:00 on December 21, (B) the baseline plus only sun vectors that occur when the outdoor ambient temperature is below $18^{\circ} \mathrm{C},(\mathrm{C})$ the baseline plus only sun vectors that provide a minimum annual solar radiation greater than 472 $\mathrm{Wh} / \mathrm{m}^{2}$, and $(\mathrm{D})$ both $(\mathrm{A})$ and $(\mathrm{B})$.
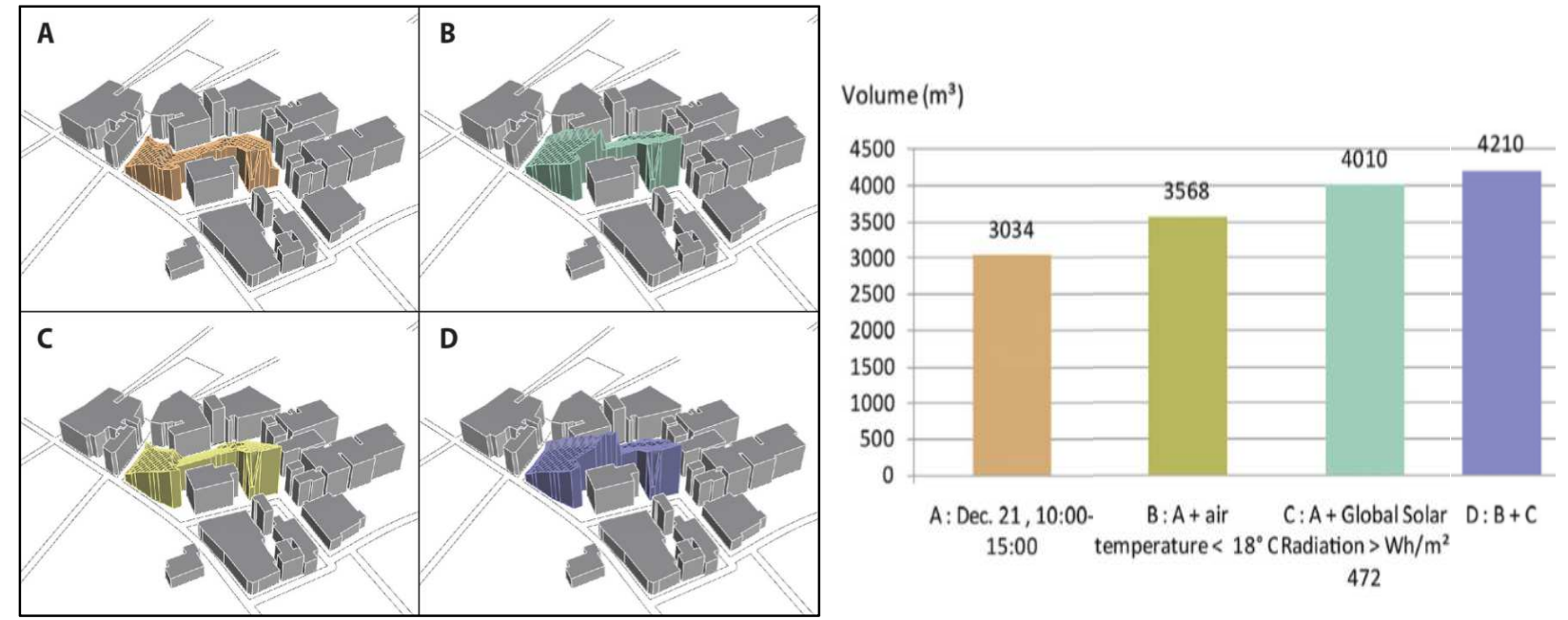

Figure 3.3.1.2. Comparison of the developable volume of the SRE created by redefining the conditions which constitute a violation of solar rights such as temperature (B) and solar radiation (C).

The results show that by increasing the input parameters and thus redefining the solar rights goals, the solar envelope volume can be increased. The authors also found that as the number of heating degree days (HDD) increase for a site, the solar volume decreases and noted the importance of context when generating solar envelope volumes.

In 2017, De Luka and Voll performed a parametric study using Grasshopper ${ }^{\mathrm{TM}}$ for Rhinoceros $\bigodot$ and the Ladybug environmental analysis suite. The purpose of the study was to develop a tool for generating the maximum buildable volume within the solar envelope. The aim was to create a tool that is user-friendly enough that it can be implemented and used by architects and urban planners to achieve the solar access requirements set by local authorities. The case study evaluated four urban sites in the City of 
Tallin, Estonia, where new development is required to provide solar access to adjacent sites equal to at least $50 \%$ of the precedent situation for each day from mid-April to mid-August (De Luka \& Voll, 2017). The authors identified that previous methods developed to create the solar envelope considered all sun rays within a specified analysis period and defined solar cut-off times. However, Estonian regulations require a solar access window of 4 hours per day but do not specify at what time of day. The authors hypothesized that by using a recursion tool to analyze each façade individually in terms of actual sunlight hours visible or not visible from that façade would increase the solar envelope volume while meeting the solar access requirements more accurately. At the time of this publication, the authors identified that the solar envelope component in Ladybug did not have the capability to input the surrounding built context. However, this was resolved by Capeluto and Plotnikov (2017) with updates to the component.

The algorithm developed by the authors is shown in figure 3.3.1.3 identifying off the shelf components in white and the parametric tools created by the authors in grey. For each façade, the hourly sun vectors output from the sun path are categorized as either visible or not visible. All sun vectors visible to the façade are then collected and organize by sun altitude angle and the top $50 \%$ (with the highest sun altitude angles) are then used to generate the solar envelope. Since each façade is evaluated individually, numerous solar envelopes are created. The solar envelopes are overlaid, and the lowest points are selected to define the maximum volume that fits the requirements of all facades to generate the final solar envelope mesh. This method is unique in that each façade is evaluated individually, and there is the potential to evaluate a solar access window by required hours per day rather than a set time. The study showed that by including the surrounding context and the required sunlight hours into the calculations, the buildable volume is significantly increased as is evident in figure 3.3.1.4. The developable volume for high-density areas increased by 4.15 times, and the developable volume in lowdensity areas increased by 1.36 times (De Luka \& Voll, 2017). De Luka and Voll recommend that future 
work involve the investigation of methods to generate the building mass from solar envelopes and to optimize building layout for solar collection while taking into consideration the potential future development volume of the surrounding context.

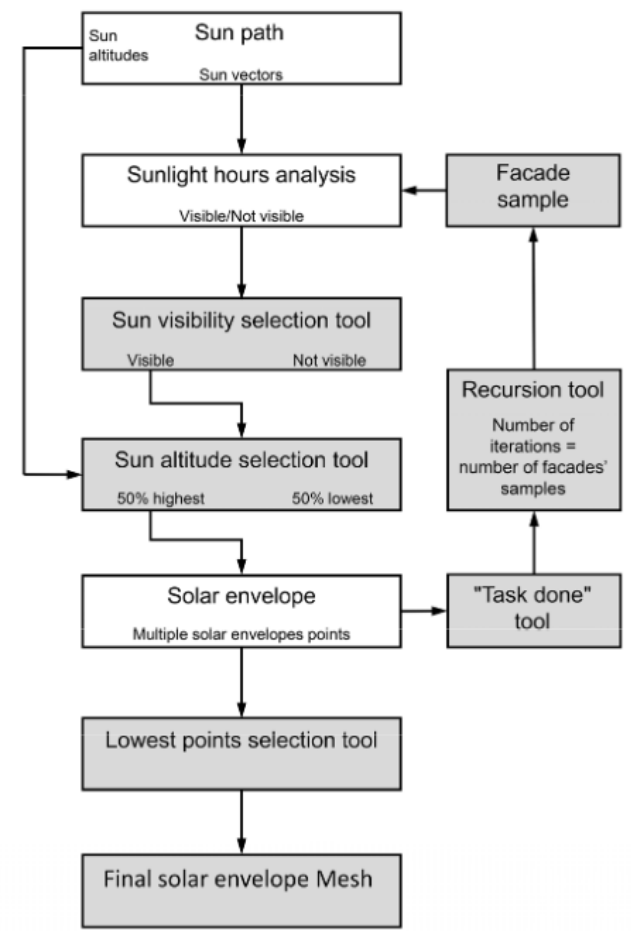

Figure 3.3.1.3. Flowchart of the algorithm developed by De Luka and Voll. Off the shelf components are in white and tools developed by the authors are in grey (Source: De Luka \& Voll, 2017).

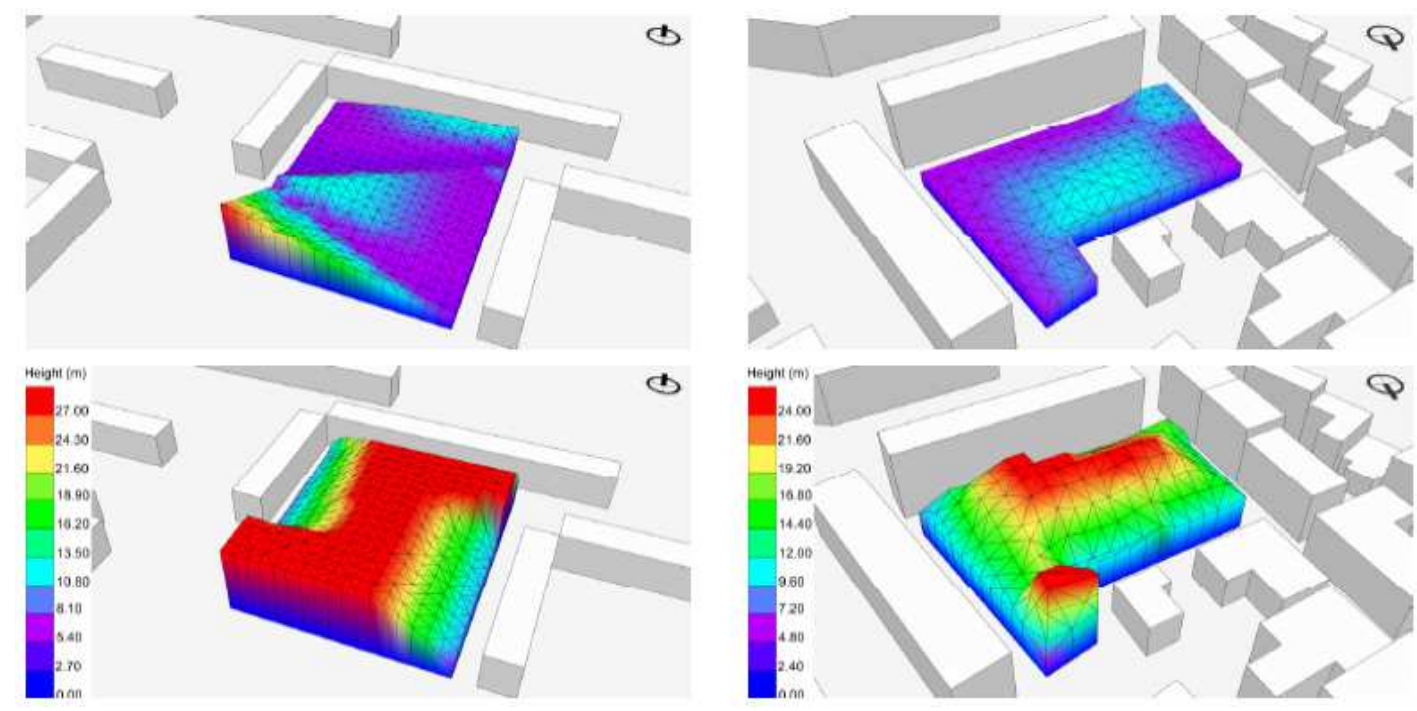

Figure 3.3.1.4. Solar envelope volume generated in a low-density area (left) and high-density area (right), showing the solar envelope created by the context only (top) and the volume created by the context and the Estonian solar access requirements (bottom) (Source: De Luka \& Voll, 2017). 


\subsection{Summary}

In general, the underlying goal of research surrounding solar energy in urban planning and the solar envelope is to optimize the balance of providing solar access in urban environments for occupant health, comfort, and energy, with the desired urban development density. To achieve this, the research has focused heavily on the development of a user-friendly tool that can be used by architects, urban planners, and authorities so help in designing for solar access in the urban environment. The tool can then be used as a method of defining desirable parameters for solar access such as climate, and then measuring and achieving specific solar access requirements regulated by authorities. As of yet, the leap from academia to practice has not been made. However, within even the last few years there have been significant advances made in the development of parametric tools that are compatible with existing and commonly used 3D modelling programs such as Rhinoceros.

Research conducted prior to that of Capeluto and Plotnikov (2017) and De Luka and Voll (2017) often underestimated the size of the solar envelope due to the rigidity of the input parameters used to define solar access. The consideration of urban climate and occupant comfort first proposed by Pereira and Nome Silva (2001) to define solar access parameters implemented by Capeluto and Plotnikov (2017), in concert with the parametric tools developed by De Luka and Voll, have significantly increased the viability of the solar envelope as a zoning method by redefining the climatic conditions within which solar access is required, resulting in a larger solar envelope volume and more accurate solar access.

Based on an extensive review of the literature, it appears that no studies have evaluated the potential for solar envelope zoning as a method for regulating urban solar access in an urban setting in a temperate climate such as Toronto, particularly using the methods described by Capeluto and Plotnikov (2017) and De Luka and Voll (2017). 


\subsection{RESEARCH IDENTIFICATION}

Based on the findings of the literature review, the purpose of this study is to investigate the potential of solar envelope zoning as a tool to integrate solar energy in urban planning in the Toronto context. To assess the viability of this method, a parametric analysis of the solar envelope will be performed on a typical site to determine the impact of design decisions on two main factors - the solar access to adjacent buildings, and the developable density of the site. Current City of Toronto zoning regulations and the Avenue's and Mid-rise Building Guidelines will be used to compare against the results of the study to answer the following questions:

1. What is the level of impact of street width and orientation on development density and solar access using the solar envelope zoning method?

2. Can the solar envelope volume be optimized to balance adequate solar access, while allowing for development density equal to or greater than existing City of Toronto zoning and the Mid-Rise Guidelines?

3. Can the solar envelope volume be increased by redefining the environmental parameters that must be met for sunlight to be required? 


\subsection{METHODOLOGY}

To develop a methodology for the evaluation of the solar envelope as a feasible zoning method in

Toronto, a "typical site" for Toronto was derived through methodical evaluation of building lots along

Eglinton Avenue West using property data maps in AutoCAD. Figure 5.0.1 shows an aerial of Eglinton

Avenue West, highlighting the section of lots directly adjacent to Eglinton that are zoned for mixed-use

commercial/residential where mid-rise buildings are being promoted, and the adjacent low-rise singe-

family residential neighbourhood to the north and south of Eglinton. The method of determining the

parameters for the typical site is described in the following paragraphs.

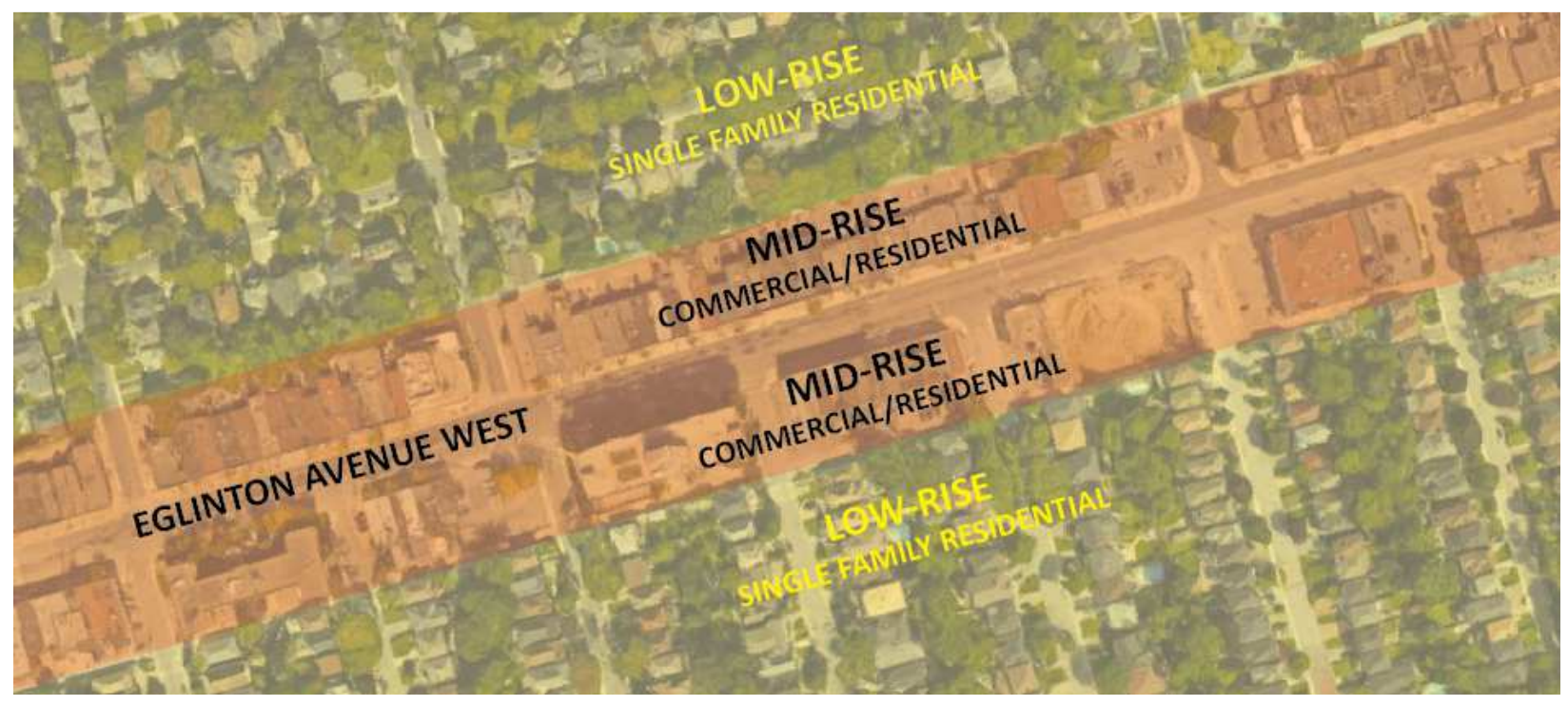

Figure 5.0.1 Aerial of Eglinton Avenue West, showing mid-rise commercial/residential buildings along the avenue, with low-rise single-family residential neighbourhoods in behind.

\section{Street Right-of-Way}

The street right-of-way (ROW) along Eglinton Avenue West was determined by evaluating property data maps in AutoCAD and isolating the boundary lines of each property along Eglinton Avenue West between Spadina Avenue and Weston Road. A line of best fit was first drawn at the edge of the street ROW on either side of Eglinton. The lines were then offset inward toward the street by typical avenue 
street widths as determined by the Toronto Avenues and Mid-Rise Buildings Study of 20, 23, 27, 30, 33, 36, and 45 meters. It was determined that the ROW for Eglinton Avenue West is $\mathbf{2 7}$ meters.

\section{Typical Lot Depth}

The typical lot depth along Eglinton Avenue West was determined using the same method as the street ROW above. However, this time the line of best fit drawn at the street ROW was offset into the lot to determine the average lot depth. The lot depth was evaluated from 20 meters to 40 meters at 2-meter intervals. Although the lot depth varies, it was determined that the most consistent lot depth is 30 meters, with a 5-meter-wide lane between the typical lot and the adjacent property to the rear.

\section{Typical Lot Width}

The typical lot width was more challenging to determine. There is no measurable consistency in the lot widths on Eglinton Avenue. However, it is likely that as development occurs in these areas, many small lots will be amalgamated for larger mixed-use buildings. Therefore, an entire block was examined. Using a similar methodology to that described above, the average block width along Eglinton Avenue West was found to be 75 meters.

\section{Street Orientation}

Eglinton Avenue is an East-West oriented street, tilted on an angle of approximately 16.75 degrees South of East. For the purpose of this study, the same tilt angle will be used for the streets that are oriented North-South, with a tilt angle of 16.75 degrees West of North.

\section{Typical Site}

Using these parameters, a typical site was created (shown in figure 5.0.2 on an East-West oriented street) with six blocks - three on the north side and three on the south side. Each block consists of one 
commercial building lot and six residential building lots. The commercial buildings were generated using the requirements as outlined in the City of Toronto zoning by-law for the site, limited by a maximum floor space index (FSI) of 2.5. The resulting buildings are 13.5 meters tall (4 stories). The residential buildings are all single-family detached homes. These were developed from evaluating a 3D model of the City of Toronto. A typical home was selected and replicated to represent a low-rise neighbourhood with pitched roofs, which is typical to Eglinton Avenue West and many avenues throughout Toronto.

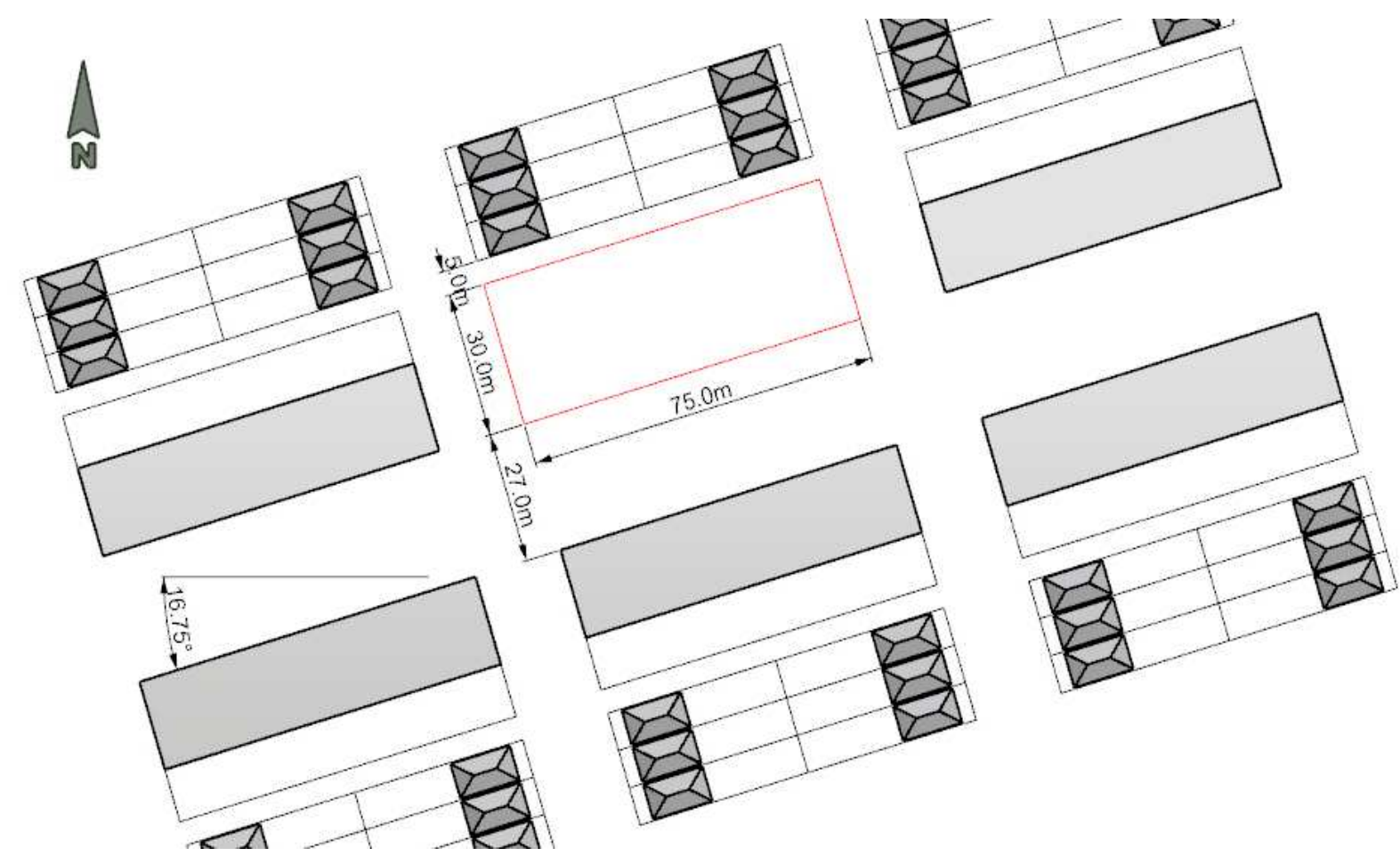

Figure 5.0.2 Six typical blocks surrounding the typical site (top middle) located on the north side of Eglinton Avenue West.

\subsection{Tools}

The building form for each zoning typology will be created in Rhinoceros ${ }^{\circledR} 5.0$, a 3D modelling software, with the use of the Grasshopper ${ }^{\mathrm{TM}}$ plug-in. Within the parametric Grasshopper ${ }^{\mathrm{TM}}$ environment, DIVA for Grasshopper ${ }^{\mathrm{TM}}$ along with the Ladybug and Honeybee environmental analysis suite will be used to create the solar envelope, as well as to simulate the solar potential. 


\section{Grasshopper}

Grasshopper $^{\mathrm{TM}}$ is a graphical algorithm editor that is integrated with Rhino3D's modelling tools. Algorithms are step by step procedures that are designed in Grasshopper ${ }^{\mathrm{TM}}$ using components, which then automate tasks in Rhino (Mode Lab, 2015).

\section{DIVA}

DIVA is a daylighting and energy-modelling plug-in for Grasshopper ${ }^{\mathrm{TM}}$ and Rhinoceros ${ }^{\circledR}$ that can generate climate-specific environmental performance evaluations such as annual surface irradiation images or calculate annual irradiation at node locations. This tool can be used on an urban or building scale to identify areas with solar energy conversion potential or areas in need of shading due to excessive solar exposure. The software utilizes the power of a RADIANCE module called GenCumulativeSky to create a continuous cumulative sky radiance distribution, which is then used in a RADIANCE backwards ray-trace simulation. According to Lagios (2015), this approach is significantly faster with minimal sacrifice in accuracy compared to other approaches that use hourly calculations.

\section{Ladybug}

Ladybug and Honeybee are two open source plugins for Grasshopper ${ }^{\mathrm{TM}}$ and Rhinoceros ${ }^{\circledR}$ that help explore and evaluate environmental performance. Ladybug imports standard EnergyPlus weather files (.EPW) into Grasshopper ${ }^{\mathrm{TM}}$ and provides a variety of 3D interactive graphics to support the decisionmaking process during the initial stages of design. Honeybee connects the visual programming environment of Grasshopper ${ }^{\mathrm{TM}}$ to four validated simulation engines - EnergyPlus, RADIANCE, Daysim and OpenStudio - which evaluate building energy consumption, comfort, and daylighting. These plugins enable a dynamic coupling between the flexible, component-based, visual programming interface of 
Grasshopper ${ }^{\mathrm{TM}}$ and validated environmental data sets and simulation engines (Sadeghipour Roudsari \& Pak, 2013).

\subsection{Modelling the Solar Envelope}

Once the typical site was developed, Grasshopper ${ }^{\mathrm{TM}}$ for Rhino was used to analyse the site parametrically. The desired outcome is the creation of a tool that can be used to evaluate the potential of the solar envelope on any given site and to assess the impact on development potential and solar access to adjacent buildings. The first step was to create the site from the Rhinoceros ${ }^{\circledR}$ model in Grasshopper ${ }^{\mathrm{TM}}$ for evaluation and simplification. A Grasshopper ${ }^{\mathrm{TM}}$ script was created to isolate the roof, façade, and footprint of the adjacent buildings. Once the surfaces were isolated, each surface category was merged (roofs, walls, base) for ease of evaluation. Figure 5.2.1 shows the adjacent buildings generated using the Grasshopper ${ }^{\mathrm{TM}}$ scripts and the boundary of the site under evaluation.
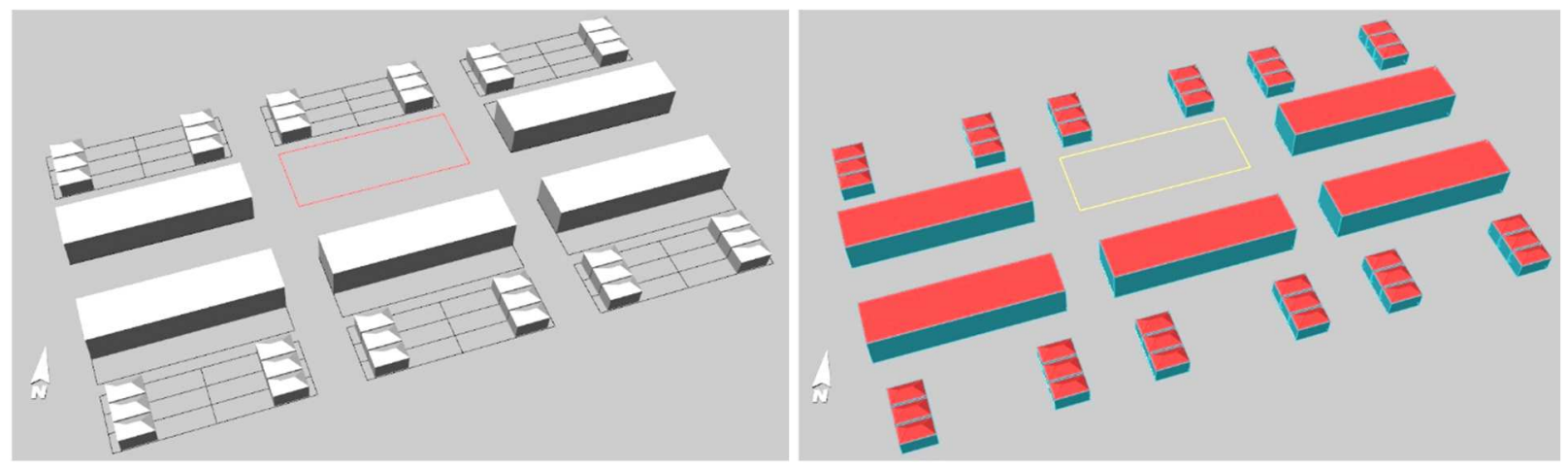

Figure 5.2.1. Typical blocks on Eglinton Avenue West generated in Rhinoceros ${ }^{\circledR}$ (left) and Grasshopper ${ }^{\mathrm{TM}}$ (right) showing the typical site on the north side of the street.

Grasshopper ${ }^{\mathrm{TM}}$ for Rhinoceros ${ }^{\circledR}$ has many plug-ins that can be installed to work in tandem with the parametric modelling developed in Grasshopper ${ }^{\mathrm{TM}}$ for evaluating metrics such as solar radiation and daylighting. Useful tools for the evaluation of solar radiation include Ladybug and DIVA for Grasshopper $^{\mathrm{TM}}$. The Grasshopper ${ }^{\mathrm{TM}}$ script used to generate the solar envelope is shown in figure 5.2.2. 


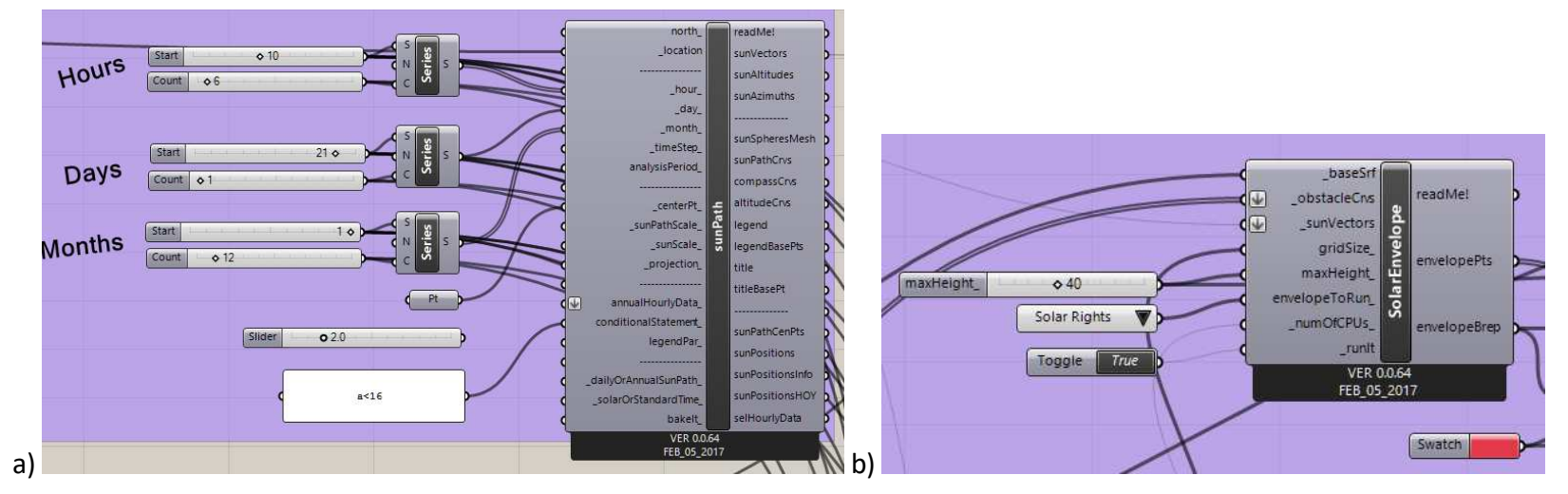

Figure 5.2.2. Screenshot of Grasshopper ${ }^{\mathrm{TM}}$ script showing a) analysis parameters for the sun path to determine the sunVectors, and b) input parameters for the Solar Envelope component.

The advanced Solar Envelope Component in Ladybug was used to develop the solar envelope volume on the site. Required input parameters include:

- _baseSrf - the boundary of the site to be evaluated (e.g. the site property lines)

- _obstacleCrvs - a collection of curves from the surrounding context to identify the limit beyond and above which no shading can occur within the given analysis constraints

- _ _sunVectors - An output of the sun rays from Ladybug's sunPath component, shown in (a)

- maxHeight_ - the maximum desired height of the building, if there is a maximum height requirement of the site

The obstacle curves for the baseline solar envelope simulation were selected to be the footprints of the adjacent buildings, meaning that no shading will occur on the adjacent buildings façade or roof within the given analysis period and resulting sun rays from the sunVectors output of the sunPath component. The sunVectors outputs a list of vectors (sun rays) indicating the direction of sunlight for each sun position on the sun path that occurs within the constraints set by the input parameters. By default, the component outputs a vector for the sun position at each hour of the year, for a total of 8,760 vectors. The number of sunVectors can then be reduced by defining the requirements for solar access using the 
input parameters, such as the analysis period including cut-off times and days and months of the year, as well as environmental parameters such as desired climate conditions.

The simulation analysis period for the baseline solar envelope study was selected to run from 10:00 to 16:00 on the $21^{\text {st }}$ day of each month, from January to December. This analysis period was chosen to include the solstice and equinox, while accounting for solar movement throughout the year. The cut-off time of 10:00 to 16:00 was selected based on findings in the literature review that a 6-hour cut-off window in Toronto is ideal for passive solar design.

The resulting Solar Envelope mesh for the site (a) is shown in the following figure 5.2.3. The figure shows that by constraining the development of the site within this boundary, the adjacent buildings will receive direct solar access within the given set of constraints. The solar envelope was then extruded to the ground plane (b), to create a full volume within which to evaluate the potential of the solar envelope for development of a typical mixed-use building. A parametric script was developed in Grasshopper ${ }^{\mathrm{TM}}$ to create a potential building form on the site to analyze for development potential. First, contours were created on the solar envelope volume to represent the floors of a building. The ground floor was set to a height of 4.5 meters, with all other floors at 3-meter height from floor to floor, based on typical mixeduse building floor to floor heights and required ground floor height. The floors were then extruded down to create storeys of a building. The resulting building model is shown in figure (c) from the south and (d) from the north. The building model was then used to extract building information for comparison, including gross floor area (GFA), volume, number of storeys, building height, and floor space index (FSI). These criteria will be used to compare the development potential created using various zoning methods to evaluate whether Solar Envelope Zoning can create development densities comparable to current Toronto Zoning and the Mid-Rise Buildings guidelines while improving solar access. 

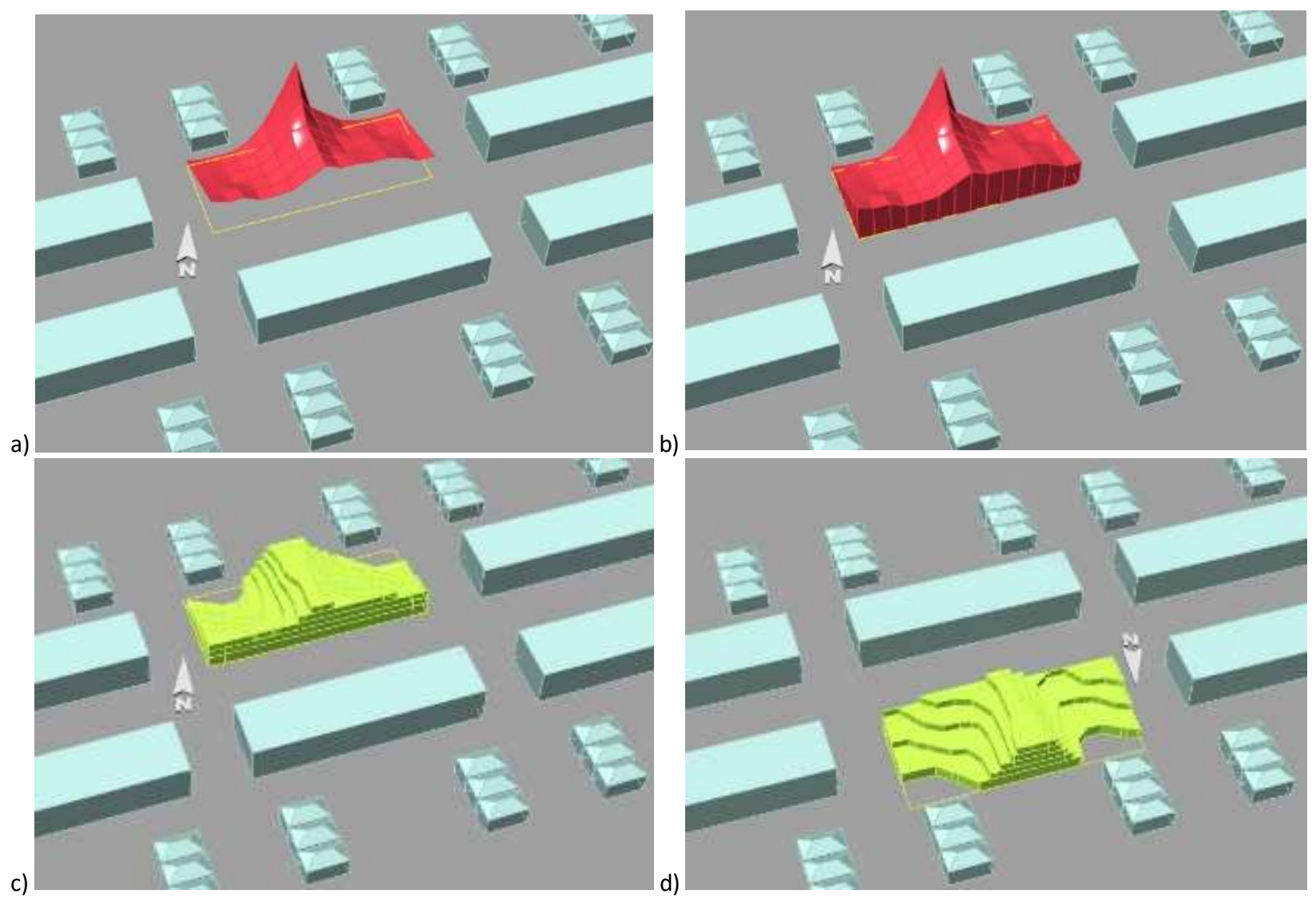

Figure 5.2.3. Creation of the solar envelope on a typical site showing a) the solar envelope mesh, b) the extruded solar envelope volume, and the solar building model c) from the south and d) from the north.

The City of Toronto zoning regulations for a typical Eglinton lot were collected to generate the potential buildable volume provided by these regulations. Table 5.2.1 lists the building density and required setbacks of the City of Toronto Zoning and compares these requirements with the Mid-Rise Buildings Guidelines and the Solar Envelope zoning method. The table shows that the Toronto Zoning regulations and the Mid-Rise Buildings Guidelines are very similar in most respects. The main difference is that the Mid-Rise Buildings Guidelines do not place a limit on FSI and the height restrictions are based on the street ROW. 
Table 5.2.1. Comparison of City of Toronto zoning regulations for a typical commercial lot on Eglinton Avenue with the Mid-Rise Buildings Guidelines and the Solar Envelope.

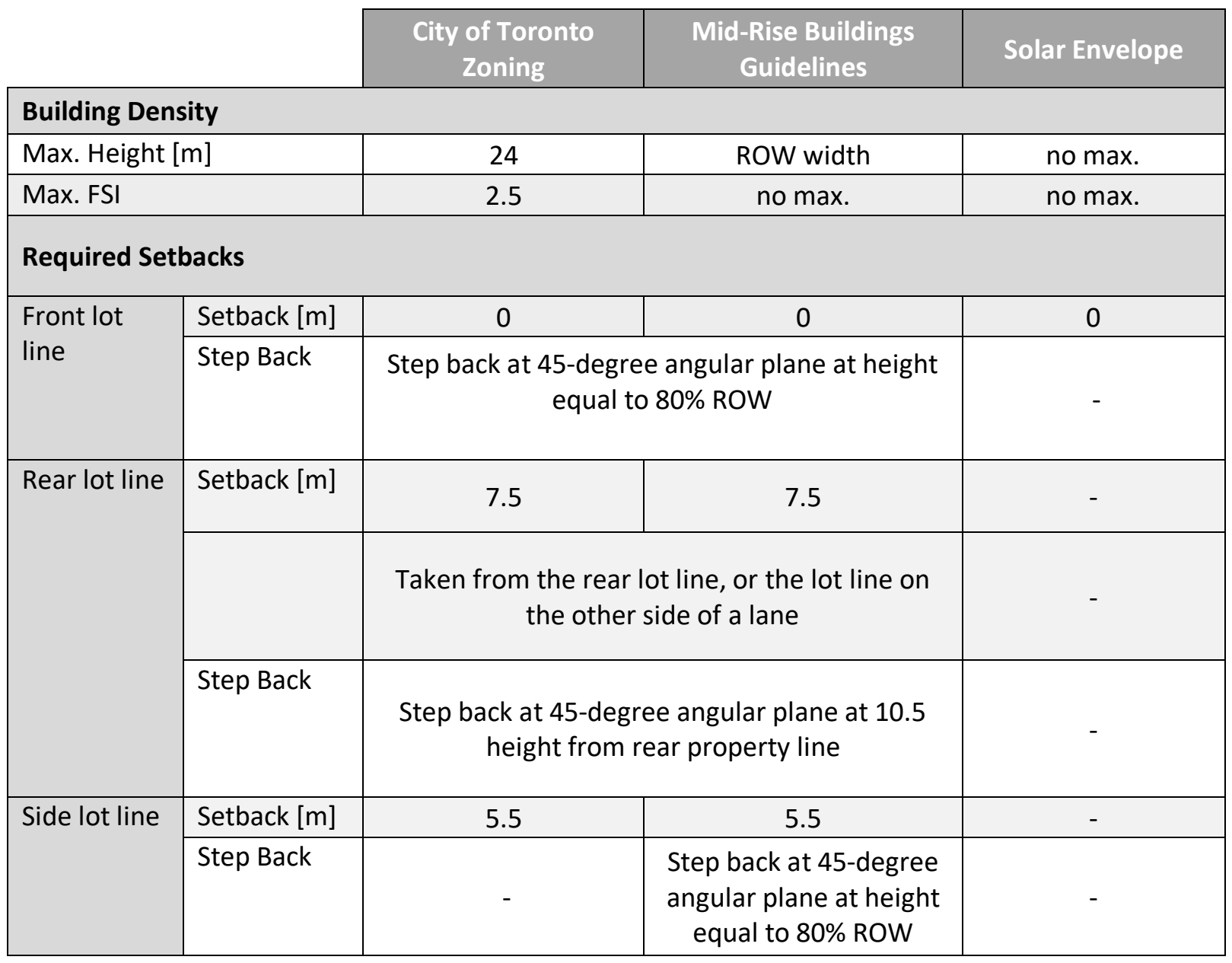

The solar envelope is included in this table to show that there are no set site restrictions on the solar envelope itself other than the site boundary. The restrictions for the solar envelope are derived from the relative motion of the sun and the solar access requirements.

Using the information provided by this table, Grasshopper ${ }^{\mathrm{TM}}$ was used to generate a developable volume based on the Toronto Zoning regulations and a developable volume based on the Mid-Rise Buildings guidelines. These volumes will be used throughout the study to compare against the results of the solar envelope zoning method. 


\subsection{Radiation Map Creation to Evaluate Solar Access}

The second criteria that was analyzed is the effect of Solar Envelope Zoning on solar access to adjacent buildings. The Ladybug and DIVA plug-ins for Grasshopper ${ }^{\mathrm{TM}}$ were used to evaluate the solar radiation incident on adjacent facades, to assess the impact of the building volume on solar access. The algorithm developed to evaluate solar access is shown in figure 5.3.1, and the resulting visualization in Rhinoceros is shown in figure 5.3.2. DIVA's Rad Map component uses the RADIANCE lighting simulation engine to calculate the total solar energy (SE) incident on a surface. The surrounding context, the site (building created by the solar envelope, MRG, or Toronto Zoning), and the ground are all given materiality (surface reflectance) and then input as surrounding objects (Obj) (built in Rhinoceros (a) and then integrated into Grasshopper (b)). Early iterations of this study included the evaluation of all surfaces within the model (roofs, facades, ground) to calculate the SED of the total area under investigation, but since many of the surfaces are not impacted by the building and some receive very little to no solar access due to their orientation, the resulting SED is skewed. Therefore, only building surfaces that would be directly affected by the proposed building volume (i.e. any buildings to the north of the site) were included in the solar radiation grid (c). A separate radiation map was created for roof surfaces and facades in order to distinguish the resulting impact of the zoning volume on solar access to adjacent roofs versus facades. The total SE output for each surface typology was divided by the total area of that surface to determine the average solar energy density (SED) in $\mathrm{kWh} / \mathrm{m}^{2}$ per year (d).

The initial intent was to evaluate and compare the impact of each building form on the solar access to adjacent roofs and to adjacent facades. Simulations performed early in this study found that the SED incident on adjacent roofs was not significantly affected by the variation in building form resulting from the scope of this study. As such, it was difficult to accurately compare the impact of solar access on roof surface. Therefore, only façade SED was used to evaluate solar access in this case. However, in future 
studies the roof surfaces should be considered similarly to façade surfaces, especially in the case of highdensity urban areas.

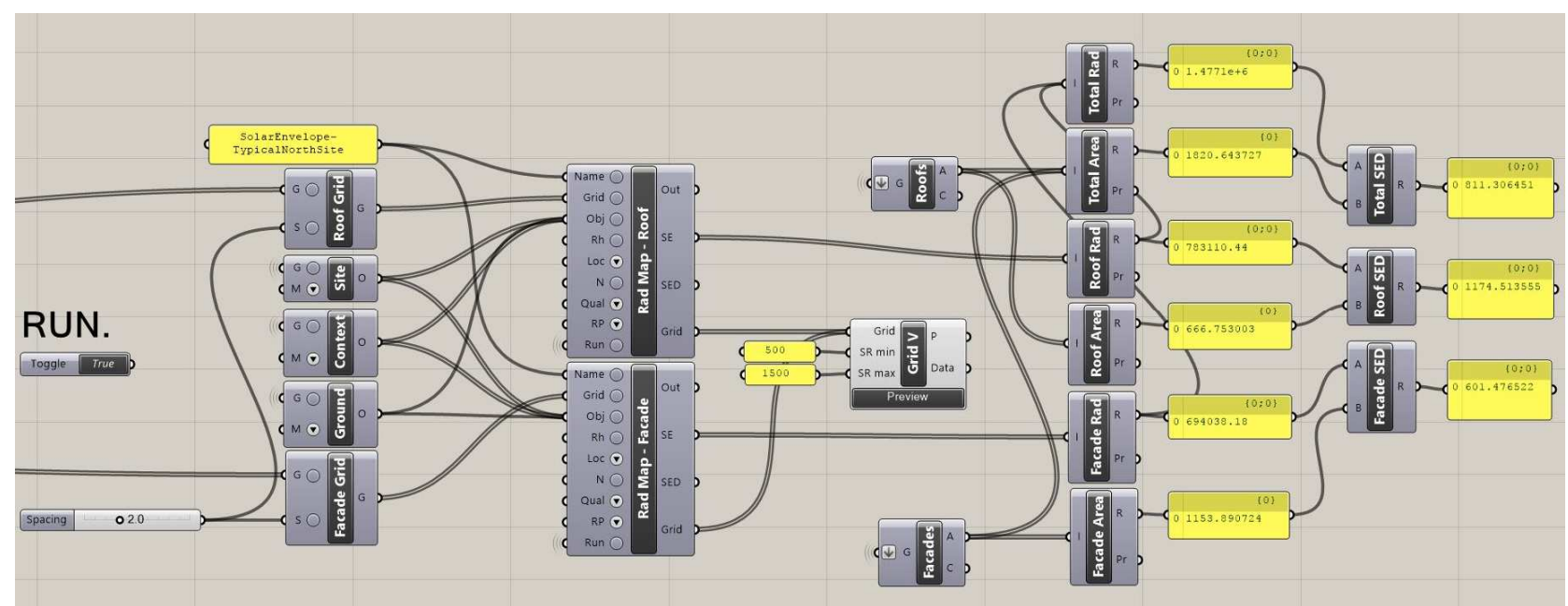

Figure 5.3.1. Grasshopper script evaluating the average annual solar energy density (SED) incident on adjacent roofs and facades.

a)
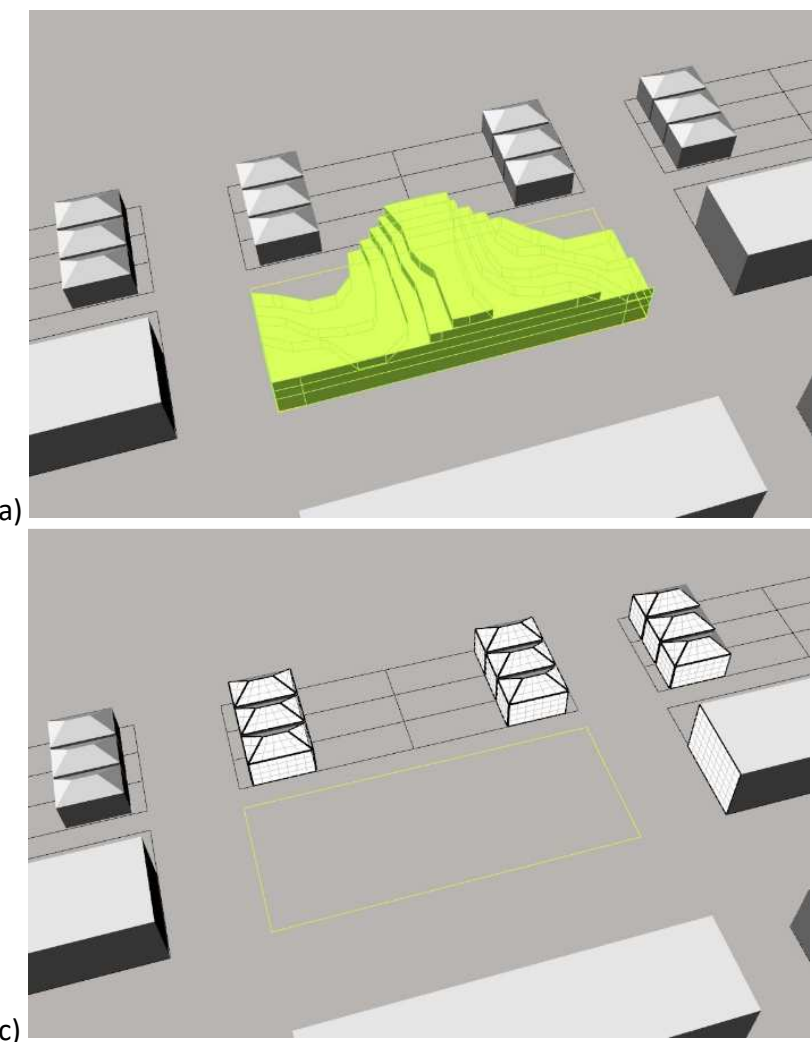

b)
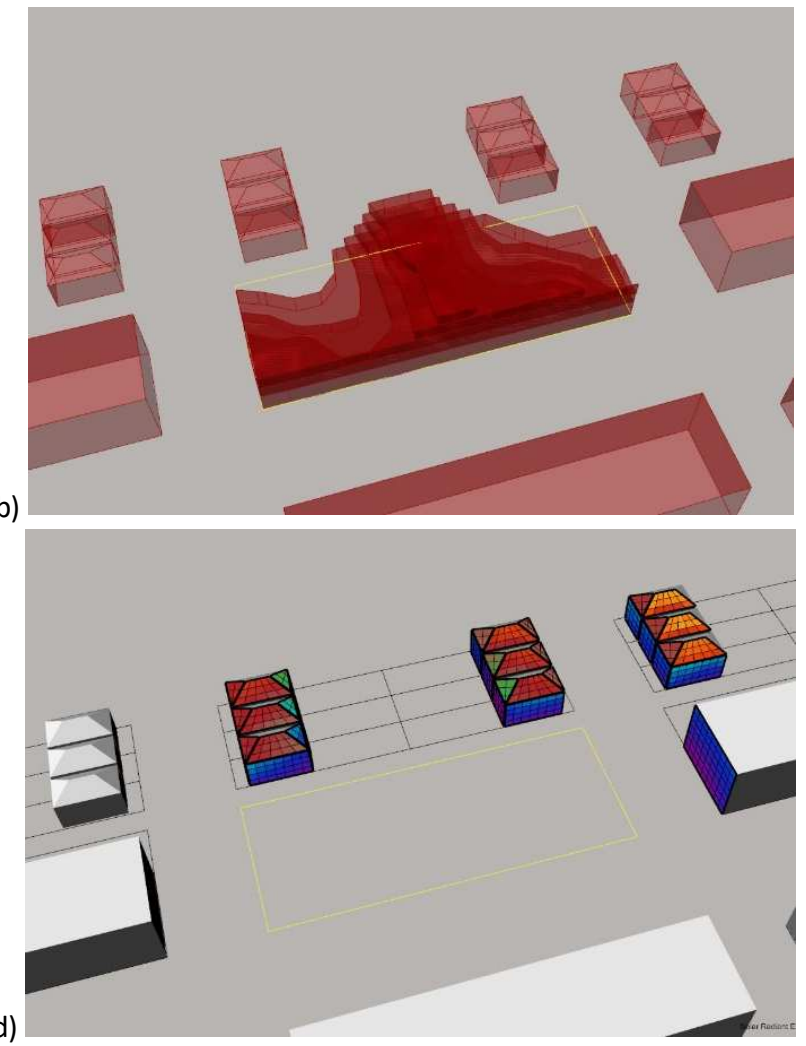

Figure 5.3.2. Creation of the radiation map simulation showing a) the surrounding context including the solar envelope, b) the surrounding context input into the radiation map component, c) the analysis grid surfaces, and d) the radiation analysis results. 


\subsection{Case Study: Eglinton Avenue West}

A site that is under review for development of an 11-storey, mixed-use, mid-rise building at 859-875

Eglinton Avenue West was selected for a parametric study using the method described in the previous section. An aerial view of the site from Google Earth is shown in figure 5.4.1 with the surrounding context (top). The figure also shows the maximum height map of the area (bottom left) and the designated land uses (bottom right). Properties located on Eglinton Avenue West are zoned for commercial/residential (CR) and have a maximum building height of either 16 meters or 24 meters.
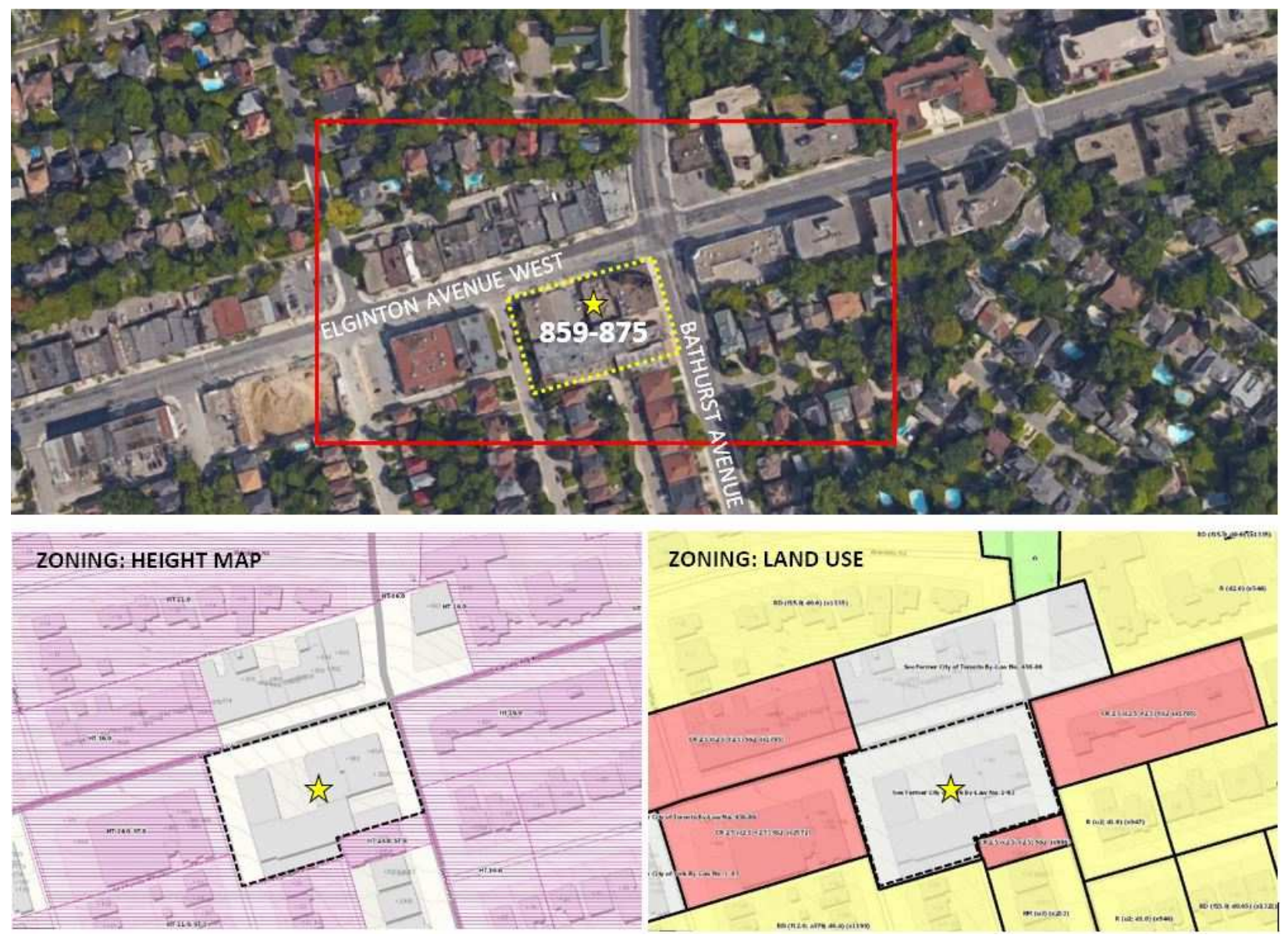

Figure 5.4.1. Google Earth view of the property 859-875 Eglinton Avenue West proposed for development of an 11-storey mixeduse commercial/residential (CR) building (top). Toronto Zoning height map showing maximum height of adjacent lots (bottom left) and Toronto Zoning designated land use map showing CR land uses in red, and residential (R) land uses in yellow (bottom right). 
3D massing models of the site were obtained in Sketchup by removing all unnecessary content and leaving only the relevant adjacent buildings to Eglinton Avenue West that will affect the solar access study. The simplified 3D massing model was imported into Rhinoceros ${ }^{\circledR}$, which required some trial and error since the programs generate surface geometry differently. LIPID Obj, a plug-in for SketchUp, was downloaded to export the 3D model as an OBJ file to be imported into Rhinoceros ${ }^{\circledR}$, which resulted in the most accurate and workable model. A property data map of the site was imported and overlaid on the 3D site massing to visualize the building lot lines and streets.

The buildings surrounding the site were selected and the surfaces were separated based on their normal direction (i.e. surfaces facing up, facing down, and facing the side), to isolate the roofs, footprints, and facades. The model was carefully evaluated to ensure that the normal of all geometry faces were pointing outwards from the building, otherwise the material of the face will not be accurately represented in the solar radiation model. Once the surfaces were isolated, each surface category was then merged (roofs, walls, base) for ease of evaluation. Figure 5.3.2 shows the development of the solar envelope on the site, including the (a) the solar envelope mesh, (b) the solar envelope volume, and the solar envelope building volume from (c) the south and (d) the north.

The solar envelope building volume generated on this site will similarly be compared to the developable volume provided by existing Toronto Zoning regulations and the Mid-rise Building Guidelines to assess the potential for development density and solar access. Using statistics derived from the submitted documents for the proposed building to be developed on this site, parameters of the solar envelope zoning method will be refined to assess whether this method can achieve the same development density without sacrificing solar access. 
a)

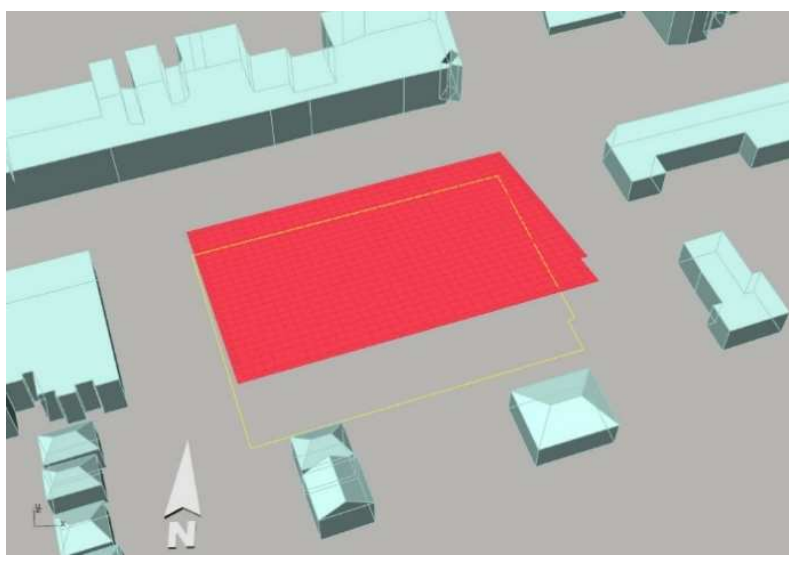

c)

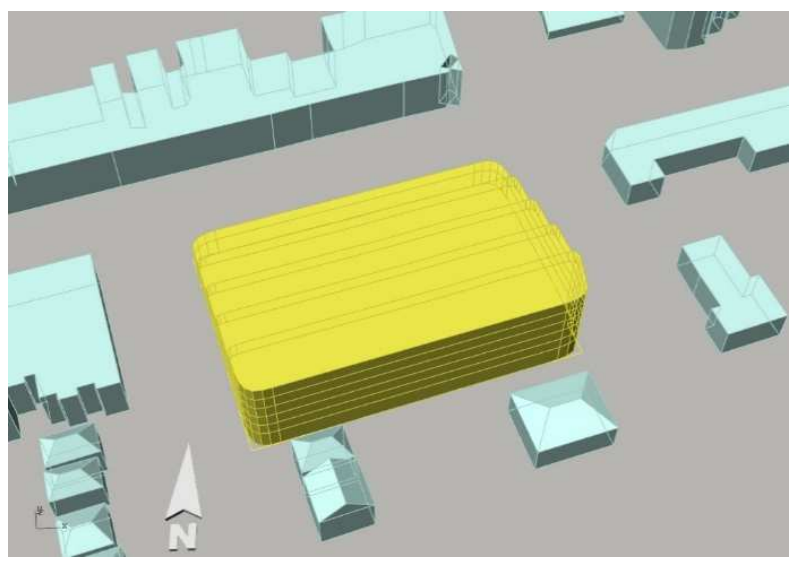

b)

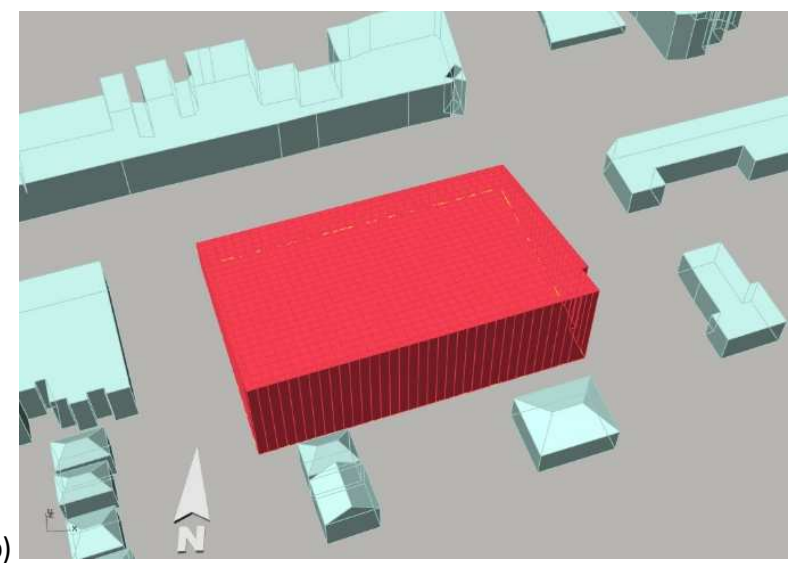

d)

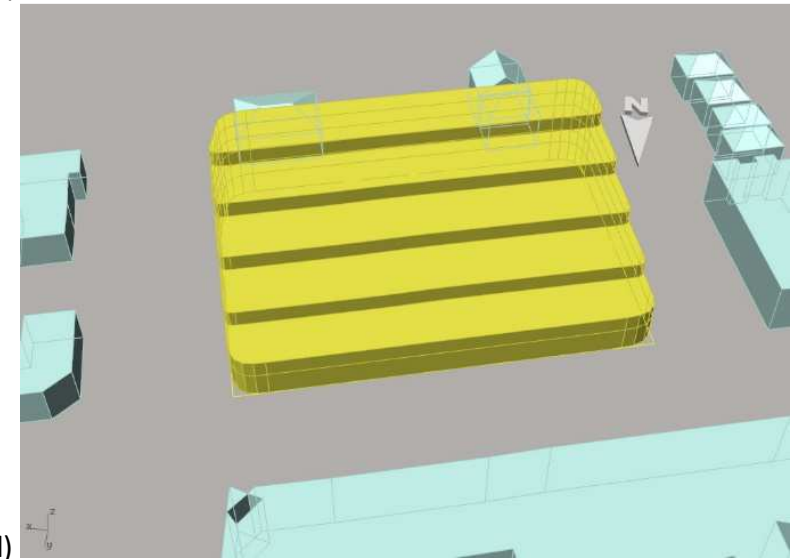

Figure 5.4.2. Creation of the solar envelope at $859-875$ Eglinton Avenue West showing a) the solar envelope mesh, b) the extruded solar envelope volume, and the solar building model c) from the south and d) from the north. 


\subsection{RESULTS AND ANALYSIS}

Two separate parametric studies were performed to evaluate the feasibility of SEZ as a method for zoning for solar access in Toronto. The first evaluation was performed on a typical site representative of an urban block on Eglinton Avenue West. The second evaluation was performed on the site at 859-875 Eglinton Avenue West to optimize the solar envelope parameters to balance solar access and development density as compared to the MRG, Toronto Zoning, and the development proposed for this site. The results and analysis of these two studies will be discussed in this section.

\subsection{Typical Site}

For the purpose of this study, each iteration of the typical site was developed using a baseline set of parameters and one variable parameter. The baseline of the solar envelope study was conducted on an east-west oriented street tilted 16.75 degrees south of east with a ROW width of 27 meters. The site is located on the north side of the street. The shadow fence height was set to the base of the adjacent buildings ( 0 meters), which means that during that analysis period, the adjacent facades or roofs will not be shaded within the proposed cut-off times.

The parametric study evaluated the impact of site orientation, shadow fence height, solar access cut-off times, and street ROW width on solar access and development density. Solar access is represented by the average solar radiation density on adjacent buildings. During early trials, it was found that many of the buildings within the site model are not impacted by the building volume under investigation due to their proximity and location. Therefore, the adjacent building surfaces to be evaluated for solar access were selected uniquely for each study so as not to skew the results. 


\subsubsection{Site Orientation}

The impact of site orientation on the solar envelope volume was evaluated using the baseline solar envelope on four different sites. The resulting building models are shown in figure 6.1.1.1. The evaluated sites include: a) the north side of an east-west oriented street, b) the south side of an eastwest street, c) the west side of a north-south street, and d) the east side of a north-south street.

a)

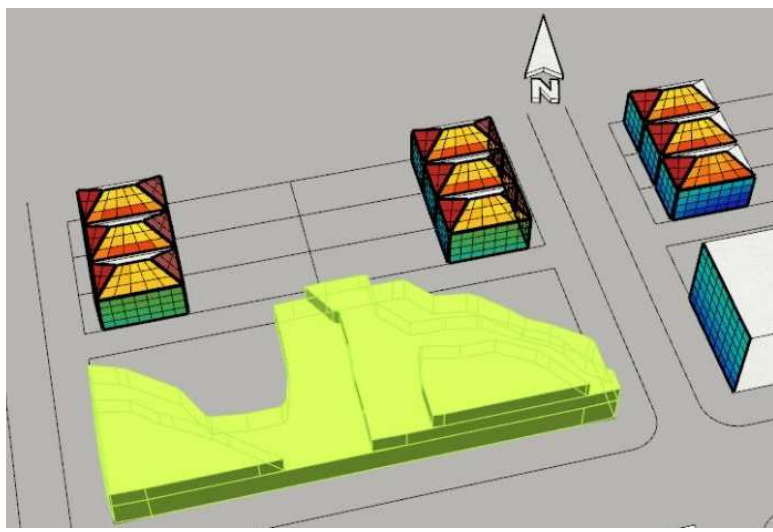

c)

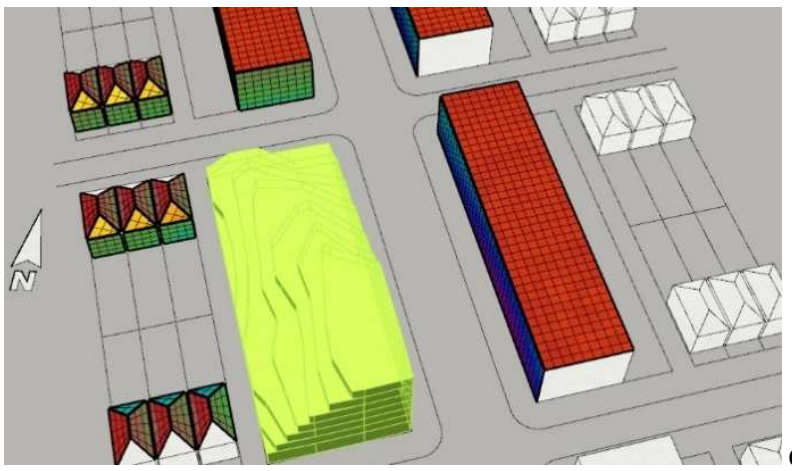

b)
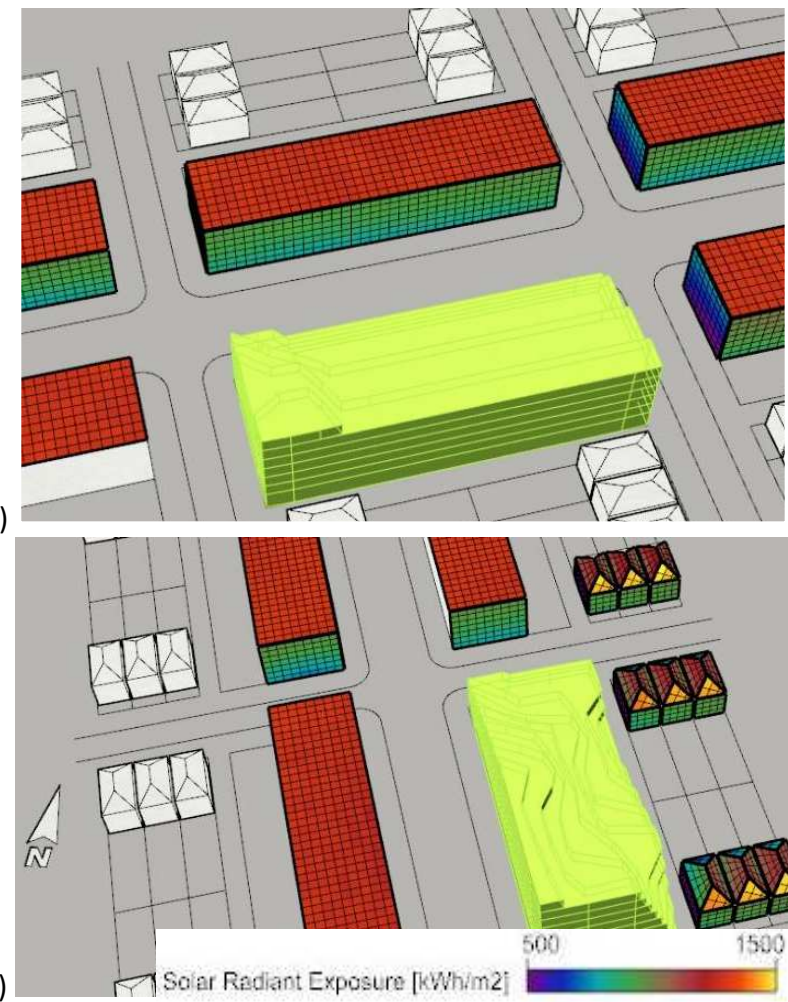

Figure 6.1.1.1. Building forms generated by solar envelope volume by varying site location and orientation. The top two images are E-W streets showing a N site (a) and S site (b). The bottom two images are N-S streets showing a W site (c) and E site (d).

Due to the nature of this investigation, the adjacent buildings affected by the proposed building volume vary depending on street orientation and location of the site. Therefore, the average radiation incident on adjacent facades, which is calculated by dividing the total annual radiation incident on the surface by the area, can not be confidently compared with one another. The DIVA radiation map can output solar radiation values at specific nodes on the façade visually in order to assess the solar irradiation on the surface. However, it is difficult to accurately compare the radiation in this way as well. Since the main 
purpose of the study is to evaluate the viability of the solar envelope zoning method against the Toronto Zoning (TZ) method and the Mid-Rise Guidelines (MRG) method, it was determined that evaluating the site using the solar energy density method as described was the most comprehensive and accurate for the purpose of evaluating solar access for all iterations, including site orientation. The results of the study are shown in table 6.1.1.1. Since the FSI for the Mid-Rise Guidelines and the Toronto Zoning regulations are independent of orientation and do not change, they are listed at the top of the table for comparison. All orientations achieve higher development density than the Toronto Zoning regulations, and the south and east sites achieve greater development density than the MRG. The highest development density of 6.08 is achieved on the east facing site, $39 \%$ greater than the MRG FSI of 4.36 ; however, solar access is reduced, but only by $11 \%$. Compared to the MRG, the south facing site is optimal since it provides better results for both solar access ( $4 \%$ increase) and development density ( $11 \%$ increase). The west site also provides a comparable FSI to the MRG of 4.13 ( $5 \%$ decrease), while achieving a $10 \%$ increase in solar access. The SE volume achieves in increase of $14 \%$ to $143 \%$ in development density compared to the Toronto Zoning method, while also achieving better solar access on north and west facing sites, and comparable solar access on south sites. The solar envelope method achieves greater solar access than the Mid-rise Guidelines in all orientations except for when the building site is located on the east side of a north-south street.

Table 6.1.1.1. Impact of street orientation and site location on development density (FSI) and solar radiation density $\left(\mathrm{kWh} / \mathrm{m}^{2}\right)$ on adjacent facades.

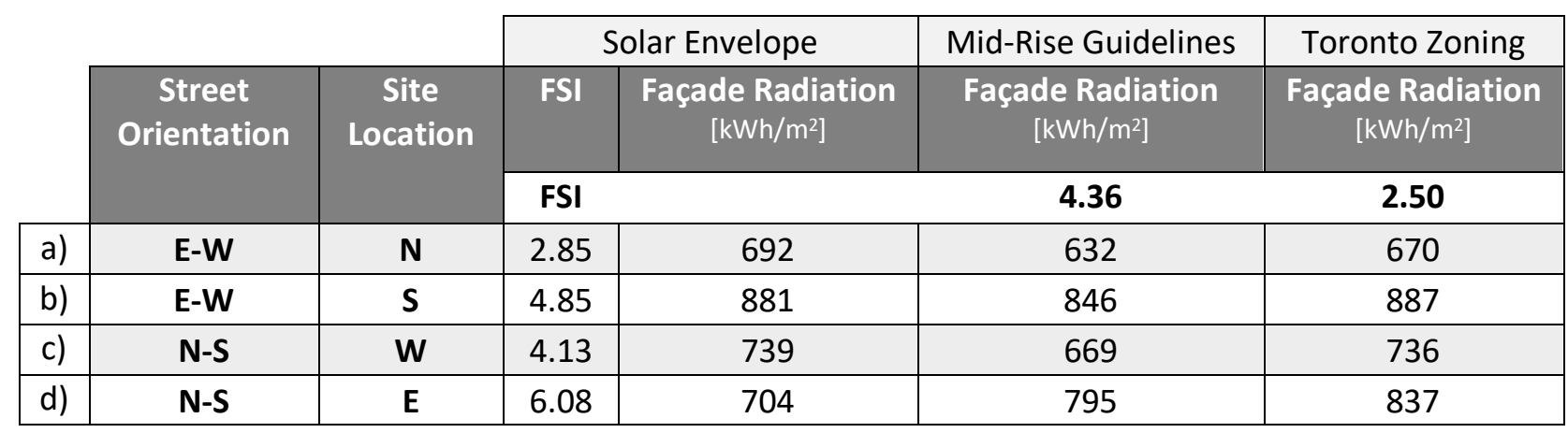




\subsubsection{Shadow Fence Height}

The building lots to the north of the baseline site are designated residential. Roofs are typically pitched, with a main wall height of roughly 6 meters and a total maximum height of 10 meters. Figure 6.1.2.1 shows the resulting solar envelope volumes generated by varying the shadow fence height. The baseline height is 0 meters. The second iteration evaluates a shadow fence height of 1.5 meters which represents solar access to ground floor windows and above. The third iteration c) evaluates a shadow fence height of 3 meters, representing solar access above the second floor, and d) at 6 meters represents solar access to the roof.

a)
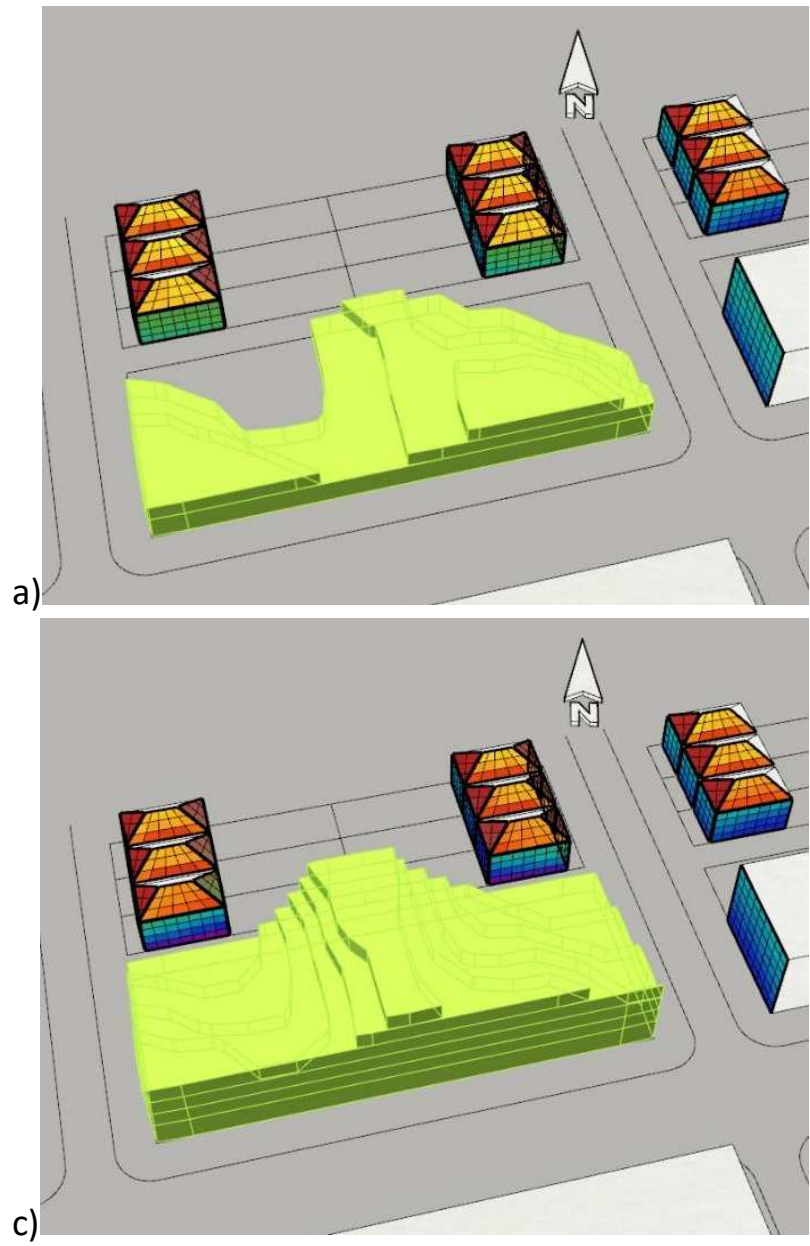

b)
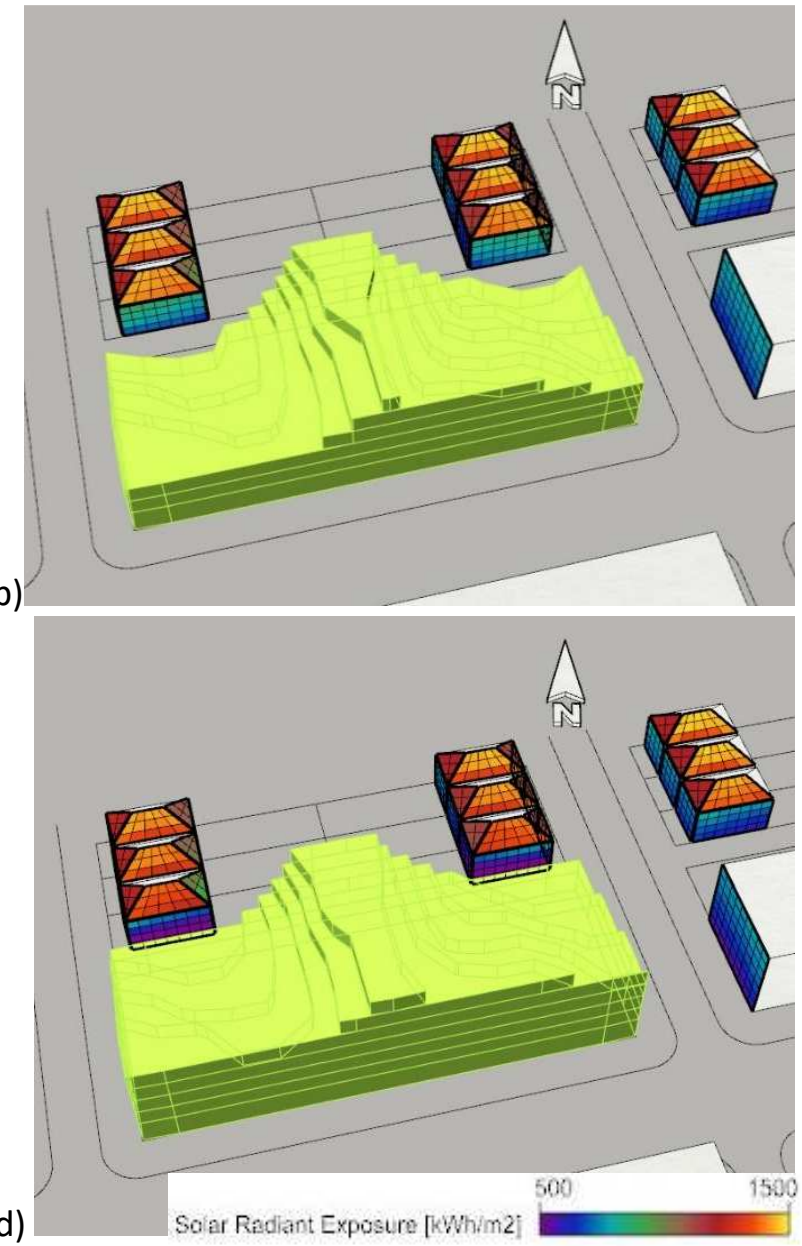

Figure 6.1.2.1. Building forms generated by solar envelope volume by varying the residential shadow fence height from a) $0 \mathrm{~m}$, b) $1.5 \mathrm{~m}, \mathrm{c}) 3 \mathrm{~m}$, and d) $6 \mathrm{~m}$. 
The resulting development density (FSI) and solar radiation access to adjacent buildings are shown in table 6.1.2.1. As the shadow fence height is increased from $0 \mathrm{~m}$, to $1.5 \mathrm{~m}$, to $3 \mathrm{~m}$, to $6 \mathrm{~m}$, the FSI also increases from 2.85 , to 3.01 ( $5.6 \%$ increase), to 3.41 ( $13 \%$ increase), to 4.26 ( $25 \%$ increase). Conversely, the façade radiation decreases from $692 \mathrm{kWh} / \mathrm{m}^{2}$, to $679 \mathrm{kWh} / \mathrm{m}^{2}$ (1.9\% decrease), to $663 \mathrm{kWh} / \mathrm{m}^{2}$ (2.4\% decrease), to $624 \mathrm{kWh} / \mathrm{m}^{2}$ (5.9\% decrease), respectively.

Table 6.1.2.1. Impact of residential Shadow Fence height on development density (FSI) and solar radiation density $\left(\mathrm{kWh} / \mathrm{m}^{2}\right)$ on adjacent facades.

\begin{tabular}{|c|c|c|c|c|c|}
\cline { 2 - 6 } \multicolumn{1}{c|}{} & $\begin{array}{c}\text { Shadow Fence } \\
{[\mathrm{m}]}\end{array}$ & FSI & $\begin{array}{c}\text { Change } \\
{[\%]}\end{array}$ & $\begin{array}{c}\text { Façade Radiation } \\
{\left[\mathrm{kWh} / \mathrm{m}^{2}\right]}\end{array}$ & $\begin{array}{c}\text { Change } \\
{[\%]}\end{array}$ \\
\hline a) & $\mathbf{0}$ & 2.85 & & 692 & \\
\hline b) & $\mathbf{1 . 5}$ & 3.01 & +5.6 & 679 & -1.9 \\
\hline c) & $\mathbf{3}$ & 3.41 & +13 & 663 & -2.4 \\
\hline d) & $\mathbf{6}$ & 4.26 & +25 & 624 & -5.9 \\
\hline \multirow{2}{*}{} & \multicolumn{4}{c}{} \\
\cline { 2 - 6 } & Mid-Rise Guidelines & 4.36 & - & 632 & - \\
\hline & Toronto Zoning & 2.50 & - & 670 & - \\
\cline { 2 - 6 } &
\end{tabular}

\subsubsection{Solar Access Cut-off Times}

Solar access cut-off times dictate the window within which solar access must be provided to adjacent sites. When Knowles (2003) evaluated the cut-off times for various sites in California, it was found that a 4-hour window was adequate, however a 6-hour window was desirable. The resulting building models are shown in figure 6.1.3.1. For this study, the baseline solar envelope (b) was generated with a 4-hour cut-off window, from 10:00 to 14:00. For Toronto's temperate climate, a larger cut-off window is desirable for passive solar design. Therefore, a 6-hour cut-off time was evaluated, from 9:00 to 15:00, shown in (a). To maximize development density on the site, a 2-hour cut-off time was evaluated from 11:00 to 13:00. The maximum building height for the solar envelope was initially set to 27 meters to 
align with the maximum height allowed by the mid-rise guidelines, shown in (c). However, by increasing the maximum building height to 50 meters (d), higher densities were achieved.
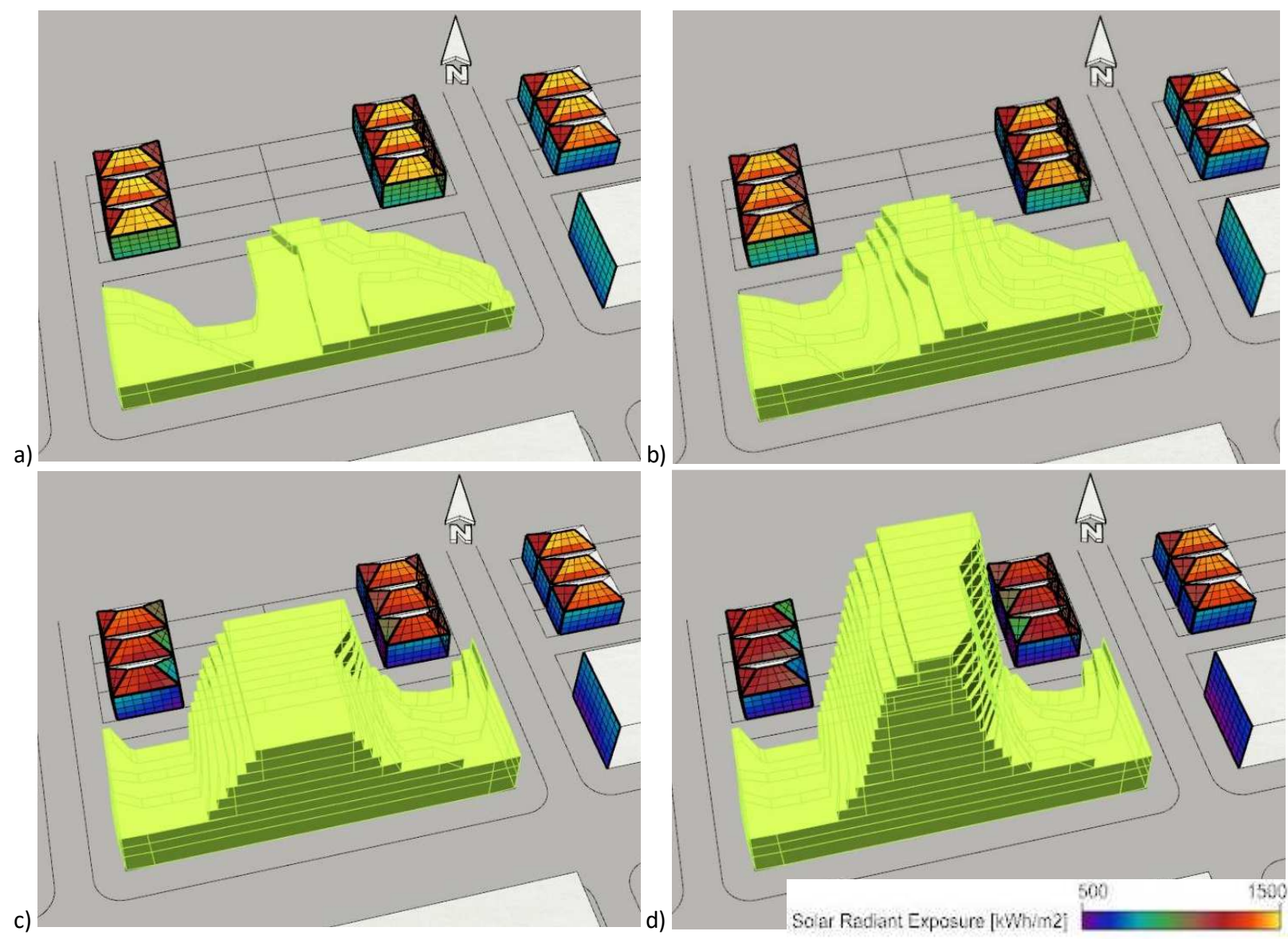

Figure 6.1.3.1. Building forms generated by solar envelope volume by varying the cut-off times from 6 hours (a), 4 hours (b), and 2 hours with a designated maximum height of $27 \mathrm{~m}(\mathrm{c})$ and $50 \mathrm{~m}(\mathrm{~d})$.

The resulting FSI and solar radiation are shown in table 6.1.3.1. As the required solar access cut-off time decreases from 6 hours to 4 hours, and from 4 hours to 2 hours, the FSI increases from 2.10, to 2.85 (36\% increase), to 5.21 ( $83 \%$ increase), respectively. Conversely, façade irradiation decreases from 720 $\mathrm{kWh} / \mathrm{m}^{2}$, to $692 \mathrm{kWh} / \mathrm{m}^{2}$ (3.9\% decrease), to $626 \mathrm{kWh} / \mathrm{m}^{2}$ (9.5\% decrease). 
Table 6.1.3.1. Impact of solar access cut-off time on development density (FSI) and solar radiation density $\left(\mathrm{kWh} / \mathrm{m}^{2}\right)$ on adjacent facades.

\begin{tabular}{|c|c|c|c|c|c|c|c|}
\hline & \multicolumn{3}{|c|}{ Cut-off Time } & \multirow{2}{*}{ FSI } & \multirow{2}{*}{$\begin{array}{c}\text { Change } \\
\text { [\%] }\end{array}$} & \multirow{2}{*}{$\begin{array}{c}\text { Façade } \\
\text { Radiation } \\
{\left[\mathrm{kWh} / \mathrm{m}^{2}\right]}\end{array}$} & \multirow{2}{*}{$\begin{array}{c}\text { Change } \\
{[\%]}\end{array}$} \\
\hline & Start Time & End Time & Hrs & & & & \\
\hline a) & 9:00 & $15: 00$ & 6 & 2.10 & & 720 & \\
\hline b) & $10: 00$ & $14: 00$ & 4 & 2.85 & +36 & 692 & -3.9 \\
\hline c) & $11: 00$ & $13: 00$ & 2 & 5.21 & +83 & 626 & -9.5 \\
\hline d) & $11: 00$ & $13: 00$ & 2 & 7.04 & +35 & 601 & -3.8 \\
\hline \multicolumn{4}{|c|}{ Mid-Rise Guidelines } & 4.36 & - & 632 & - \\
\hline \multicolumn{4}{|c|}{ Toronto Zoning } & 2.50 & - & 670 & - \\
\hline
\end{tabular}

\subsubsection{Right-of-Way (ROW) Width}

The street right-of-way widths were evaluated for all ROWs proposed along Toronto's Avenues. The south site was used for this investigation, since a north site would not be impacted by the ROW. Figure 6.1.4.1 shows the building volume generated by the solar envelope for ROW widths of 20 meters, 23 meters, and 27 meters as a sample of the investigation.

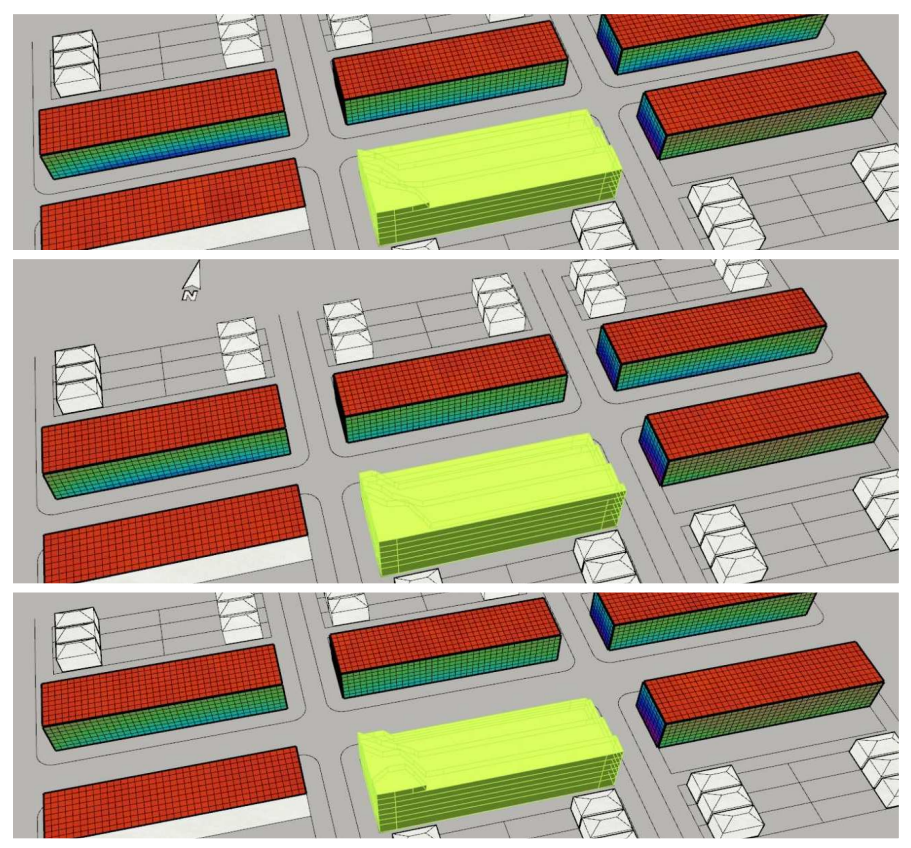

Figure 6.1.4.1. Building forms generated by solar envelope volume on a south lot by varying right-of-way width. From top to bottom, examples shown are $20 \mathrm{~m}, 23 \mathrm{~m}$, and $27 \mathrm{~m}$ ROW. 
The resulting development density (FSI) and solar radiation access to adjacent building facades are shown in table 6.1.4.1. As the ROW width increases, the FSI increases. Except for rows (c) and (f), each iteration evaluates a 3-meter incremental increase in ROW width. In these instances, the results show a relatively consistent increase in $\mathrm{FSI}$ from the previous iteration of $7.6 \%, 6.4 \%, 5.6 \%$, and $6.6 \%$, with an average increase of $6.5 \%$ per 3-meter increase in ROW. As the ROW width increases, façade radiation also increases. The greatest increase in solar access occurs when the ROW is increased from 20 meters to 23 meters. Using the data from the table, the rate at which the façade radiation increases per meter of ROW width increase was calculated by dividing the change in façade radiation as a percent by the change in ROW width. It was found that as the ROW width increases, the percent change per meter decreases.

Table 6.1.4.1. Impact of right-of-way (ROW) width on development density (FSI) and solar radiation density $\left(\mathrm{kWh} / \mathrm{m}^{2}\right)$ on adjacent facades.

\begin{tabular}{|c|c|c|c|c|c|}
\hline & $\begin{array}{l}\text { ROW } \\
{[\mathrm{m}]}\end{array}$ & FSI & $\begin{array}{c}\text { Change } \\
{[\%]}\end{array}$ & $\begin{array}{c}\text { Façade Radiation } \\
{\left[\mathrm{kWh} / \mathrm{m}^{2}\right]}\end{array}$ & $\begin{array}{c}\text { Change } \\
{[\%]}\end{array}$ \\
\hline a) & 20 & 4.10 & & 854 & \\
\hline b) & 23 & 4.41 & +7.6 & 868 & +1.6 \\
\hline c) & 27 & 4.85 & +10.0 & 881 & +1.5 \\
\hline d) & 30 & 5.16 & +6.4 & 888 & +0.8 \\
\hline e) & 33 & 5.45 & +5.6 & 894 & +0.7 \\
\hline f) & 36 & 5.81 & +6.6 & 899 & +0.6 \\
\hline g) & 45 & 7.67 & +32 & 907 & +0.9 \\
\hline & Mid-Rise Guidelines & 4.36 & - & 846 & - \\
\hline & Toronto Zoning & 2.50 & - & 887 & - \\
\hline
\end{tabular}




\subsubsection{Discussion}

The parametric study of the typical lot on Eglinton Avenue evaluated the impact of site orientation, shadow fence height, solar access cut-off times, and street ROW on solar access and development density. Based on the results of the analysis, the following deductions can be made for the Solar Envelope Zoning method on the typical site:

1. All SEZ volumes achieve higher a FSI than the Toronto Zoning typology.

2. As the ROW width increases, FSI and solar access both increase.

3. As the solar access window increases, FSI decreases and solar access increases.

4. As the shadow fence height increase, FSI increases and solar access decreases.

No discernible deductions can be made for site orientation, except that the best results for balancing solar access and site density are achieved on south, east, and west-facing sites. All orientations achieve a higher FSI than the Toronto Zoning typology, and the highest FSI is achieved on the east facing site. However, the south facing site provides the optimal balance between solar access and development density, with a higher FSI and greater solar irradiation on adjacent facades than the MRG and comparable solar access to the Toronto Zoning method. Based on these findings, the optimal orientation for implementing the SEZ method is not surprisingly on south-facing sites (sites located on the south side of east-west oriented streets). Future research should evaluate the feasibility of other orientations more closely to optimize the parameters required to balance solar access and development density, since this study is limited to a baseline north-facing site.

Although increasing the shadow fence height results in an increase in FSI in general, none of the SEZ volumes achieve an FSI higher than the MRG. However, all SEZ volumes achieve better solar access, 
except for the 6-meter shadow fence height. Based on these results, it is evident that the shadow fence height alone can not achieve the desired development density on the site and must be considered in combination with other parameters. Furthermore, a 6-meter shadow fence height is not recommended as it does not achieve the desired solar access to adjacent facades compared to the TZ and MRG. All shadow fence height iterations achieve a higher FSI than the Toronto Zoning method, and shadow fence heights of 0 meters to 3 meters also achieve superior or comparable solar access. The optimal shadow fence height is found to be 3 meters for the adjacent low-rise residential neighbourhood, since a good balance is achieved between the development density and solar access. Future research should evaluate the optimal shadow-fence height for other land uses, such as commercial spaces.

The solar access window defined by the solar cut-off times significantly impacts both development density and solar access. High-densities can be achieved by limiting the solar access window to 2 hours. However, a minimum of 2.5 hours of solar access is recommended for optimal health when considering the bacteriological benefits of the sun (Pereira, Nome Silva, \& Turkienikz, 2011), and a minimum of 6hour solar access is recommended for passive solar design (Knowles, 1981). Therefore, a minimum 4hour solar access window is recommended to balance development density and solar access. However, other parameters should be optimized to increase the development density of the site, since an FSI of 2.85 is not sufficient for the densification of urban areas. It is also possible to set requirements for solar access at certain times of the year (De Luka \& Voll, 2017) or to shift the solar access cut-off times from 10:00 to 14:00, to 11:00 to 15:00 for example (Capeluto \& Plotnikov, 2017) to optimize the balance between solar access and development density. Future work should build on the method developed by De Luka and Voll (2017) in determining a simplified method to set a 4-hour solar access window per day that is undefined by specific solar cut-off times, to evaluate the effect on the solar envelope volume in the Toronto context. 
As the ROW width increases, both solar access and development density increase. These findings are consistent with the guidelines put forth in the Mid-Rise Guidelines, which stipulate a maximum building height equal to the ROW width. As such, as ROW increases, the development density provided by the MRG also increases. The results of the Solar Envelope Zoning method show that the development density increases at an average rate of $6.5 \%$ per 3 -meter increase in width. Although solar access increases as ROW width increases, the rate which the façade radiation increases per meter of ROW width is reduced. In other words, as the ROW becomes increasingly wide, the impact of increasing ROW width on solar access is reduced.

In summary, the evaluation of the typical site shows that solar envelope zoning (SEZ) method is feasible as a zoning tool in all site orientations along Toronto's avenues, with the excepting of sites located on the north of east-west streets adjacent to low-rise residential neighbourhoods. Higher development density can be achieved on streets with greater ROW widths without negatively impacting solar access to adjacent buildings.

During the study, some limitations of the SEZ method have been identified based on the site and context-specific nature of the solar envelope. The benefits of this method are clear and have been discussed throughout this paper. However, there are some disadvantages that may result in push-back from property developers. As is evident in the results, the site orientation has a significant impact on the development density of the site. Therefore, integrating solar access regulations using the SEZ method would result in a variation in the allowable FSI for each site and therefore varying saleable area and profit potential from a developer perspective. This limitation should be investigated in future work. 


\subsection{Case Study: Eglinton Avenue West}

A parametric investigation was performed on the proposed site at 859-875 Eglinton Avenue West described in the Section 5.3. Eglinton Avenue West is an east-west oriented street tilted 16.75 degrees south of east with a ROW width of 27 meters. The site is located on the south side of the street. to assess the optimum parameters involved in the creation of the solar envelope to balance solar access to adjacent building, measured in average annual solar radiation $\left(\mathrm{kWh} / \mathrm{m}^{2}\right)$ and the development density of the site, in FSI. The results of the solar envelope volume investigation were compared to the potential solar access and development density of the site provided by the buildable volume created by the City of Toronto zoning regulations (a), the Mid-Rise Buildings Guidelines (b), and the proposed development of the site (c) shown in figure 6.2.1. For the purpose of this study, each iteration of the solar envelope zoning study was evaluated against a baseline solar envelope (d). The resulting development density and solar access achieve by each typology above is shown in table 6.2.1. The results show that the baseline solar envelope achieves the greater solar access to adjacent facades, and the proposed development provides the lowest solar access. However, the proposed development achieves the highest development density. The SEZ method provides a development density of 4.27 , a decrease of $40 \%$ from the proposed development FSI of 7.27. This is a trade-off between solar access and development density. This section will evaluate various parameters with the aim to balance FSI and solar access to optimize the solar envelope volume and assess the feasibility of this method in Toronto.

The baseline solar envelope was given a cut-off time of 4 hours, from 10:00 to 14:00. The shadow fence height is set to the base of the adjacent buildings (0 meters), which means that during the analysis period, the adjacent facades or roofs will not be shaded within the proposed cut-off times. The results of each parametric study will be discussed in the following paragraphs. 


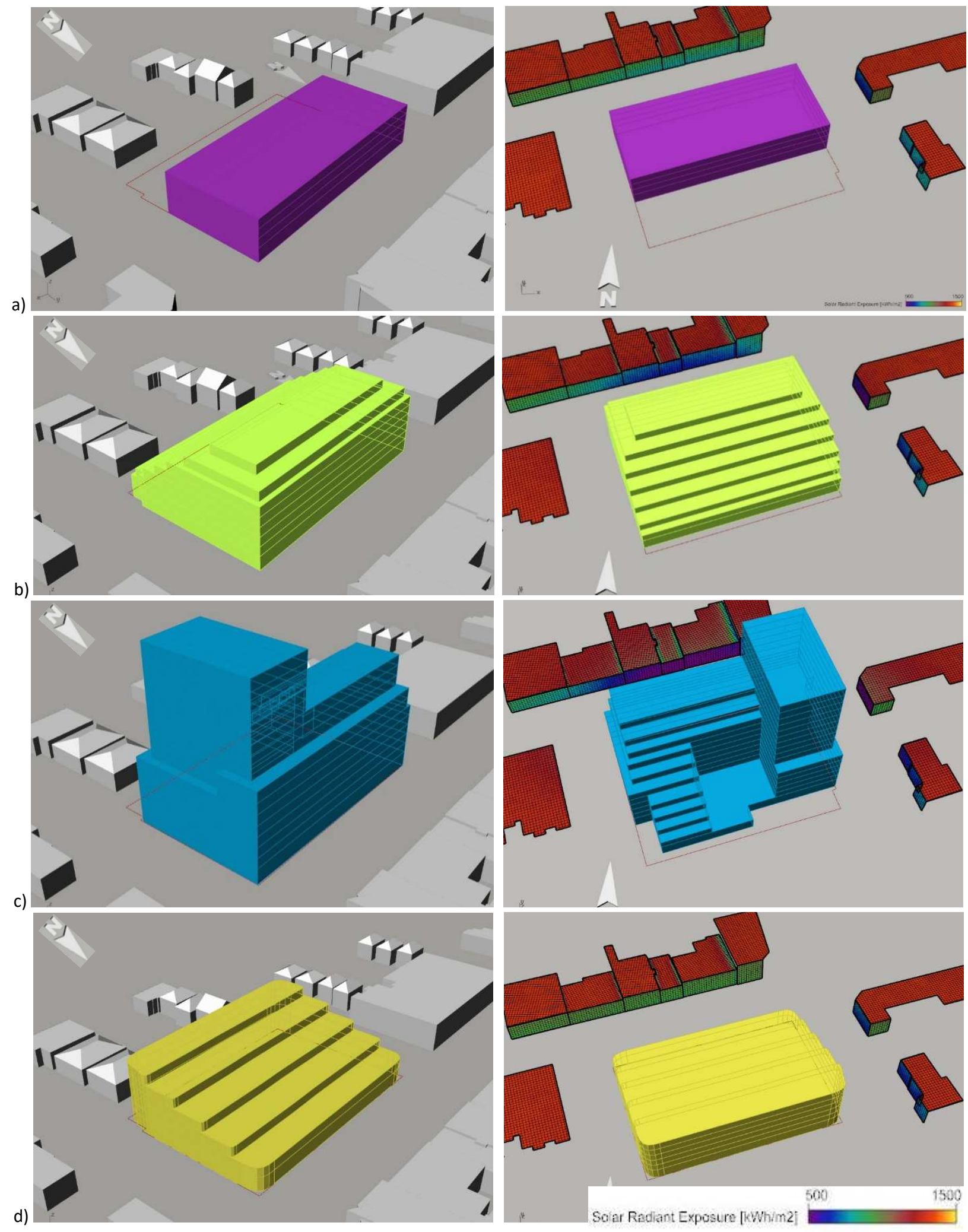

Figure 6.2.1. Resulting building volume (left) and solar radiation map (right) resulting from (a) City of Toronto zoning, (b) mid-rise guidelines, (c) proposed development, and (d) baseline solar envelope. 
Table 6.2.1. The development density (FSI) and annual average façade solar radiation density $\left(\mathrm{kWh} / \mathrm{m}^{2}\right)$ for various potential building typologies.

\begin{tabular}{|ll|c|c|}
\cline { 3 - 4 } \multicolumn{1}{c|}{ Building Typology } & FSI & $\begin{array}{r}\text { Façade Radiation } \\
{\left[\mathrm{kWh} / \mathrm{m}^{2}\right]}\end{array}$ \\
\hline a) & City of Toronto Zoning & 2.50 & 857 \\
\hline b) & Mid-Rise Guidelines & 5.68 & 747 \\
\hline c) & Proposed Development & 7.27 & 622 \\
\hline d) & Solar Envelope Zoning & 4.27 & 883 \\
\hline
\end{tabular}

\subsubsection{Shadow Fence Height}

The building lots to the north of the baseline site, across the street, are designated commercial/ residential (CR). Figure 6.2.1.1 shows the resulting solar envelope volumes generated by varying the shadow fence height and the resulting solar radiation on adjacent buildings. The site and surrounding context is shown in (a). The baseline height of the solar envelope is 0 meters, shown in (b). The second iteration evaluates a shadow fence height of 4.5 meters, representing solar access above the second floor, and d) at 10.5 meters represents solar access above the third storey, which is currently the recommended step-back for a podium in the Mid-Rise Buildings guidelines.

The resulting development density (FSI) and average solar radiation to adjacent building facades are shown in table 6.2.1.1. As the shadow fence height is increased, the development density potential increasing significantly. However, the average solar radiation incident on the adjacent facades decreases. The results also show that the rate at which FSI increases grows by $48 \%$ (from $31 \%$ to $46 \%$ increase) as the solar fence height increases from 4.5 meters to 10.5 meters. The same is true for the decrease in solar access, with a rate of reduction nearly double ( $87 \%$ higher from $4.6 \%$ to $8.6 \%$ decrease) in solar access from 4.5 meters to 10.5 meters.

The solar envelope achieves superior solar access in all cases compared to the proposed development and the MRG, and a higher FSI compared to the Toronto Zoning typology. A shadow fence height of 10.5 
meters results in the highest $\mathrm{FSI}, 13 \%$ and $45 \%$ greater than the proposed development and the MRG, respectively. A shadow fence height of 4.5 meters achieves a FSI comparable to the MRG (1.6\% lower) and provides a $13 \%$ increase in solar access.

a)

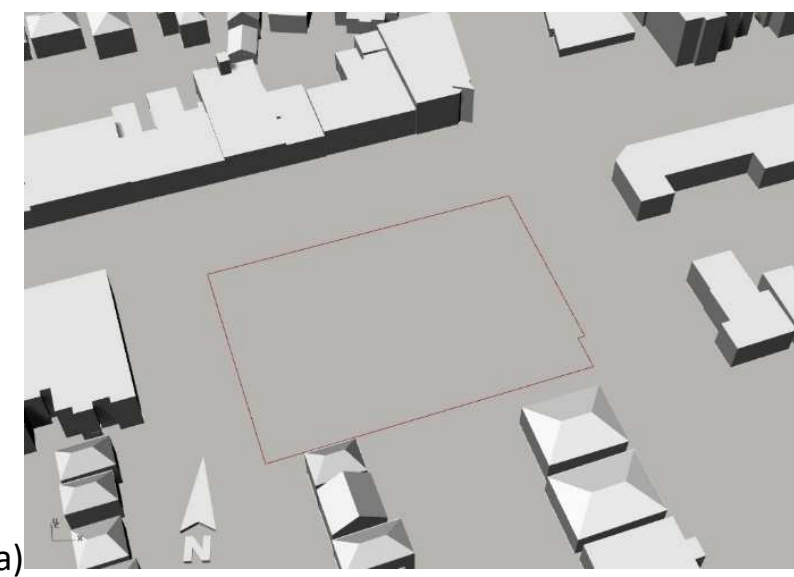

c)

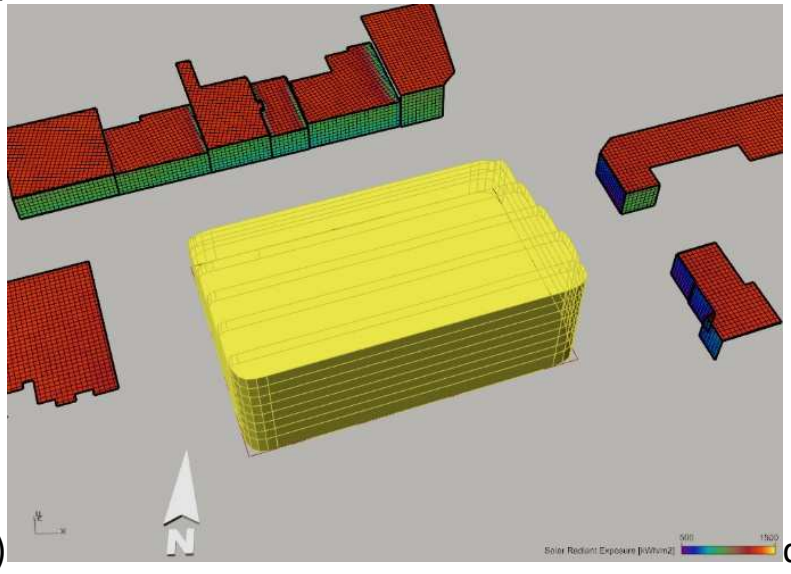

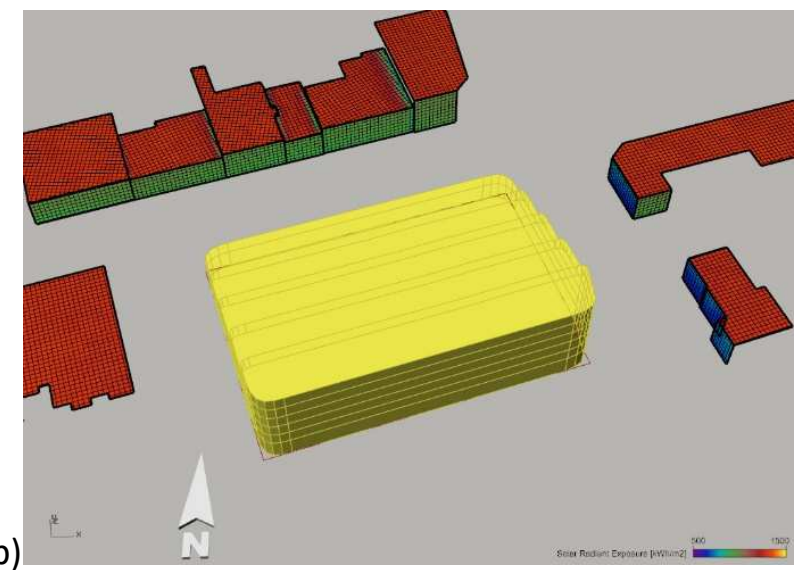

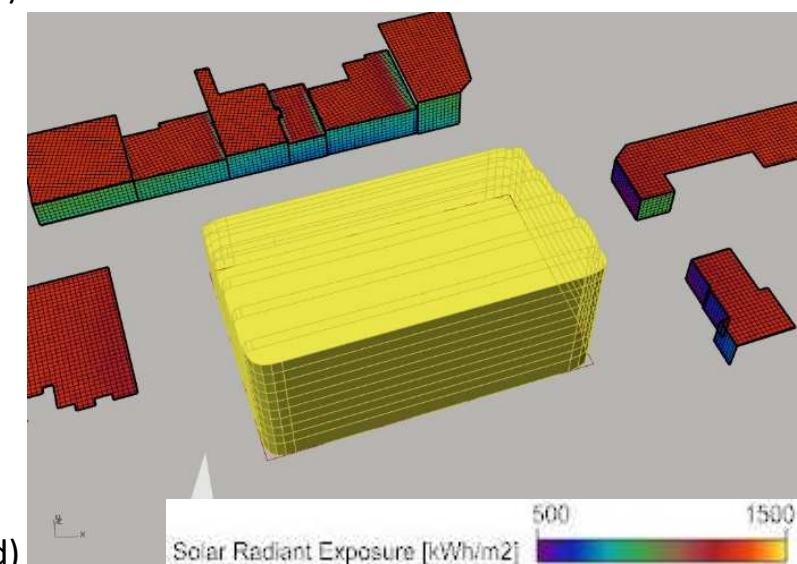

Figure 6.2.1.1. Building forms generated by solar envelope volume by varying the shadow fence height from a) site and context, b) $0 \mathrm{~m}, \mathrm{c}) 4.5 \mathrm{~m}$, and d) $10.5 \mathrm{~m}$.

Table 6.2.1.1. Impact of shadow fence height on development density (FSI) and solar radiation density $\left(\mathrm{kWh} / \mathrm{m}^{2}\right)$ on adjacent facades.

\begin{tabular}{|c|c|c|c|c|c|}
\hline & $\begin{array}{c}\text { Shadow Fence } \\
{[\mathrm{m}]}\end{array}$ & FSI & $\begin{array}{l}\% \text { Change } \\
\text { [from previous] }\end{array}$ & $\begin{array}{c}\text { Façade Radiation } \\
{\left[\mathrm{kWh} / \mathrm{m}^{2}\right]}\end{array}$ & $\begin{array}{l}\% \text { Change } \\
\text { [from previous] }\end{array}$ \\
\hline b) & 0 & 4.27 & & 884 & \\
\hline c) & 4.5 & 5.59 & +31 & 843 & -4.6 \\
\hline d) & 10.5 & 8.25 & +46 & 770 & -8.6 \\
\hline & Toronto Zoning & 2.50 & - & 857 & - \\
\hline & Mid-Rise Guidelines & 5.68 & - & 747 & - \\
\hline & Proposed Development & 7.27 & - & 622 & - \\
\hline
\end{tabular}




\subsubsection{Solar Access Cut-off Times}

The solar access cut-off times were evaluated for 6-hour, 4-hour, and 2-hour solar access windows. The resulting building models are shown in figure 6.2.2.1. For this study, the baseline solar envelope c) was generated with a 4-hour cut-off window, from 10:00 to 14:00. For Toronto's temperate climate, a larger cut-off window is desirable for passive solar design. Therefore, a 6-hour cut-off time was evaluated, from 9:00 to 15:00, shown in a1). A second 6-hour cut-off window was evaluated from 10:00 to 16:00, shown in (a2). To maximize development density on the site, a 2-hour cut-off time was evaluated from 11:00 to $13: 00$ (d).

$\left.\mathrm{a}_{1}\right)$
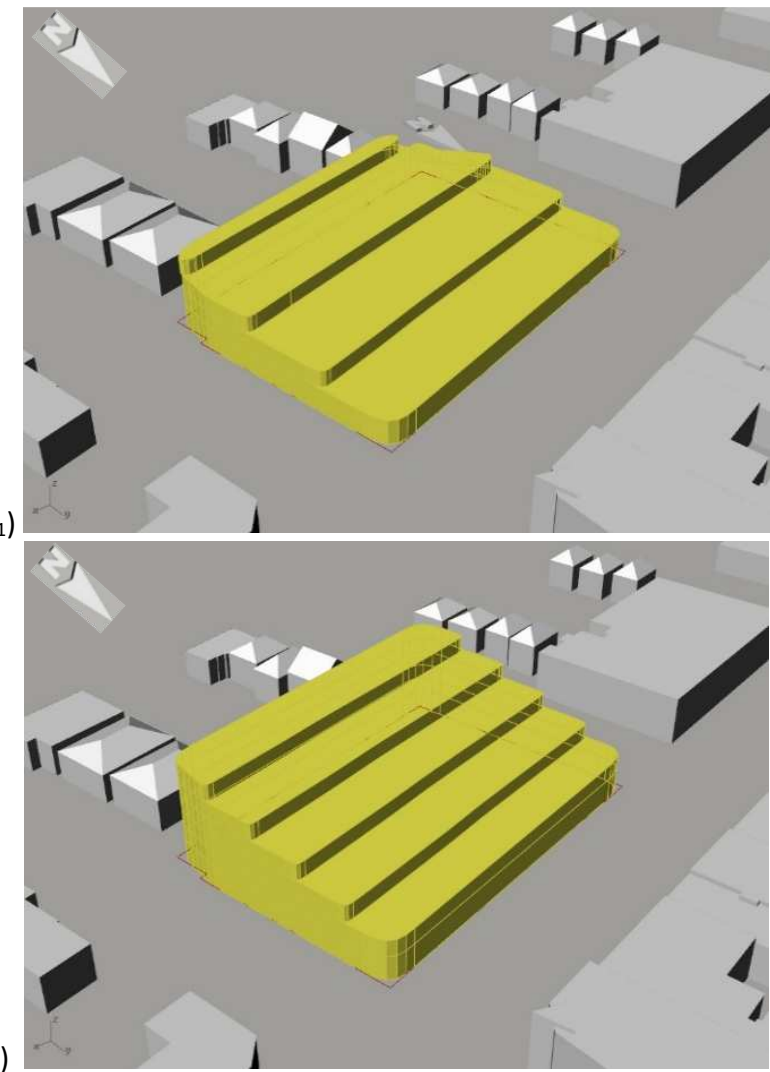

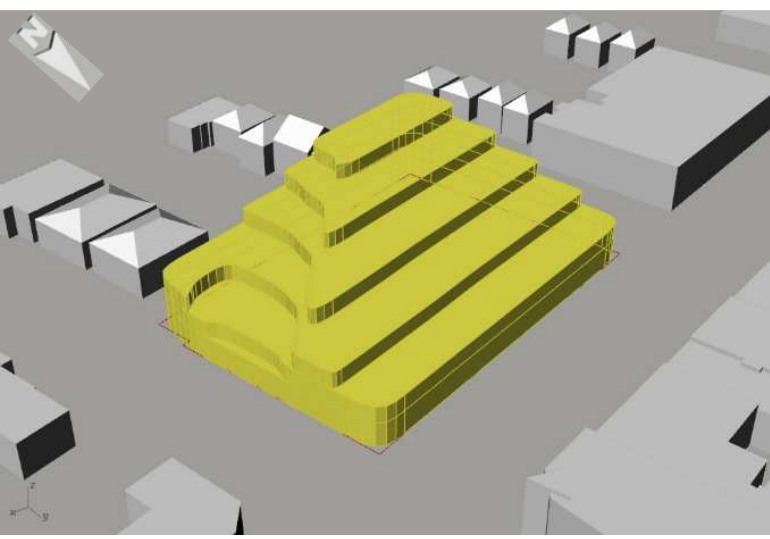

$\mathrm{a}_{2}$

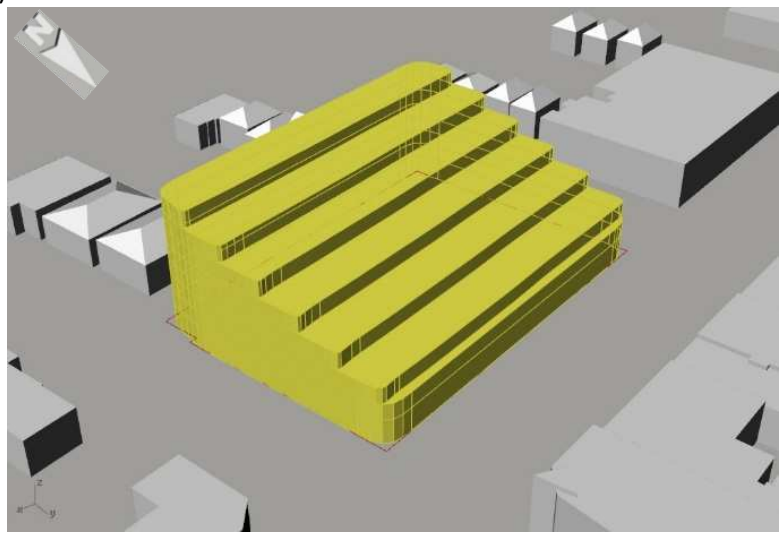

Figure 6.2.2.1. Solar envelope volume resulting from varying solar access cut-off time from (a)9:00 to 15:00 (6h), (b)10:00 to 16:00 (6h), (c)10:00 to $14: 00(4 h)$, and (d)11:00 to $13: 00(2 h)$.

The resulting development density (FSI) and solar access $\left(\mathrm{kWh} / \mathrm{m}^{2}\right)$ are shown in table 6.2.2.1. It was found that as the designated solar access cut-off time decreases (i.e. less hours of solar access are 
required), the FSI increases. From a 6 -hour cut-off time to 4 hours, the FSI increases by $46 \%$, and from 4 hours to 2 hours, the FSI increases by $27 \%$. These findings indicate that as the solar access window is increased, the impact on the rate of reduction to FSI grows by nearly a factor of two. The inverse is true as the solar access window is reduced. In terms of solar access, façade radiation decreases as the solar access window decreases by $4.7 \%$ and $3.9 \%$ from 6 hours to 4 hours and from 4 hours to 2 hours, respectively. A second 6-hour solar access window was evaluated by shifting the solar cut-off times from 9:00 to $15: 00$ (a1) to 10:00 to $16: 00$ (a2). The resulting solar envelope volume shows increase of $29 \%$ in $\mathrm{FSI}$ and a decrease of $2.5 \%$ in solar access. All solar envelope volumes resulting from this study achieved a higher FSI than the Toronto Zoning typology, and all except the 2-hour solar access window saw an improvement in solar access. None of the SE volumes achieved a FSI higher than the MRG or the proposed development, however all SE volumes achieved better solar access.

Table 6.2.2.1. Impact of solar cut-off time on development density (FSI) and solar radiation density $\left(\mathrm{kWh} / \mathrm{m}^{2}\right)$ on adjacent facades.

\begin{tabular}{|c|c|c|c|c|c|c|c|}
\hline & \multicolumn{3}{|c|}{ Cut-off Time } & \multirow{2}{*}{ FSI } & \multirow{2}{*}{$\begin{array}{l}\text { \% Change } \\
\left.\text { [from } \mathrm{a}_{1}\right]\end{array}$} & \multirow{2}{*}{$\begin{array}{l}\text { Façade Radiation } \\
\qquad\left[\mathrm{kWh} / \mathrm{m}^{2}\right]\end{array}$} & \multirow{2}{*}{$\begin{array}{l}\text { \% Change } \\
\text { [from } \mathrm{a}_{1} \text { ] }\end{array}$} \\
\hline & Start Time & End Time & Hours & & & & \\
\hline$\left.a_{1}\right)$ & 9:00 & $15: 00$ & 6 & 2.76 & & 928 & \\
\hline b) & 10:00 & $14: 00$ & 4 & 4.27 & +46 & 884 & -4.7 \\
\hline c) & $11: 00$ & $13: 00$ & 2 & 5.43 & +27 & 849 & -3.9 \\
\hline \multirow[t]{4}{*}{$\left.a_{2}\right)$} & $10: 00$ & $16: 00$ & 6 & 3.56 & +29 & 905 & -2.5 \\
\hline & \multicolumn{3}{|c|}{ Toronto Zoning } & 2.50 & - & 857 & - \\
\hline & \multicolumn{3}{|c|}{ Mid-Rise Guidelines } & 5.68 & - & 747 & - \\
\hline & \multicolumn{3}{|c|}{ Proposed Development } & 7.27 & - & 622 & - \\
\hline
\end{tabular}

\subsubsection{Environmental Parameters}

Using the annual hourly data from the imported .epw file for Toronto, and the method described by Capeluto and Plotnikov (2017), the total sunVectors used to generate the solar envelope were reduced 
by setting limitations on the required hourly global horizontal radiation (GHR) and the dry-bulb temperature. The Grasshopper ${ }^{\mathrm{TM}}$ script is shown in figure 6.2.3.1, showing the Ladybug importEPW component and corresponding hourly data, the defined analysis period of hours, days, and months of the year, and the sunPath component which outputs the resulting sunVectors that occur within the given parameters. For this study, the analysis period was run for every day of the year within the given cut-off time hours.

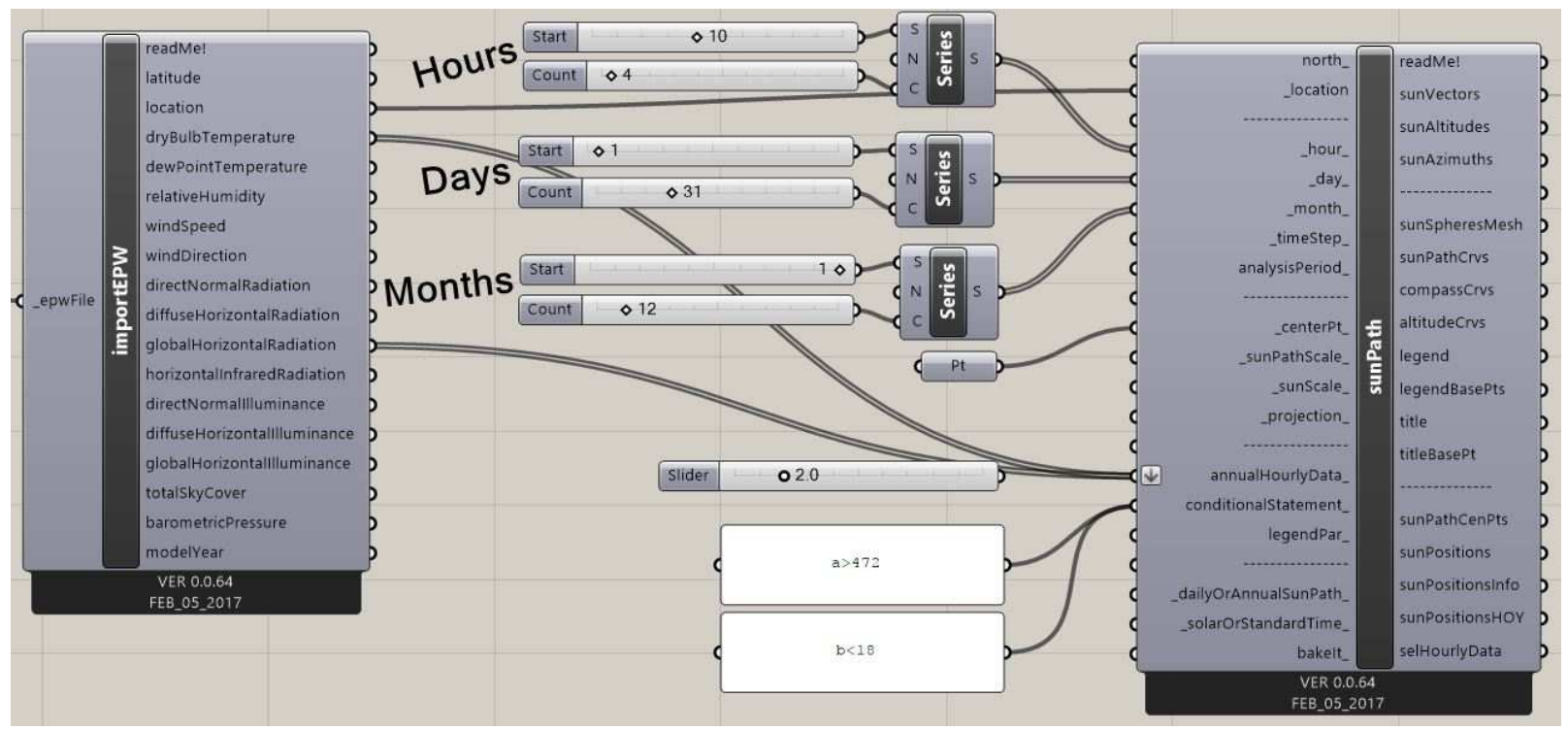

Figure 6.2.3.1. Grasshopper ${ }^{\mathrm{TM}}$ script defining the sunVectors from the sunPath used to generate the solar envelope volume.

The resulting development density (FSI) and average solar radiation to adjacent building facades are shown in table 6.2.3.1, with corresponding images of the resulting solar envelope volumes (left) and the solar radiation on adjacent buildings (right) generated by varying the environmental solar access parameters shown in figure 6.2.3.2. The solar envelope baseline (a) is shown for reference. First, the sunVectors were reduced from the baseline by isolating only sunVectors that occur when the outdoor dry-bulb temperature is below $18^{\circ} \mathrm{C}$, when the adjacent buildings will benefit most from passive solar access. Second, the sunVectors were reduced to eliminate those that provide an hourly GHR less than 
$472 \mathrm{kWh} / \mathrm{m}^{2}$. The GHR was evaluated with a solar cut-off time of 10:00 to 14:00 (c), and a solar cut-off time of 10:00 to $16: 00$ (d).

a)
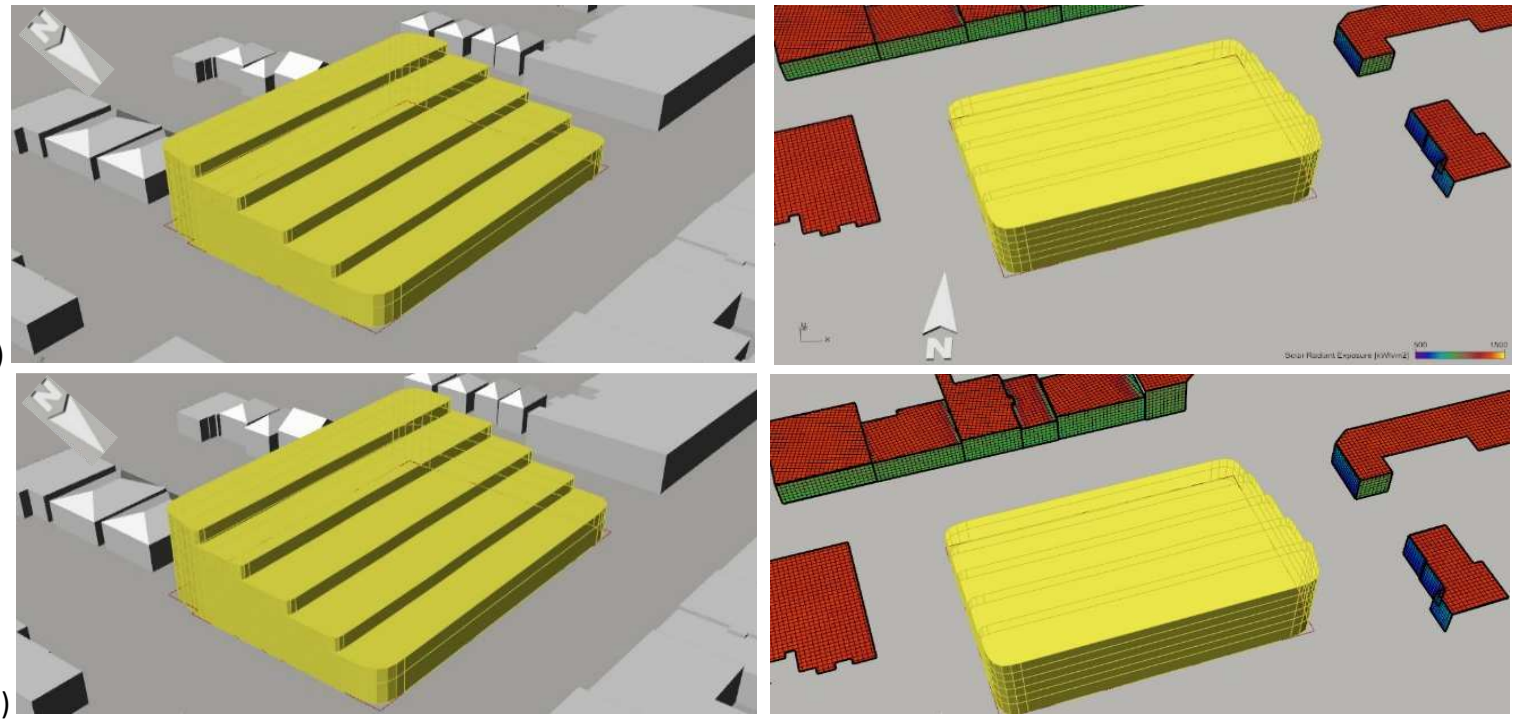

b)
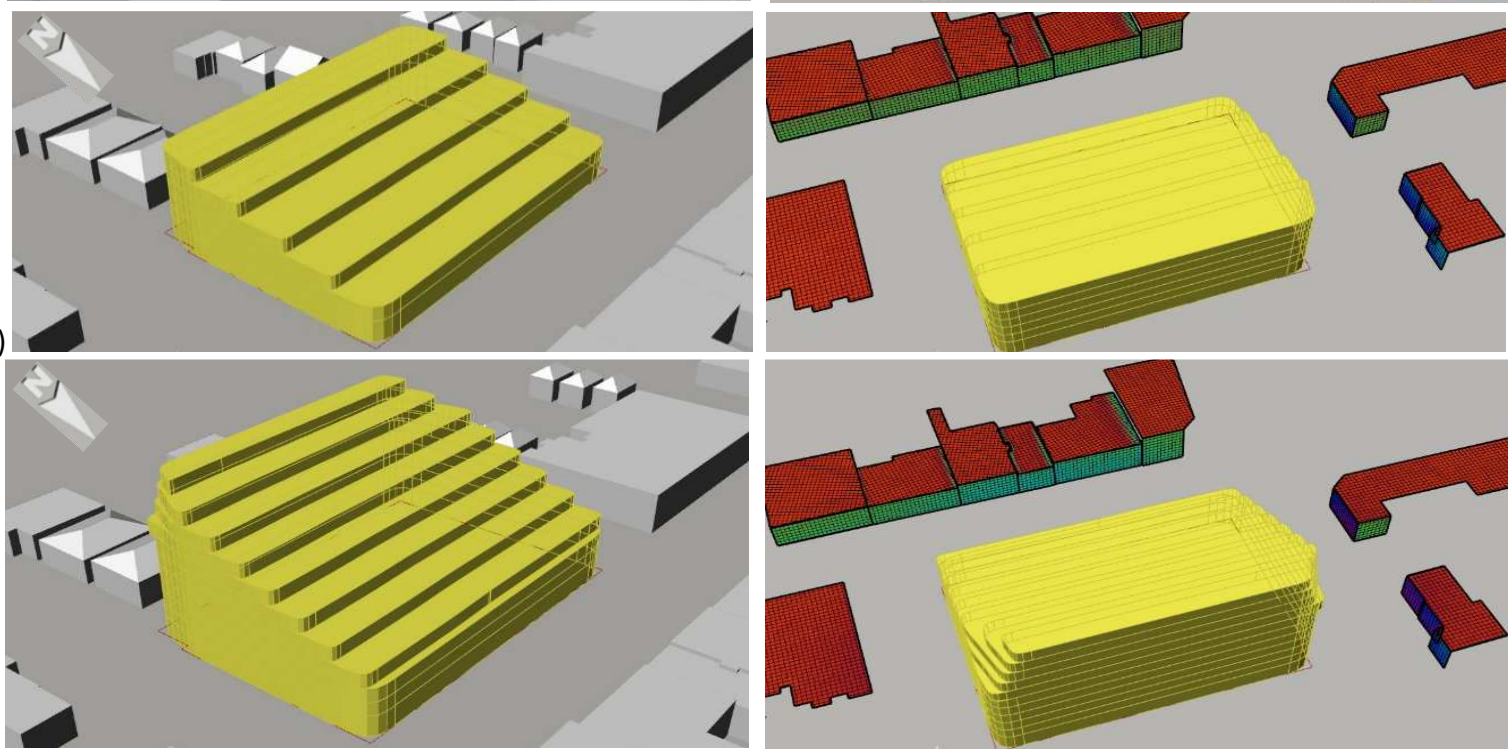

c)

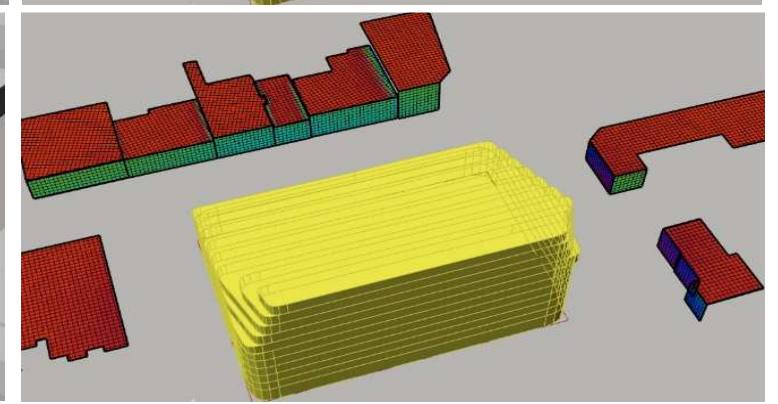

d)
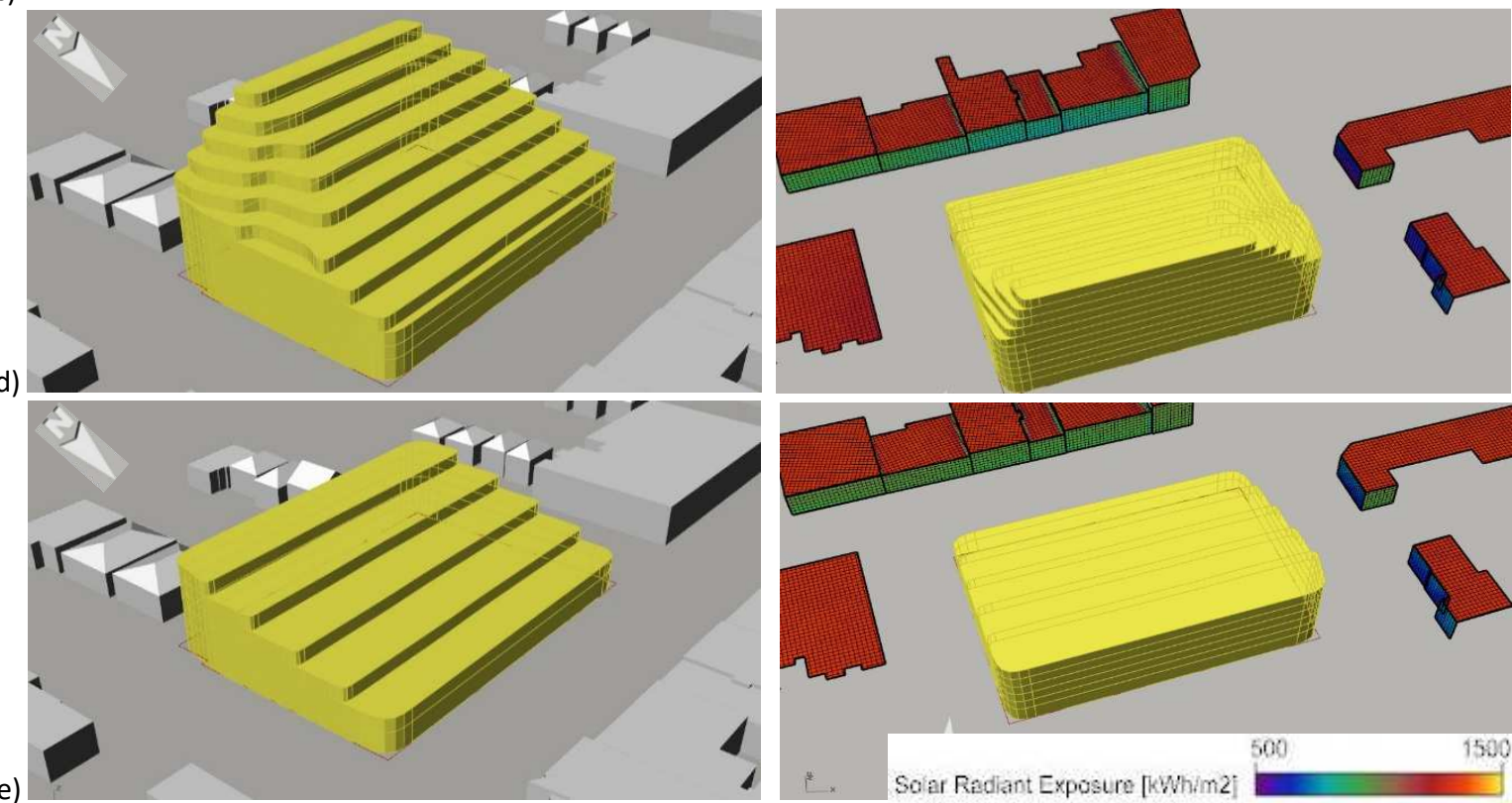

Figure 6.2.3.2. Building forms generated by the solar envelope volume showing $(a)$ the baseline solar envelope, (b) $a+T d b<18 C$, (c) $a+G H R<472 W h / m 2$, (c) by varying the shadow fence height from a) site and context, b) $0 \mathrm{~m}, \mathrm{c}$ ) $4.5 \mathrm{~m}$, and d) $10.5 \mathrm{~m}$. 
The results show that limiting the sunVectors to those below $18^{\circ} \mathrm{C}$ does not have an impact on the development density or solar access compared to the baseline. This is also true when combined with a minimum GHR of $472 \mathrm{Wh} / \mathrm{m}^{2}$. However, by specifying a minimum GHR of $472 \mathrm{Wh} / \mathrm{m}^{2}$ from the baseline, the FSI nearly doubles from 4.05 to 8.05 (98\% increase). However, the façade radiation decreases by 9.4\%. By taking the previous solar envelope parameters from (c) and increasing the solar access window from 4 hours to 6 hours, the solar access is improved by 1.5\%, while still achieving a high FSI of 7.84 compared to 8.03 (2.4\% reduction).

The SE volume achieves superior solar access in all cases compared to the MRG and the proposed development. By specifying a minimum GHR of $472 \mathrm{Wh} / \mathrm{m}^{2}$ it is also possible to achieve a higher FSI, even with a 6-hour solar access window.

Table 6.2.3.1. Impact of environmental parameters on development density (FSI) and solar radiation density $\left(\mathrm{kWh} / \mathrm{m}^{2}\right)$ on adjacent facades.

\begin{tabular}{|c|c|c|c|c|c|}
\hline & Evaluation Parameter & FSI & $\begin{array}{l}\% \text { Change } \\
\text { [from previous] }\end{array}$ & $\begin{array}{l}\text { Façade Radiation } \\
\left.\qquad \mathrm{kWh} / \mathrm{m}^{2}\right]\end{array}$ & $\begin{array}{l}\% \text { Change } \\
\text { [from previous] }\end{array}$ \\
\hline a) & Baseline & 4.05 & & 887 & \\
\hline b) & $\mathrm{T}_{\mathrm{db}}<18^{\circ} \mathrm{C}$ & 4.05 & 0 & 887 & 0 \\
\hline c) & $\mathrm{GHR}>472 \mathrm{Wh} / \mathrm{m}^{2}$ & 8.03 & +98 & 804 & -9.4 \\
\hline d) & c) +6 h solar fence & 7.84 & -2.4 & 816 & +1.5 \\
\hline \multirow[t]{4}{*}{ e) } & b) + c) & 4.05 & 0 & 887 & 0 \\
\hline & Toronto Zoning & 2.50 & - & 857 & - \\
\hline & Mid-Rise Guidelines & 5.68 & - & 747 & - \\
\hline & Proposed Development & 7.27 & - & 622 & - \\
\hline
\end{tabular}

\subsubsection{Discussion}

The parametric study of the proposed site at 859-875 Eglinton Avenue West evaluated the impact of solar fence height, solar access cut-off time, and environmental solar access parameters such as global horizontal irradiance and outdoor dry-bulb temperature to assess the optimum parameters involved in 
the creation of the solar envelope to balance solar access to adjacent buildings and the development density of the site. A preliminary investigation of the site found that the baseline solar envelope as described in the methodology achieves the greatest solar access to adjacent facades compared to the Toronto Zoning typology, Mid-Rise Guidelines, and the proposed development on the site. The proposed development provides the least solar access. However, the proposed development achieves the highest development density $-40 \%$ greater than the $\mathrm{FSI}$ of the solar envelope. As a result, further environmental parameters were evaluated to increase the solar envelope volume generated by the SEZ method to achieve a comparable FSI to the proposed development while maintaining optimum solar access to adjacent facades.

Similar to the study on the typical lot, the study of 859-875 Eglinton Avenue West showed that as the shadow fence height is increased, the FSI increases and solar access to adjacent buildings decreases. The solar envelope achieves superior solar access in all cases compared to the proposed development and the MRG, and a higher FSI compared to the Toronto Zoning typology. The SE with a shadow fence height of 10.5 meters achieves a greater development density than the proposed development and the MRG, respectively, while also improving solar access. Based on these results, SEZ presents a viable method for zoning in Toronto to balance solar access and development density, particularly for sites located on the south side of east-west oriented streets. However, it should be noted that the SEZ volume is a solid volume extruded from the constraints of the site boundary and does not consider certain building requirements such as maximum building widths for daylighting and views, etc. Integrating these would results in a lower FSI and should be investigated in a further study.

The study also showed that as the designated solar access cut-off time decreases, the FSI increases and solar access decreases. The study also indicates that as the solar access window is increased, the impact on the rate of reduction to FSI grows by nearly a factor of two. The inverse is true as the solar access 
window is reduced. All solar envelope volumes resulting from this study achieved a higher FSI than the Toronto Zoning typology, and all except the 2-hour solar access window saw an improvement in solar access. None of the SE volumes achieved a FSI higher than the MRG or the proposed development, however all SE volumes achieved better solar access. Therefore, solar access cut-off time alone cannot achieve the desired balance between solar access and development density and must be proposed in conjunction with other solar access parameters.

An interesting observation from this study is that by shifting the solar access window beyond the constraints of straddling 12:00 noon (which has been recommended by Knowles, 2003), the development density of the site is increased by $29 \%$ and the solar access is decreased by $2.5 \%$. These results call into question the rigid parameters that have been used to create the solar envelope in past studies and presents an opportunity to re-evaluate the metrics used to qualify solar access, since shifting the solar access window but retaining the total required sunlight hours significantly impacts the solar envelope volume and resulted in a reduction in solar access in this case (although minimal). Several authors have begun to develop methods to understand the parameters that define when solar access is desired and when it is not, to aid in optimizing the solar envelope volume for development density and solar access in a more dynamic and context-dependent manner (Capeluto \& Plotnikov, 2017) (De Luka \& Voll, 2017).

To determine when solar access is desired and when it is not, it is important to look at specific adjacent land uses. By doing so, we are able to better identify the times of day the buildings are occupied and when solar access is desired or required. For example, residential buildings are typically unoccupied during the day and therefore solar access may only be desirable before 9:00 and after 17:00. By contrast, commercial buildings are typically only occupied during the day, and therefore solar access may be desirable for longer periods between 9:00 and 17:00. The window of desirable solar access will 
significantly impact the form of the solar envelope created and therefore the potential development density. Future research should evaluate these specific time-of-use parameters in more depth to understand the implications on the solar envelope volume and to better define the threshold for desirable solar access in Toronto. Findings of such research could help to guide urban planning regulations in forming legislation around right-to-light that is best suited for Toronto's unique climate and context. The tool developed by this author using Grasshopper and the Ladybug and DIVA components has the potential to be used to further evaluate these opportunities.

The final stage of the study began to evaluate this concept by redefining the environmental conditions that constitute a violation of solar rights such as setting a minimum required GHR and a minimum ambient dry-bulb temperature, as proposed by Capeluto and Shaviv (2017). The results show that limiting the sunVectors to those that occur below $18^{\circ} \mathrm{C}$ does not have an impact on the potential development density or solar access compared to the baseline solar envelope. This is also true when combined with a minimum GHR of $472 \mathrm{Wh} / \mathrm{m}^{2}$, which means that the temperature is the limiting factor. Due to Toronto's northern latitude and extremes in temperature, winter temperatures can reach below $-30^{\circ} \mathrm{C}$ and the sun is very low in the sky and more easily obstructed by adjacent buildings. Since the solar envelope is defined by the most limiting parameters, in order to meet all solar access requirements, it is not surprising that the solar envelope is not impacted by specifying a temperature below $18^{\circ} \mathrm{C}$ since the sunVectors with the lowest sun angle will occur at times when the outdoor temperature is below $18^{\circ} \mathrm{C}$. Further research should be conducted to determine how outdoor temperature can be combined with other parameters such as time of day and time of year to optimizing passive solar for heating, but also for building energy use. The study then evaluated minimizing sunVectors to those that provide a minimum GHR of $472 \mathrm{Wh} / \mathrm{m}^{2}$, and found that the FSI nearly doubles. Also, a higher FSI is achieved compared to the MRG and the proposed development while providing better solar access. 
Based on the findings of this case study, it is evident that the SEZ method is viable as a method for Toronto's avenues, particularly on this site and sites located on the south of east-west oriented streets.

By redefining the environmental parameters that constitute a violation of solar access rights, it is possible to achieve a higher FSI that the Toronto Zoning typology, the MRG, and the proposed development on this site, while achieving superior solar access. Future work should evaluate a variety of sites on Toronto's avenues to confirm the viability of SEZ for all site typologies (varying orientation, ROW, site dimensions). 


\subsection{CONCLUSION}

Without access to the sun, we cannot use it. These words from Knowles (2003) are so simple, and yet so impactful. It has been proven that the sun is critical to the health, comfort, and resiliency of cities and current trends toward rapid urban development are causing the sun's energy to be underutilized. This study evaluated the potential for solar envelope zoning (SEZ) as a method for achieving solar access in urban environments, particularly in the context of Toronto, Canada, while maintaining desirable urban development density. The purpose of the study was to assess the viability to SEZ compared to the current zoning regulations set by the City of Toronto and the guidelines proposed by the Mid-Rise Buildings Study. This conclusion summarises the responses to three research questions identified in this study:

1. What is the level of impact of street width and orientation on development density and solar access using the solar envelope zoning method?

The findings show that street width (ROW) and site orientation have a significant impact on development density and solar access. In general, as street ROW increases, both development density and solar access increase. In terms of orientation, south sites provide the optimal solar envelope to balance solar access and development density. However, further research is required to refine the tool and to help develop solar access regulations. Although the Mid-Rise Building Guidelines provide considerations for solar access through their prescriptive guidelines, they are limited in that they are not site specific and do not address the relative motion of the sun. These guidelines are beneficial in that they provide "rules-of-thumb" for designing for better solar access using the 45-degreee angular plane at a height specified by the street ROW. However, since they are independent of context they are uniform despite site orientation, size, location, and surrounding context and therefore do not 
adequately address solar access. With advancements in computer-aided design and environmental analysis tools, it is becoming increasingly feasible to utilize these tools to more accurately and holistically create zoning volumes that achieve solar access without compromising on development density, and to make these tools available to the public.

2. Can the solar envelope volume be optimized to balance adequate solar access, while allowing for development density equal to or greater than existing City of Toronto zoning and the Mid-Rise Guidelines?

The findings show that the solar envelope volume can be optimized to achieve better solar access and higher development density than the City of Toronto zoning regulations and the Mid-Rise Guidelines and therefore it is a feasible method for zoning sites in Toronto. There are two research paths that should occur in tandem in order to advance this authors research and to improve the solar access provided by development in Toronto and other high-density urban environments. First, the tool described in this paper should be developed further to better define the threshold for desirable solar access in Toronto by integrating parameters specific to land use to optimize the balance between development density and solar access. These parameters can be expanded to include not only implications for solar access in terms of passive solar heating and active solar energy generation, but also for building energy use, natural daylighting, occupant health, and urban agriculture. The outcome of this future research should help develop customized solar access requirements for Toronto based on science, that can be directly integrated into urban zoning regulations to improve not only the quantity but the quality of solar access. Once urban planning regulations have defined and set requirements for solar access, there needs to be a simple way of evaluating new development proposals to meet these requirements. As such, the second research path is to refine the methods and tools described in this work to provide a tool that can be easily used by architects and urban planners to guide in designing and planning for solar access and 
to demonstrate compliance with the solar access requirements set out by the municipality. The method and/or tool should have the potential to integrate well with the existing 3D building database of the City of Toronto, so that architects, urban planners, and developers are only required to select the building site, and the tool will output the solar envelope within which to build in order to meet the solar access requirements. Such a tool would be complementary to current urban planning methods; however, it would require further development of the 3D building database to include building information such as occupancy type.

3. Can the solar envelope volume be increased by redefining the environmental parameters that must be met for sunlight to be required?

The method described by this author, adapted from previous studies, uses accessible software programs commonly used by architects to optimize the solar envelope volume on a given size. As such, it is feasible that with some refinement, this method can be used by architects and urban planners to guide the development of urban sites and urban blocks in a more dynamic and context-dependent manner through the SEZ method. Furthermore, be redefining the environmental parameters that constitute a violation of solar access rights, such as setting a minimum hourly global horizontal radiation value, the built environment can more accurately achieve prescribed solar access requirement while achieving higher developable densities. In the context of Toronto, there is ample opportunity for the densification of the city through mid-rise buildings along Toronto's main avenues, while optimizing development to improve solar access for passive and active solar energy.

To achieve health, comfort, and resiliency in the urban environment, we must embrace and encourage development patterns that support solar access for both passive and active solar energy, and it is possible to achieve this through the solar envelope zoning method. 


\subsection{FUTURE WORK}

Throughout this study, the author has identified a significant amount of future work that could positively contribute to the existing body of knowledge on solar envelope zoning and solar access. Building upon this research, potential future studies should:

- Evaluate the parameters that define when solar access is desired and not desired based on adjacent land uses in terms of occupancy for passive solar purposes, and desired access for active solar generation in terms of time-of-use pricing, peak energy demand of buildings, etc.

- Evaluating the integrating of building code requirements for buildings, such as maximum building width, into the SEZ study to assess the true FSI of the SEZ method as allowed by the building code (the Ontario Building Code in the case of Toronto)

- Evaluating the optimal parameters on each site orientation to achieve a comparable FSI, to address the limitation that site orientation significantly impacts FSI and therefore saleable area for development.

- Build on the method developed by De Luka and Voll (2017) in determining a simplified method to set a 4-hour solar access window per day that is undefined by specific solar cut-off times, to evaluate the effect on the solar envelope volume in the Toronto context. 


\section{WORKS CITED}

Amado, M., \& Poggi, F. (2014). Solar urban planning: a parametric approach. Energy Procedia, 48: 15391548. Retrieved from Science Direct.

Bernier, E. K. (2015). Shining a light on solar energy in Ontario's planning process: Lessons from international best practices in solar energy (Major research project). Ryerson University, Toronto.

Brook Mcllroy Planning \& Urban Design/Pace Architects. (2010). Avenues \& Mid-Rise Buildings Study. Prepared for the City of Toronto; in collaboration with E.R.A. Architects, Quadrangle Architects Ltd, \& Urban Marketing Collaborative.

Burda, C. and Collins-Williams, M. (2015). Make Way for Mid-Rise: How to build more homes in walkable, transit-connected neighbourhoods. The Pembina Institute: Ontario Home Builders' Association.

Capeluto, I. G. (2003). Energy performance of the self-shading building envelope. Energy and Buildings, 35: 327-336. Retrieved from Elsevier.

Capeluto, I. G., \& Plotnikov, B. (2017). A method for the generation of climate-based, context-dependent parametric solar envelopes. Architectural Science Review, 60(5): 395-407. Retrieved from Elsevier.

Capeluto, I. G., \& Shaviv, E. (2001). On the use of 'solar volume' for determining the urban fabric. Solar Energy, 70(3): 275-280. Retrieved from Elsevier.

Cheng, V., Steemers, K., Montavon, M., \& Compagnon, R. (2006). Urban form, density and solar potential. Proceedings of the $23^{\text {rd }}$ Conference on Passive and Low Energy Architecture (PLEA2006). Geneva, Switzerland. Retrieved from ResearchGate. 
Chwieduk, D. A. (2009). Recommendation on modelling of solar energy incident on a building envelope. Renewable Energy, 34: 736-741. Retrieved from Elsevier.

City of Toronto. (2014). Eglinton Connects Planning Study. Retrieved from http://www1.toronto.ca/wps/portal/contentonly?vgnextoid=44ae86664ea71410VgnVCM1000007 $\underline{1 \mathrm{~d} 60 f 89 R C R D \& t a b=1}$

City of Toronto. (2010a). Toronto Green Standard: Making a sustainable city happen. Retrieved from https://www1.toronto.ca/city_of_toronto/city_planning/developing_toronto/files/pdf/Ir_res_tech. pdf

City of Toronto. (2010b). Toronto Official Plan. Retrieved from http://www1.toronto.ca/static_files/CityPlanning/PDF/chapters1_5_dec2010.pdf

Colucci, A. (2013). Making Toronto solar ready: Proposing building formations for the integrations of solar strategies (Master thesis). Ryerson University, Toronto.

Cotton, J. F. (1996). Solid modeling as a tool for constructing solar envelopes. Automation in Construction, 5: 185-192. Retrieved from Elsevier.

De Luca, F., \& Voll, H. (2017). Computational method for variable objectives and context aware solar envelopes generation. Proceedings of the Symposium on Simulation for Architecture and Urban Design (SimAUD) 2017 (pp. 335-342). Toronto, ON: Simulation Councils, Inc.

EcoSmart. (2014). Solar Maps of Canada: Fixed racking. Retrieved from EcoSmart website: https://ecosmartsun.com/services/canada-solar-maps/ 
Environment Canada. (2012). Canada's Emissions Trends 2012. Environment and Climate Change Canada: Canada's GHG Emissions and Projections. Retrieved from https://www.ec.gc.ca/gesghg/default.asp?lang=En\&n=022badb5-1

European Renewable Energy Council (EREC). Rethinking 2050: A 100\% Renewable Energy Vision for the European Union. Brussels, Belgium; 2010.

Fath, K., Stengel, J., Sprenger, W., Wilson, H. R., Schultmann, F., \& Kuhn, T. E. (2015). A method for predicting the economic potential of (building-integrated) photovoltaics in urban areas based on hourly RADIANCE simulations. Solar Energy, 116: 357-370.

Freitas, S., Catita, C., Redweik, P., \& Brito, M. C. (2015). Modelling solar potential in the urban environment: State-of-the-art review. Renewable and Sustainable Energy Reviews, 41: 915-931. Retrieved from Elsevier.

Gibson, G. (2014). Finding the balance: Solar access in the intensified city. Report prepared for Sector Growth \& Sector Development Office, City of Toronto, Canada.

Hachem, C., \& Athienitis, A. (2013). Using passive design. ASHRAE Journal: Engineers Notebook, 55(1): 72-74. Retrieved from ProQuest.

Hachem, C., Athienitis, A., \& Fazio, P. (2014). Energy performance enhancement in multistory residential buildings. Applied Energy, 116, 9-19. Retrieved from ScienceDirect.

Hachem, C., Athienitis, A., \& Fazio, P. (2011a). Design of solar-optimized neighbourhoods. ASHRAE Transactions, 117, 228-235. Retrieved from ProQuest. 
Independent Electricity System Operator (IESO). (2016). About MicroFIT. Retrieved from http://microfit.powerauthority.on.ca/about-microfit

Intergovernmental Panel on Climate Change (IPCC). (2014). Climate Change 2014: Impacts, Adaptation, and Vulnerability. Part A: Global and Sectoral Aspects. Contribution of Working Group II to the Fifth Assessment Report of the Intergovernmental Panel on Climate Change [Field, C.B., V.R. Barros, D.J. Dokken, K.J. Mach, M.D. Mastrandrea, T.E. Bilir, M. Chatterjee, K.L. Ebi, Y.O. Estrada, R.C. Genova, B. Girma, E.S. Kissel, A.N. Levy, S. MacCracken, P.R. Mastrandrea, and L.L. White (eds.)]. Cambridge, United Kingdom and New York, NY, USA: Cambridge University Press.

International Energy Agency (IEA). (2015). Solar Heating \& Cooling Programme Task 51: Solar energy in urban planning. Retrieved from http://task51.iea-shc.org/publications

International Renewable Energy Agency (IRENA). (2015). Renewable Power Generation Costs in 2014. Retrieved from http://www.irena.org/DocumentDownloads/Publications/IRENA RE Power Costs 2014 report.pd $\underline{f}$

Morrison Hershfield. (2015). 2015 Reference Guide: Mid-Rise Wood Construction in the Ontario Building Code (Report No. 2150027.00). Retrieved from Wood Works! Website: http://wood-works.ca/wpcontent/uploads/Ontario-Mid-Rise-Reference-Guide-2015.pdf

Juyal, M., Kensek, K., \&Knowles, R. (2003). SolCAD: 3D Spatial Design Tool to Generate Solar Envelope. Proceedings of the 2003 Annual Conference of the Association for Computer Aided Design in Architecture (ACADIA), 411-419. Indianapolis, IN: Ball State University.

Kanters, J., \& Horvat, M. (2012). Solar energy as a design parameter in urban planning. Energy Procedia, 30, 1143-1152. 
Kanters, J., Horvat, M., \& Dubois, M. (2014). Tools and methods used by architects for solar design. Energy and Buildings, 68: 721-731. Retrieved from Elsevier.

Kanters, J., Wall, M., \& Dubois, M. (2014). Development of a facade assessment and design tool for solar energy (FASSADES). Buildings, 4(1): 43-59.

Kanters, J., Wall, M., Kjellsson, E. (2014a). The solar map as a knowledge base for solar energy use. Energy Procedia, 48, 1597-1606. Retrieved from ScienceDirect.

Kanters, J., Wall, M., Kjellsson, E. (2014b). Typical values for active solar energy in urban planning. Energy Procedia, 48: 1607-1616. Retrieved from ScienceDirect.

Kettles, C. M. (2008). A comprehensive review of solar access law in the united states: Suggested standards for a model statute and ordinance. Retrieved from the Solar America Board for Codes and Standards website: http://www.solarabcs.org/about/publications/reports/solar-access/

Knowles, R. (2003). The solar envelope: Its meaning for energy and buildings. Energy and Buildings, 35: 15-25. Retrieved from Elsevier.

Knowles, R. L. (1981). The Solar Envelope. Solar Law Reporter, 2(2), 263-297. Retrieved from HeinOnline: http://home.heinonline.org/

Krivitsky, J. Canadian Institute of Resource Law (CIRL) Occasional Paper \#31: Solar Rights and Renewable Energy in Alberta. University of Calgary, Calgary AB.

Leveratto, M. J. (2002). Urban planning instruments to improved winter solar access in open public spaces. Environmental Management and Health, 13(4): 366-372. 
Marques, B., Corvacho, H., \& Alves, F. B. (2016). Assessment of solar access in urban environment: The case of the renewal of a city block in Espinho, Portugal. Indoor and Building Environment, 25 (7): 1075-1084.

McNeil, A., \& Chadwell, R. (2012). About RADIANCE: Detailed description. RADSITE. Retrieved from https://www.radiance-online.org/about/detailed-description.html\#section-5

Mode Lab. (2015). The Grasshopper ${ }^{\mathrm{TM}}$ Primer: Third Edition V3.3. Mode Lab. Retrieved from http://modelab.is/Grasshopper ${ }^{\mathrm{TM}}$-primer/

Moore, A. A. (2013). Trading density for benefits: Toronto and Vancouver compared.

Morello, E. \& Ratti, C. (2009). Sunscapes: 'Solar Envelopes' and the Analysis of Urban DEM's. Computers, Environment and Urban Systems, 33: 26-34. Retrieved from Elsevier.

Niemasz, J., Sargent, J., \& Reinhart, C. F. (2011). Solar Zoning and energy in Detached Residential Dwellings. In Attar, R. 2011 Proceedings of the Symposium on Simulation for Architecture and Urban Design. Paper presented at the Symposium on Simulation for Architecture and Urban Design, Boston, MA (p. 37-45). San Diego, CA: Society for Computer Simulation International.

Okiel, A. (2010). A holistic approach to energy efficient building forms. Energy and Buildings, 42, 14371444. Retrieved from ScienceDirect.

O'Neill, K. (1986). Solar Access Zoning. Journal of Planning Literature, 1(2): 260-268.

Perlin, J. (2013). Let it shine: The 6000-year story of solar energy. Novato, California: New World Library.

Pereira, F. O. R., Nome Silva, C. A., \& Turkienikz, B. (2001). A methodology for sunlight urban planning: A computer-based solar and sky vault obstruction analysis. Solar Energy, 70(3): 217-226. Retrieved from Elsevier. 
Raboudi, K., \& Ben Saci, A. (2013). A morphological generator of urban rules of solar control. In proceedings of the $30^{\text {th }}$ International Conference on Passive and Low Energy Architecture (PLEA2013). Munich, Germany: Sept 10-12. Retrieved from ResearchGate.

Ratti, C., \& Morello, E. (2005). Sun Scapes: extending the 'solar envelopes' concept through 'iso-solar surfaces. In proceedings of the 22nd international conference on Passive and Low Energy Architecture (PLEA2005). Beirut, Lebanon: Nov 13-16.

Robinson, D., \& Stone, A. (2004). Irradiation modelling made simple: the cumulative sky approach and its applications. In proceedings of the $21^{\text {st }}$ Conference on Passive and Low Energy Architecture (PLEA2004). Eindhoven, The Netherlands: Sept 19-21.

Sadeghipour Roudsari, M., \& Pak, M. (2013). Ladybug: a parametric environmental plugin for Grasshopper $^{\mathrm{TM}}$ to help designers create an environmentally-conscious design. In proceedings of the 13th International IBPSA Conference. Lyon, France: Aug 25-30. Retrieved from (http://www.ibpsa.org/proceedings/BS2013/p 2499.pdf)

Sanaiein, H., Tenpierik, M., van den Linden, K., Seraj, F. M., \& Shemrani, S. M. M. (2014). Review of the impact of urban block form on thermal performance, solar access and ventilation. Renewable and Sustainable Energy Reviews, 38: 551-560. Retrieved from ScienceDirect.

Statista. (2016). Average electricity prices globally in 2015, by select country (in U.S. dollars per kilowatt hour). Statista: The Statistics Portal. Retrieved from http://www.statista.com/statistics/477995/global-prices-of-electricity-by-select-country/

Treberspurg, M. (2008). SolarCity: Linz Pichling. Wien: Springer 
Touchette, Y. (2015). G20 subsidies to oil, gas and coal production: Canada. International Institute for Sustainable Development. Retrieved from https://www.odi.org/sites/odi.org.uk/files/odiassets/publications-opinion-files/9988.pdf

United Nations (UN), Department of Economic and Social Affairs, Population Division. (2014). World Urbanization Prospects: The 2014 Revision, Highlights (ST/ESA/SER.A/352). Retrieved from https://esa.un.org/unpd/wup/Publications/Files/WUP2014-Highlights.pdf

Van Esch, M. M. E., Looman, R. H. J., \& de Bruin-Hordijk, G. J. (2012). The effects of urban and building design parameters on solar access to the urban canyon and the potential for direct passive solar heating strategies. Energy and Buildings, 47, 189-200.

Vonderohe, A. P. (1986). Geometry of Solar Envelopes. Journal of Surveying Engineering, 112(1): 3-17.

Zimmerman, K. A. (2017). History of Computers: A Brief Timeline. Live Science. Retrieved from https://www.livescience.com/20718-computer-history.html 


\section{GLOSSARY}

Avenues: Important corridors along major streets where reurbanization is anticipated and encouraged to create new housing and job opportunities while improving the pedestrian environment, the looks of the street, shopping opportunities and transit service for community residents

Density: see Floor Space Index (FSI).

Energy: The ability to do work, to make things happen, and to cause changes.

Energy Consumption: A measure of how much energy a given building, appliance, or geographic area uses to power its operation. Electrical energy consumption is often measures in kilowatt-hours (kWh). To simplify analysis of energy consumption, the standard unit of equivalent kilowatt-hours (ekWh) is used to represent both electrical and thermal energy.

Energy Demand: The rate at which energy is used by a building, appliance, or area. Using energy quickly creates a larger demand. Electrical demand is often measures in kilowatts (kW).

Floor Space Index (FSI): The ratio of a building's total floor area in relation to the size of the plot on which it is built. [E.g. FSI = 0 when no buildings on site; FSI = 2 when total floor area is double the site area].

Peak Load: The maximum rate at which energy is drawn from the grid by a specific area, appliance, or building. Often measure in kWp.

Reurbanization: A coordinated approach to the redevelopment of land within the existing urban fabric to accommodate regional growth. It improves and makes better use of existing urban infrastructure and services before introducing new ones on the urban fringe, reducing impacts on the natural environment and improving livability of the urban region. 
Right to Light: A legally enforceable proportion of the natural, unobstructed flow of direct solar radiation

Shadow Fence: The designated boundaries for shading, or avoidance of unacceptable shading, on adjacent properties. It can be determined by windows, party walls, adjacent land uses, etc.

Solar Access: The ability to have uninterrupted direct rays of sunlight fall onto one's property.

Solar Easement: The ability of one property to continue to receive sunlight across property lines without obstruction from another's property (buildings, foliage, or another impediment). (Kettles, 2008)

Solar Envelope: The largest developable volume on a parcel of land to ensure adjacent neighbouring properties a specified minimum direct solar access time per day throughout the year. It is a construct of space and time, and is latitude and orientation specific.

Solar Map: Solar maps or solar cadastres are GIS systems providing annual solar irradiation on building surfaces. Most are accompanied by the output of solar thermal or photovoltaic systems (Kanters, Wall, and Kjellsson, 2014).

Solar Right: The ability to install solar energy systems on residential and commercial property that is subject to private restrictions (i.e. covenants, conditions, restrictions, bylaws, condominium declarations, as well as local government ordinances and building codes. (Kettles, 2008)

Urban canyon: The space constituted by the facades, ground and imaginary plain between roofs of a street continuously lined with buildings 